SANDIA REPORT

SAND94-2217 • UC-721

Unlimited Release

Printed September 1995
RECEIVED

OCT 111995

OSTI

\title{
Accelerator Production of Tritium Project Process Waste Assessment
}

Susan D. Carson, Phyllis K. Peterson

\section{Prepared by}

Sandia National Laboratories

Albuquerque, New Mexico 87185 and Livermore, California 94550

for the United States Department of Energy

under Contract DE-AC04-94AL85000

Approved for public relase, ofistitibution is unlimited.

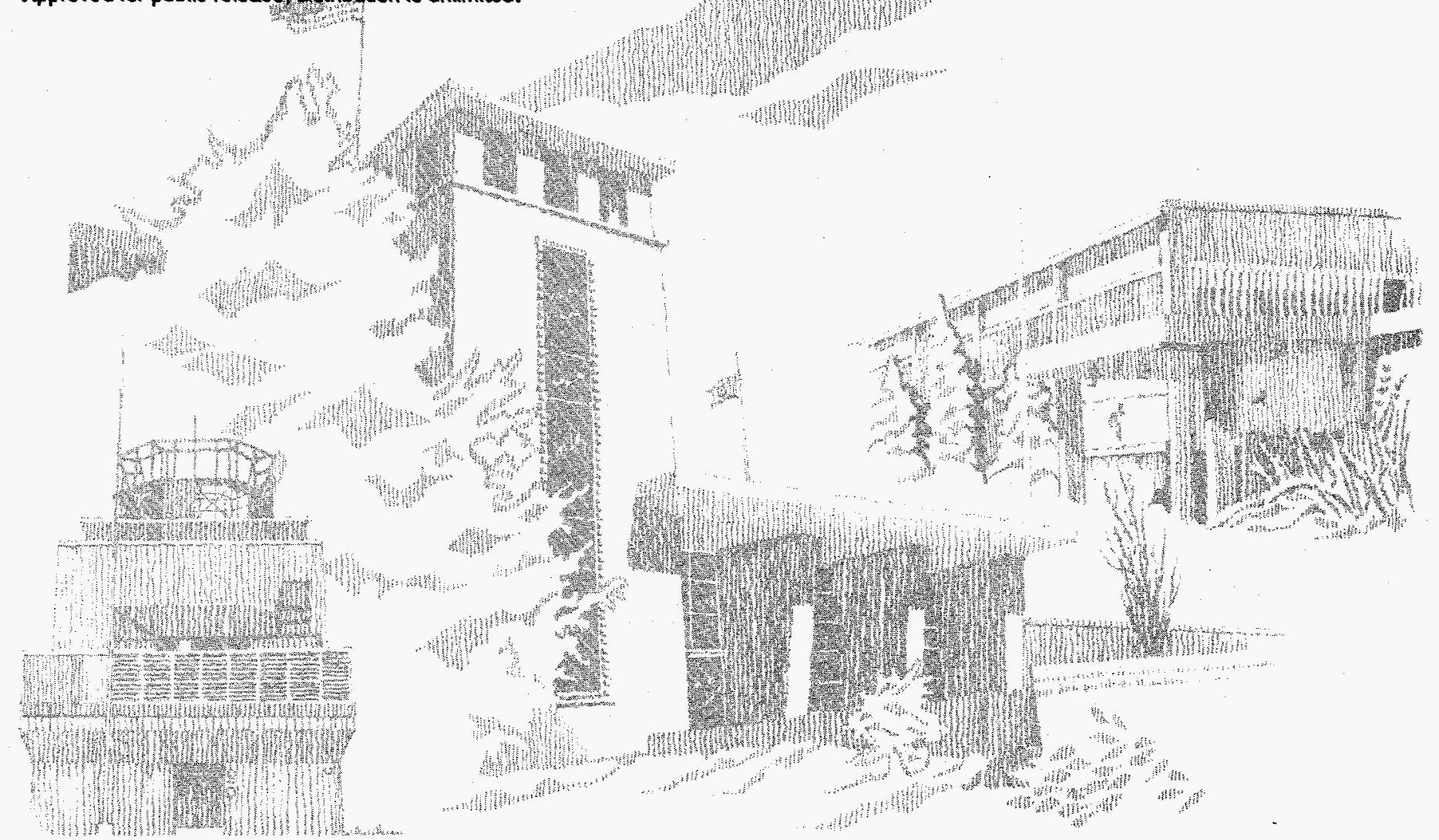


Issued by Sandia National Laboratories, operated for the United States Department of Energy by Sandia Corporation.

NOTICE: This report was prepared as an account of work sponsored by an agency of the United States Government. Neither the United States Government nor any agency thereof, nor any of their employees, nor any of their contractors, subcontractors, or their employees, makes any warranty, express or implied, or assumes any legal liability or responsibility for the accuracy, completeness, or usefulness of any information, apparatus, product, or process disclosed, or represents that its use would not infringe privately owned rights. Reference herein to any specific commercial product, process, or service by trade name, trademark, manufacturer, or otherwise, does not necessarily constitute or imply its endorsement, recommendation, or favoring by the United States Government, any agency thereof or any of their contractors or subcontractors. The views and opinions expressed herein do not necessarily state or reflect those of the United States Government, any agency thereof or any of their contractors.

Printed in the United States of America. This report has been reproduced directly from the best available copy.

Available to DOE and DOE contractors from

Office of Scientific and Technical Information

PO Box 62

Oak Ridge, TN 37831

Prices available from (615) 576-8401, FTS 626-8401

Available to the public from

National Technical Information Service

US Department of Commerce

5285 Port Royal Rd

Springfield, VA 22161

NTIS price codes

Printed copy: A06

Microfiche copy: A01 


\section{DISCLAIMER}

Portions of this document may be illegible in electronic image products. Images are produced from the best available original document. 
SAND94-2217

Unlimited Release

Distribution

Printed July 1995 Category UC-721

\title{
Accelerator Production of Tritium Project Process Waste Assessment
}

\author{
Susan D. Carson \\ Environmental Risk Assessment \& Regulatory Analysis Department \\ Phyllis K. Peterson \\ Waste Management \& Regulatory Projects Department \\ Sandia National Laboratories \\ Albuquerque, NM 87185
}

\begin{abstract}
This report identifies and quantifies waste streams associated with two facility designs for accelerator production of tritium, and assesses treatment and disposal options for each waste stream.
\end{abstract}


This page intentionally left blank. 


\section{Contents}

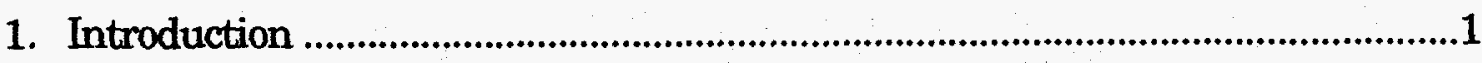

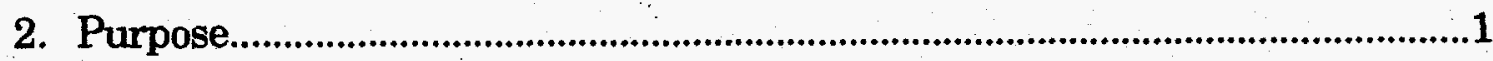

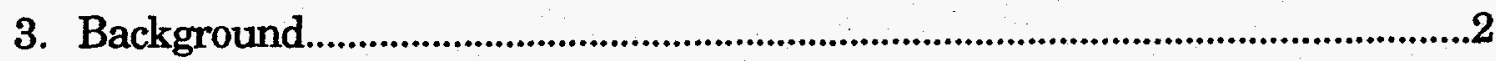

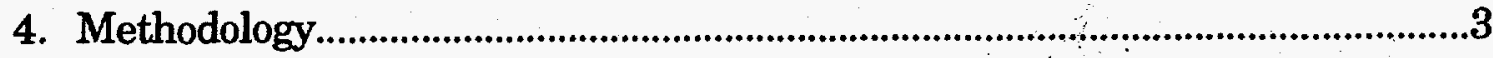

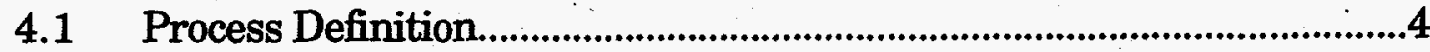

4.2 Process Characterization....................................................................4

4.3 Waste Minimization Assessment.......................................................5

4.4 Waste Treatment and Disposal....................................................5

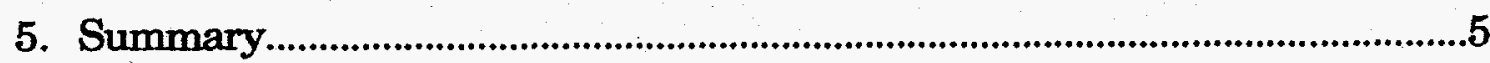

5.1 Process Waste Streams................................................................6

5.2 Waste Treatment and Disposal..........................................................8

5.2.1 Waste Treatment.........................................................................8

5.2.2 Waste Disposal.............................................................10

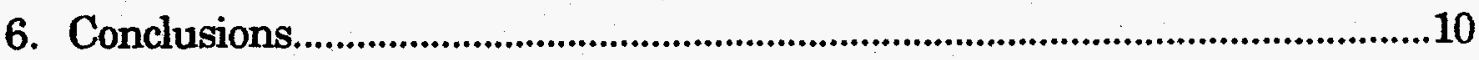

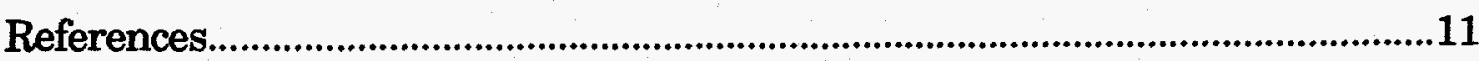

Appendix A - APT Processes and Operations.................................................14

Appendix B - APT Waste Streams....................................................................33

Appendix C - Treatment and Disposal of APT Waste....................................89

Appendix D - Waste Stream Inventory by Waste Type..............................101

Appendix E - Waste Stream Inventory by Type and Source - PEIS

Format.........................................................................................104

Appendix F - Waste Stream Inventory by Waste Treatment Category......116

\section{Tables}

1 Estimated Annual Waste Generation Rates for APT...............................6

2 Treatment Options for APT Waste..............................................................9 


$\begin{array}{ll}\text { Al } & \text { aluminum } \\ \text { ALNICO } & \text { aluminum-nickel-cobalt } \\ \text { APT } & \text { accelerator production of tritium } \\ \text { ASTM } & \text { American Society of Testing and Materials } \\ \text { B } & \text { boron } \\ \text { BDAT } & \text { Best Demonstrated Available Technology } \\ \text { BNL } & \text { Brookhaven National Laboratory } \\ \text { CAI } & \text { Controlled Air Incinerator } \\ \text { CCL } & \text { coupled-cavity LINAC } \\ \text { CFR } & \text { Code of Federal Regulations } \\ \text { Gi } & \text { curies } \\ \text { CLP } & \text { Contract Laboratory Program } \\ \text { Cu } & \text { copper } \\ \text { D } & \text { deuterium isotope of hydrogen } \\ \text { D\&D } & \text { decontamination \& decommissioning } \\ \text { DOE } & \text { Department of Energy } \\ \text { DSSI } & \text { Diversified Scientific Services } \\ \text { D2O } & \text { deuterium oxide (heavy water) } \\ \text { EPA } & \text { Environmental Protection Agency } \\ \text { ES\&H } & \text { environmental safety \& health } \\ \text { F } & \text { Fahrenheit } \\ \text { FFCA } & \text { Federal Facilities Compliance Act } \\ \text { GeV } & \text { giga (billion) electron volts } \\ \text { GPM } & \text { gallons per minute } \\ \text { H } & \text { hydrogen (protium isotope) } \\ \text { He-3 } & \text { helium-3 } \\ \text { HEPA } & \text { High Efficiency Particulate Air } \\ \text { HVAC } & \text { heating, ventilation and air conditioning } \\ \text { HW/MWDF } & \text { Hazardous Waste/Mixed Waste Disposal Facility } \\ \text { INEL } & \text { Idaho National Engineering Laboratory } \\ \text { KD-0 } & \text { Key Decision Zero } \\ \text { LANL } & \text { Los Alamos National Laboratory } \\ \text { LAMPF } & \text { Los Alamos Meson Physics Facility } \\ \text { LiAl } & \text { lithium-aluminum } \\ \text { LLW } & \text { low-level waste } \\ \text { m3 } & \text { cubic meters } \\ \text { Linac } & \text { Linear Accelerator } \\ \text { MeV } & \text { million electron volts } \\ \text { MHz } & \text { mega hertz } \\ \text { MLLW } & \text { mixed low-level waste } \\ \text { MW } & \text { mega watts } \\ \text { MIG } & \text { metal inert gas (metal-gas arc welding) } \\ \text { Na } & \text { sodium } \\ \text { NEPA } & \text { National Environmental Policy Act } \\ \text { NPDES } & \text { National Pollutant Discharge Elimination System } \\ \text { NPR } & \text { new production reactor } \\ & \end{array}$


NTS Nevada Test Site

$\mathrm{Pd}$ palladium

PEIS

Programmatic Environmental Impact Statement

PPE

PWA personal protection equipment

RCRA

RF

RHR

RTF

SEG

SILC Process Waste Assessment

SNL/NM

SRS

$\mathrm{T}$ Resource Conservation and Recovery Act radio frequency

residual heat removal

replacement tritium facility

Scientfic Ecology Group

spallation-induced lithium conversion

TCLP

Sandia National Laboratories/New Mexico

Savannah River Site

tritium isotope of hydrogen

TSCA

TSTA

WAC

WERF

Toxicity Characteristic Leaching Procedure

Toxic Substances Control Act

Tritium Systems Test Assembly

waste acceptance criteria

WRAP

Waste Experimental Reduction Facility

Waste Receiving and Processing Facilities 
This page intentionally left blank. 


\section{Accelerator Production of Tritium Project}

\section{PROCESS WASTE ASSESSMENT}

\section{Introduction}

Los Alamos National Laboratory (LANL), Sandia National Laboratories/New Mexico (SNL/NM), Brookhaven National Laboratories (BNL) and private industry have jointly developed a pre-conceptual design for Accelerator Production of Tritium (APT), and have presented it as a tritium production technology that could be an alternative to the reactor concepts proposed for Complex-21. The plan for APT is to produce 3/8 of the New Production Reactor (NPR) program baseline tritium production goal (3/8 goal) using a 200 $\mathrm{mA} 1.0-\mathrm{GeV}$ proton beam from a LANL-designed linear accelerator (linac).

There are currently two APT target concepts that can be used with the LANL linear accelerator. A BNL team is developing the Spallation-Induced Lithium Conversion (SILC) target design, based on the lithium-aluminum (LiAl) technology used by the Savannah River Site (SRS) over the last four decades. A LANL team is developing a target design based on a helium-3 (He-3) conversion process.

Major objectives of the current U.S. Department of Energy (DOE)-sponsored study of APT are to demonstrate the technical feasibility of the target and other design features, more accurately quantify the development, capital, and operating costs for this technology, and assess any potential environmental, safety and health benefits resulting from the use of this alternative technology.

\section{Purpose}

DOE has made a commitment to compliance with all applicable environmental regulatory requirements. In this respect, it is important to consider and design all tritium supply alternatives so that they can comply with these requirements. The management of waste is an integral part of this activity and it is therefore necessary to estimate the quantities and specific wastes that will be generated by all tritium supply alternatives. A thorough assessment of waste streams includes waste characterization, quantification, and the identification of treatment and disposal options. The waste assessment for APT has been covered in two reports. The first report was a process waste assessment (PWA) that identified and quantified waste streams associated with both target designs and fulfilled the requirements of APT Work Breakdown Structure (WBS) Item 5.5.2.1. This second report is an expanded version of the first that includes all of the data of the first report, plus an assessment of treatment and disposal options for each waste stream identified in the initial report. The latter information was initially planned to be issued as a separate Waste Treatment and Disposal Options Assessment Report (WBS Item 5.5.2.2); however, it was felt that a combined document would be more 
useful for the reader. The combined report provides waste stream characterization and quantification information required to meet the waste generation and waste minimization requirements defined in 40 CFR 268 (Land Disposal Restrictions), 40 CFR 260-5, DOE Orders 5820.2A, 6430.1A, and the 5400.xx and 5480.xx series.

The management and ultimate disposal of waste is a costly and complicated activity involving established internal procedures, permitting, and other regulatory issues. The costs and lead times associated with these issues should be estimated and considered along with other design and engineering costs. This PWA provides data for cost-benefit analysis of the potential environmental benefits of APT, is an integral part of waste minimization, and is required by DOE for any activity that will generate radioactive, hazardous, and mixed wastes. It will also serve to put APT in a better position to meet future requirements since it is anticipated that regulatory and other requirements will continue to become more restrictive and demanding. A PWA is essential for the evaluation of the two target designs proposed for the APT. A key factor in target and other design feature selection is the assessment of waste streams and quantities produced. Waste stream analysis will demonstrate whether advantages in terms of waste volumes and characteristics result from the use of a certain target and/or other design features.

Finally, a PWA is needed for evaluation of the potential Environmental, Safety and Health (ES\&H) benefits of the APT concept over the Heavy Water Reactor Tritium Production Facility, the Light Water Reactor, and the Modular High Temperature Gas Reactor. The quantification and analysis of waste streams will demonstrate whether APT offers substantial advantages in the areas of radioactive materials inventory and waste types produced.

\section{Background}

The DOE is responsible for research, development, and testing of nuclear weapons for the Department of Defense. These responsibilities include production of certain critical materials required for the weapons. One such material is tritium, a gaseous isotope used to enhance the explosive power of nuclear warheads. Tritium is radioactive, and about 5.5 percent is lost each year through natural decay. Because of this loss, existing weapons must be resupplied periodically with tritium in order to maintain their readiness.

In the 1950 's, DOE began producing tritium in nuclear reactors located at the Savannah River Site near Aiken, South Carolina. Concerns about the operational safety of these reactors led DOE to shut them down in 1988. Alternatives are now being considered for meeting future requirements for tritium production.

Proposals to use accelerators for tritium production have been made since the 1950 's, although no accelerators have been constructed for this purpose. 
Because of the reduction in the perceived need for U.S. tritium production, along with recent advances in proton accelerator technology due to extensive development activities for the Strategic Defense Initiative in the 1980's, there now exists the potential to produce the desired amount of tritium using accelerator rather than reactor technology. Smaller tritium requirements enhance the attractiveness of APT and reduced tritium demand provides more time to demonstrate the capability of the technology.

DOE decided to fund an APT design study in FY 1992/1993 to provide input to the Complex-21 Programmatic Environmental Impact Statement (PEIS). As a result, considerable progress has been made by the three DOE Laboratories and their industrial partners in the resolution of some of the key APT technical issues, especially in development of a reference design for the high-power accelerator system and for the two target concepts.

The proposed APT Facility is a non-reactor nuclear facility with some systems/attributes of reactors, e.g., decay heat and a high power density target with cooling requirements; however, there are no criticality issues. The major advantages of the accelerator system are a smaller radionuclide inventory and its safety and environmental characteristics. These advantages arise principally from the difference in the nuclear processes used to generate neutrons. In both reactor and accelerator systems the key to making tritium is generating enough neutrons. In a reactor system, the neutrons are generated by nuclear fission, while in the accelerator system the neutrons are generated by spallation. The spallation process occurs when protons from the accelerator strike heavy metal (tungsten or lead) target atoms and generate free neutrons.

\section{Methodology}

This PWA is concerned with a characterization of all waste streams generated during normal operations of an accelerator facility to produce tritium. Because the APT facility design is only in the pre-conceptual design phase, waste streams generated at the end of the life of the facility during the decontamination and decommissioning (D\&D) process and wastes from accidents are not examined. Sanitary sewage and wastewater are generated regardless of whether the production facility is a reactor or an accelerator, and their generation is based on employment estimates. Qualitative and quantitative assessments were performed for all other process-specific waste streams, and non-process activities such as maintenance and repair. The envelope examined includes all production feed materials through the actual processing of tritium.

There are four parts to this PWA: process definition, process characterization, waste minimization assessment, and waste treatment and disposal . "Process" is used broadly here to include any operation that generates a waste or pollutant, or uses a hazardous or radioactive material. 


\subsection{Process Definition}

Process definition briefly describes the overall operations and the specific processes or operations that consume or generate hazardous and/or radioactive materials or wastes. When the process definition differs for the two target types, parallel sections are provided. Each of these processes is discussed in Appendix A, APT Operations and Processes. For this discussion, APT processes were organized into four categories:

Accelerator Operations

Target/Blanket Operations (including target fabrication)

Tritium Processing

Support Facilities

\subsection{Process Characterization}

Process characterization collects information about the quantity and nature of the hazardous and/or radioactive materials used in processes and the wastes and other pollutants generated. This information was obtained from a variety of sources such as design teams, experience of existing tritium facilities, and in some cases the use of engineering judgment. Several processes are still in the pre-conceptual design stage and the information needed for a complete characterization is not yet available. Many wastes identified are not the result of a process, but rather are from site-wide maintenance of process equipment or from failure of process equipment and components through usage or exposure to harsh environments.

Wastes from all processes were grouped into waste streams with similar characteristics and modes of generation. Some waste streams list very specific information while others are quite general. For example, Target Fabrication Wastes are discussed in very general terms because the fabrication process has not yet been defined. In contrast, wastes associated with tritium extraction from the LiAl targets (e.g., LiAl Melts and Crucibles) are well defined because they are based on processes currently in use at SRS.

Appendix B provides the following information for each of forty-four waste streams that may contain hazardous and/or radioactive constituents:

Type: Low-level, hazardous, or mixed waste. No high-level or transuranic waste is generated by APT. Where a waste stream can be more than one waste type, for roll-up purposes, the total weight and volume is divided 50:50 for a combination of any two of the three waste types and 40:40:20 for low-level, mixed and hazardous wastes.

Description: Chemical composition, physical matrix, RCRA components (e.g., characteristic heavy metals or solvents) or radionuclides present and anticipated concentration levels. 
Generation: A description of the process(es) or activity which produced the waste stream.

Annual Quantities: Annual generation rate in both mass and volume. Comments: Additional information needed to understand the nature of the waste stream.

\subsection{Waste Minimization Assessment}

The waste minimization assessment identifies and evaluates various alternatives for reducing or eliminating hazardous or radioactive wastes generated in a process. A detailed understanding of how hazardous materials are used and wastes are generated in the process is critical to the success of this effort. Waste minimization is addressed for each waste stream listed in Appendix B.

\subsection{Waste Treatment and Disposal}

APT wastes will need to be managed for treatment and disposal according to waste type; i.e., low-level, mixed or hazardous waste, in accordance with the requirements of DOE Order 5820.2A and other applicable Orders. Treatment options that currently exist or are expected to be available by the time an APT facility is built are listed for each waste stream in Appendix B. If more than one treatment method is feasible for a particular waste stream, no attempt is made to prioritize or recommend specific treatments; such recommendations would necessarily be based on cost-benefit analyses and risk assessments that would be performed at a later stage of design development. If a treatment generates secondary waste that also requires treatment, this is discussed in the context of the primary APT waste stream and the secondary waste is not listed as a separate waste stream.

A description of treatment technology options that are currently available or expected to be available by the time a new tritium production facility is built and the waste acceptance criteria for DOE-approved low-level and mixed waste disposal facilities are presented in Appendix C, Treatment and Disposal of APT Wastes.

\section{Summary}

This PWA was based on pre-conceptual design information. A conceptual design of a 3/8 goal APT plant with primary and backup target designs will not be available until 1995 or later. The numbers reported here reflect design data in the LANL APT Monthly Status Report for January 1994; data received in a LANL briefing on April 26, 1994; Revision 1 of the LANL APT ${ }^{3} \mathrm{He}$ Target/Blanket Topical Report, dated March 1994; the BNL pre-conceptual design report, ATD/APT93-0025 (Rev. 0), dated 9/30/93, and the 6/10/94 revision of the latter document. PWA will be an iterative process with waste stream information being refined as the design progresses. 


\subsection{Process Waste Streams}

Forty-four waste streams have been identified and are described in Appendix B. Estimates of annual waste generation rates based on the information in Appendix B are presented in Table 1. A similar table has been developed for the Programmatic Environmental Impact Statement (PEIS) Input Submittal report. In addition to waste classification according to waste type (low-level, hazardous or mixed), data in the PEIS are broken out by waste source; i.e., accelerator waste, target waste, and tritium extraction and purification waste for the two target designs. A waste stream summary data table by waste type is listed in Appendix D and PEIS summary data are presented in Appendix E. The two summaries agree to within round-off error.

\section{Table 1}

\section{Estimated Annual Waste Generation Rates for APT}

Waste Type

Transuranic

High-Level

Low-Level

Hazardous

Mixed

Liquid Sanitary

Sewage

Solid Sanitary

Sewage
LiAl Target Design Mass, kg/yr Volume, $\mathrm{m}^{3} / \mathrm{vr}$

0

0

349,000

2,060

15,700

$34,890,000$

34,890

385,000
0.0

0.0

416.0

1.9

5.1

385
He-3 Target Design Mass, $\mathrm{kg} / \mathrm{yr}$ Volume, $\mathrm{m}^{3} / \mathrm{yr}$

0

0.0

0.0

55.3

0.9

2.8

The numbers given here should not be considered the total wastes for APT; they are the totals for waste streams that can be quantified at this time. Appendix B has a number of waste streams for which the quantities cannot be determined at the current design stage, and the numbers presented do not include contingency for these streams. However, it is estimated that streams which have not been quantified constitute less than $2 \%$ of the total waste for each target design.

While hazardous and mixed waste estimates are comparable for the two target designs, the data in the above table show that estimated total low-level waste for the He-3 target design is roughly $16 \%$ of the estimate for the LiAl target design. This difference (and the smaller differences seen in the hazardous and mixed waste totals) is largely due to the fact that tritium extraction in the LiAl design is a separate process that, based on past experience at SRS, is 
estimated to produce significant amounts of "job control waste," i.e., plastic shoe covers, plastic sheeting, rubber gloves, plastic suits and air hoses, etc. In contrast, tritium extraction in the He-3 design occurs continuously in conjunction with production and produces essentially no job control waste.

In their Topical Report?, BNL estimates job control waste at $390 \mathrm{~m} 3 / \mathrm{yr}$, with $2 / 3$ of this total resulting from extraction activities, and 1/3 from tritium purification. This total is based on operating data from SRS and includes failed equipment. This PWA has assumed that waste streams for failed equipment such as vacuum pumps, valves and piping will be approximately the same for both target designs. Based on data from SRS, the total estimate presented here for personal protection equipment (PPE) low-level waste streams for the $\mathrm{LiAl}$ design is $\sim 260,000 \mathrm{~kg} / \mathrm{yr}(369 \mathrm{~m} 3 / \mathrm{yr})$ or $\sim 74 \%$ of the total weight and $\sim 89 \%$ of the total volume of LLW. All PPE volumes are for uncompacted waste. If failed equipment is removed from the BNL estimate, the two PPE totals differ by only $9 \mathrm{~m}^{3}$, or less than $2.5 \%$.

PPE waste streams for the He-3 target design were estimated to be $\sim 20 \%$ of SRS totals for PPE associated with tritium purification. Using this metric, total low-level PPE is estimated at $23,660 \mathrm{~kg} / \mathrm{yr}(\sim 33.5 \mathrm{~m} 3 / \mathrm{yr})$, which is $\sim 42 \%$ of the total weight and $61 \%$ of the total He-3 volume of low-level waste. This estimate is also based upon over ten years' operating experience at the LANL Tritium Systems Test Assembly (TSTA), which has processed approximately $100 \mathrm{~kg}$ of tritium during this period ${ }^{9} \mathrm{using}$ the triple containment techniques proposed for He-3 target design tritium purification. During this ten-year period of continuous facility operation (all of the following statements are from Reference 11),

- TSTA has never had a spill.

- Glove box gloves have not needed to be changed.

- Approximately ten pairs of latex gloves have been used.

- Approximately $100 \mathrm{~kg}$ of plastic sheeting has been used.

- Approximately $45 \mathrm{~kg} / \mathrm{yr}$ of plastic bags are used.

- Plastic shoe covers are used an average of less than once a year.

- Plastic suits and air hoses have never been used.

Based on these data, the estimates presented for PPE waste streams for the He-3 target design are considered reasonable and conservative.

Routine maintenance and repair activities at current tritium facilities were the basis for approximately $30 \%$ of the waste streams identified in Appendix B. A new tritium facility will be designed to minimize the need for "plastic suit work" and the resulting wastes. A double or triple containment system such as that 
used at TSTA or the Replacement Tritium Facility (RTF) at SRS will allow for many maintenance activities to be performed in glove boxes and would minimize waste.

\subsection{Waste Treatment and Disposal}

\subsubsection{Waste Treatment}

Treatment options for APT wastes are summarized in Table 2. Waste streams in each treatment category are listed in Appendix F. Wastes that may be either compacted or thermally destroyed include water treatment filters and the PPE waste streams. Metal wastes from disassembly of target/blanket modules and LiAl melts and crucibles may be shredded and compacted to achieve volume reduction for disposal. The possibility of metals recycling should also be investigated. Wastes that are listed as requiring no treatment are those whose estimated volumes are so small that compaction would not be practical. Examples include the waste from refurbishment of accelerator ion pumps $\left(0.002 \mathrm{~m}^{3}\right)$ and the tungsten rods used as the neutron source in the He-3 target design $\left(0.034 \mathrm{~m}^{3}\right)$. Wastes that require encapsulation are those that contain RCRA-listed heavy metals, such as batteries, instrumentation and lead target material. Because of the small total volume, stabilization of liquid wastes such as spent solvents is recommended.

PPE wastes would be most effectively treated using incineration followed by stabilization of the ash residue. Incineration combined with stabilization would reduce the waste volume by roughly a factor of 20 . If thermal treatment is not used for PPE wastes, the majority of APT wastes ( $97 \%$ of $\mathrm{LiAl}$ wastes and $-75 \%$ of $\mathrm{He}-3$ wastes) would receive only the most basic treatment (compaction) prior to disposal. This would achieve a volume reduction of 3-5. In addition to providing greater volume reduction, at least one study has shown incineration to be more economical. A recent comparison of waste compaction with off-site treatment and disposal vs. on-site incineration conducted by SRS for their Consolidated Incineration Facility concluded that annual operating costs would be $\$ 20.3 \mathrm{M}$ for compaction and $\$ 13.5 \mathrm{M}$ for incineration ${ }^{25}$.

Sites currently under consideration for a tritium production facility are the Idaho National Engineering Laboratory (INEL), the Nevada Test Site (NTS), the Oak Ridge complex, Pantex, and the Savannah River Site (SRS). None of these facilities currently has the capacity to treat all APT wastes on-site. NTS is a disposal site for low-level waste (see Section C3.1), but has no on-site treatment capabilities, and none are planned. Pantex only has encapsulation facilities; future plans do not include facilities that could handle APT waste types and volumes. The other three sites all have existing and/or planned incineration and compaction capabilities suitable for APT waste. Existing and planned treatment facilities for each site are discussed in detail in Appendix C. 


\section{Table 2}

Treatment Options for APT Waste

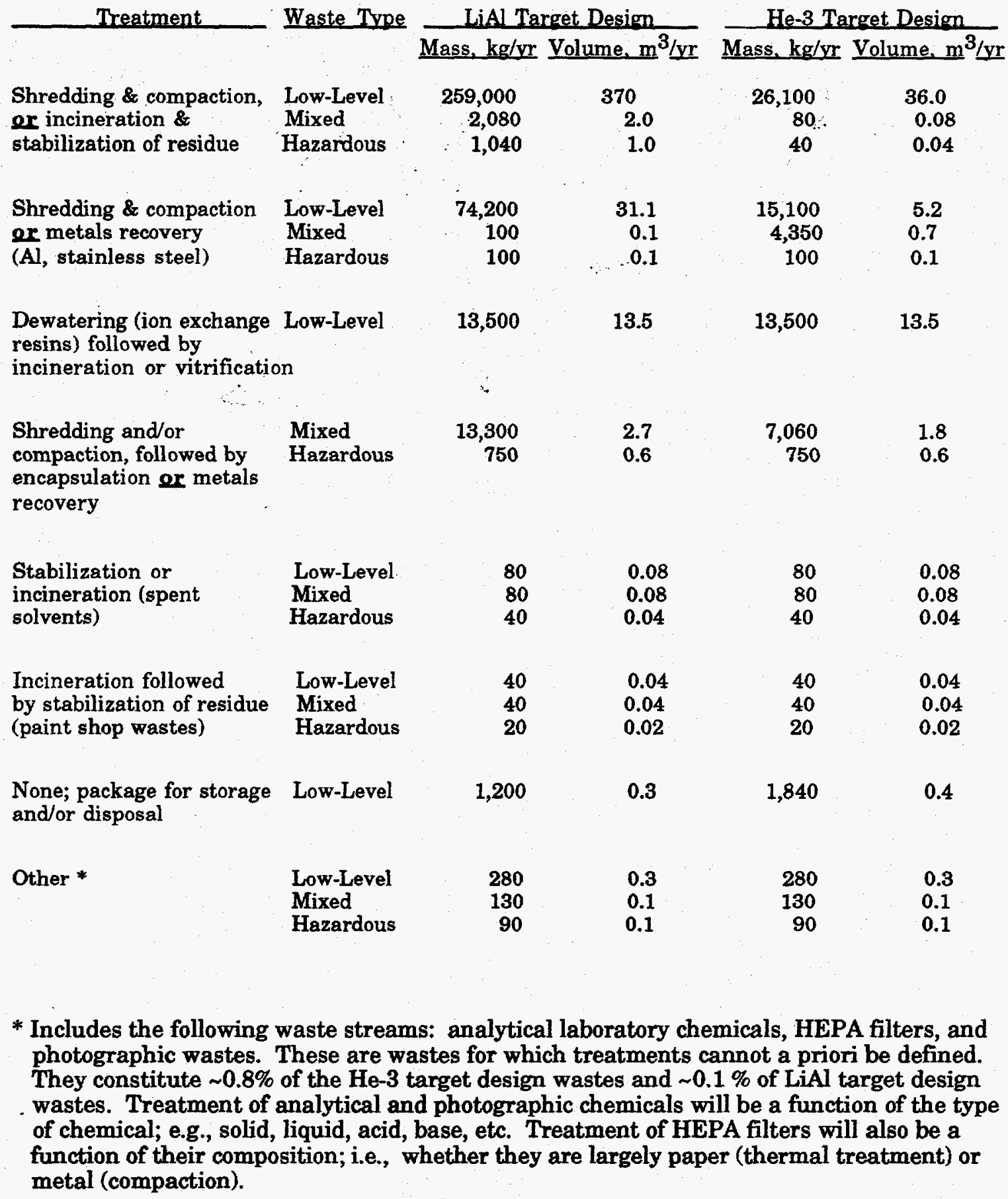




\subsubsection{Waste Disposal}

DOE Order 5820.2A requires that all DOE low-level waste (LLW) be disposed of at a DOE disposal facility. Of the sites being considered for APT, INEL, NTS, Oak Ridge and SRS are authorized LLW waste disposal facilities; Pantex is not. At the present time, there are only three DOE facilities that accept offsite waste for disposal: Hanford, NTS, and SRS. Barring policy changes, if APT were built at Pantex, LLW that meets the disposal site's Waste Acceptance Criteria (WAC) would be sent to one or more of these facilities. A formal application and approval process must be completed before waste can be shipped to any of these sites. Since Pantex is currently shipping LLW to NTS, they would merely have to revise their waste application to ship APT waste there.

No DOE facility is currently authorized to accept off-site mixed low-level waste (MLLW) for disposal; however, Hanford has accepted some shipments for storage on a case-by-case basis. Hanford, LANL NTS and SRS all have planned MLLW disposal facilities that are in the conceptual design phase and the preliminary stages of RCRA Part B permit applications. DOE currently allows mixed waste to be shipped to one permitted commercial facility, Envirocare of Utah, Inc., on a case-by-case basis.

APT hazardous waste could be disposed of at any DOE-approved commercial facility that would accept it.

\section{Conclusions}

APT has several advantages over reactor technology for tritium production. Reactors generate significant amounts of spent fuel requiring on-site management and/or storage; APT generates no spent fuel, and therefore no fission products are produced. Both target designs use material feedstocks that are readily available non-radioactive materials. APT will not be dependent on the uranium enrichment processes currently used for reactorbased production. Elimination of the need to produce enriched uranium would have significant environmental and economic effects within the nuclear weapons complex. 


\section{References}

1. APT Confirmatory Engineering and Development Program (Four Year Plan 9/93 - 9/97) Draft.

2. APT Monthly Status Report for January 1994.

3. APT Programmatic Environmental Impact Statement Input Submittal, Rev. 1, May 10, 1993.

4. APT SILC Target Pre-Conceptual Design, APT Quarterly Review Meeting, June 7-9, 1993, APT Project Team, Department of Nuclear Energy, BNL.

5. BNL, A Draft Pre-Conceptual Design for a Spallation-Induced Lithium Conversion (SILC) Target for the Accelerator Production of Tritium (APT), ATD/APT93-0001 (REV. 2), March 22, 1993.

6. BNL, Topical Report on a Pre-conceptual Design for the SpallationInduced Lithium Conversion (SILC) Target for the Accelerator Production of Tritium (APT), ATD/APT93-0025 (REV. 0), September 30, 1993.

7. BNL, Topical Report on Revision-1 of a Preconceptual Design for the Spallation-Induced Lithium Conversion (SILC) Target for the Accelerator Production ofTritium (APT)", ATD/APT-xxx (Rev. 0), June 10, 1994.

8. J.D. Brady, Fate of Tritium, Carbon-14, and Iodine-131 in Wet Scrubber Air Pollution Control Systems on Chemical and Medical Waste Incinerators, 1992 Incineration Conference, Albuquerque, New Mexico, May 11-15, 1992.

9. Briefing on APT for Steve Sohinki, presented at LANL, April 26, 1994.

10. Conversation with John Lucas, president of Ramp Industries, May 4, 1994.

11. Conversation with Luke Bartlein of the TSTA facility, April 26, 1994.

12. Envirocare of Utah, Inc. Information Package, received August, 1993.

13. Federal Facilities Compliance Act Mixed Waste Inventory Report, DOE, April 1993.

14. Framework for DOE Low-Level and Mixed Low-Level Waste Disposal: Current Overview, Draft Document, DOE Office of Waste Management (EM-30), November 19, 1993. 
15. L.J. Guillebaud, Memo: Results of Working Group Meeting (July 21-22, 1993)at LANL, dated 04 August 1993.

16. L.K. Heung et al, "Tritium Confinement in a New Tritium Processing Facility at the Savannah River Site", Fusion Technology, Vol. 21, March 1992.

17. LANL, APT ${ }^{3}$ He Target / Blanket Topical Report, LA-12670-MS, September 1993.

18. LANL, APT ${ }^{3}$ He Target / Blanket Topical Report, Volume 1, Revision 1, LA-CP-94-27, March 1994.

19. LANL, APT ${ }^{3}$ He Target/Blanket Tritium Extraction Facility Technical Report, LA-UR-93-3113, September 1993.

20. LANL, Tritium Systems Test Assembly Final Safety Analysis Report.

21. J. B. Mason, Modular Enviroglass TM Vitrification Technology for LowLevel Radioactive and Mixed Wastes, VECTRA Document No. SP-501001, Rev.2, VECTRA Technologies, Inc., Richland, WA.

22. Theodore Motyka, "The Replacement Tritium Facility", Fusion Technology, Vol 21, March 1992.

23. Nuclear Science: The Feasibility of Using a Particle Accelerator to Produce Tritium, U.S. General Accounting Office, February 1990.

24. M.S. Ortman, et al, "Tritium Processing at the Savannah River Site: Present and Future", J. Vac. Sci. Technol., A 8(3), May/Jun 1990.

25. H.L. Pope, C. McVay and T. Holm-Hansen, "A 'Fresh Look' at a U.S. Department of Energy Mixed Waste Incinerator," 1994 International Incineration Conference, Houston, TX, May 9-12, 1994.

26. Proposed Rules, Federal Register, Vol 58, No. 176, Tuesday, September 14, 1993.

27. L. Rosengrant and L. Lopez, Treatment Technology Background Document, U.S. Environmental Protection Agency Office of Solid Waste, January, 1991.

28. M.P. Sherman, Memo: Tritium Handling for the Accelerator Production of Tritium, dated 03 August 1992.

29. M.P. Sherman, Trip Report: To Savannah River for APT Program, dated 31 July 1992. 
30. SNL, Accelerator Production of Tritium Programmatic Environmental Impact Statement Input Submittal, SAND93-2094, November 1, 1993.

31. SNL/NM, Conceptual Site Treatment Plan for Mixed Waste, Appendix B, Rev. 1, October 15, 1993.

32. Gheorghe Vasaru, Tritium Isotope Separation . CRC Press, Inc., 1993.

33. Brad Wilson et al, 1992 Process Waste Assessment, Tritium Facility LowLevel Waste,Savannah River Site, NMP-STE-93 Draft. 


\section{Appendix A}

\section{APT Processes and Operations}

There are few true chemical processes in APT. Tritium is produced through nuclear processes, and the tritium is recovered and purified through a number of operations using physical separation processes. Many waste streams are materials that cannot be recycled or reused because they have become activated or contaminated through exposure to the nuclear process used to produce tritium. Other waste streams are system components which fail through usage or exposure to harsh environments, or which may be replaced due to obsolescence. As operations and processes are discussed, process outputs and system components that result in waste streams are identified.

The processes and operations associated with the accelerator production of tritium are organized into the following sections:

A1. Accelerator Operations

A2. Target/Blanket Operations

A2.1 Target Fabrication

A2.2 Target/Blanket Beam Exposure Operations

A2.3 Target Change-out

A3. Tritium Processing

A3.1 Tritium Extraction Operations

A3.2 Tritium Purification Processes

A3.3 Tritium Storage

A3.4 Tritium Recovery Systems

A4. Support Facilities 


\section{A1. Accelerator Operations}

The accelerator design is based on existing proton linear accelerators (linacs) similar to the Los Alamos Meson Physics Facility (LAMPF). The APT accelerator is made up of several types of linear accelerators that provide efficient energy gain to the beam over specific velocity ranges, with an average accelerating gradient of approximately $1 \mathrm{MV} / \mathrm{m}$. A continuous stream of protons is generated in an ion source (plasma chamber) and injected at an energy of $75 \mathrm{keV}$ into a radio-frequency $(\mathrm{RF})$ quadrupole linac where it is formed into bunches at the frequency of the RF power system (350 MHz) and accelerated to $7 \mathrm{MeV}$. These bunches are then further accelerated to $20 \mathrm{MeV}$ in a drift-tube linac, and combined longitudinally with a second bunch train at that energy (funneling). The combined proton beam is accelerated to $100 \mathrm{MeV}$ in a bridge-coupled drift-tube linac and then to full energy $(1000 \mathrm{MeV})$ in a series of coupled-cavity linac (CCL) modules. The latter structures, which are powered by 700-MHz RF power tubes (klystrons), make up the bulk of the accelerator. The average current in the CCL would be $200 \mathrm{~mA}$ for a $3 / 8$ goal production system, and the average beam power would be $200 \mathrm{MW}$. Because the beam power and current are large compared with existing linear accelerators, there is a significant potential for activation of accelerator structures and tunnel air if even a small fraction of the beam is lost on a continuous basis.

The accelerator is housed within a concrete tunnel that is buried under 12 to 15 meters of earth for radiation shielding. The overall length of the system is about $1200 \mathrm{~m}$. At the end of the accelerator the beam is directed to one of two target/blanket assemblies in the target area by a beam transport and switchyard system. This system consists of bending and focusing magnets and evacuated pipes through which the beam travels. The system also provides the correct expanded beam size and shape at the target and switches the beam between target/blanket assemblies as required.

Before the beam is directed into one of the tritium-producing target areas, the beam is sent through a third transport channel to a full-power beam stop for tuning the accelerator prior to target operations. The beam stop can also be used to dump the beam any time it is necessary to divert it from the target area without shutting off the accelerator. The beam stop will accept the full $200 \mathrm{MW}$ for an unlimited time. The beam stop is designed to passively radiate the deposited power to an actively cooled structure.

The tunnel is sealed during operation. During shutdown conditions, the air in the tunnel is exhausted to the atmosphere through a delay line and a stack. Air in the accelerator tunnel is activated by radiation from beam loss along the accelerating structure and beam path. Since the isotopes produced decay very rapidly (half lives of minutes to hours), the tunnel air is isolated from the environment during the beam operation and for an appropriate isolation period after shutdown. Since the dominant activated air products are short-lived radionuclides, an isolation period of one hour will reduce the amount of radioactivity by a factor of ten. 
The composition of activity released from the accelerator tunnel is shown below4:

\begin{tabular}{cc} 
Isotope & Activity Distribution (\%) \\
\cline { 2 - 2 } C-10 & 0.8 \\
C-11 & 48.4 \\
N-13 & 18.6 \\
N-16 & 0.2 \\
O-14 & 1.1 \\
O-15 & 24.8 \\
Ar-41 & 6.1
\end{tabular}

The amount of radioactivity released from the accelerator due to air leakage from the tunnel during normal beam operations and due to air exhaust from the tunnel following shutdown for maintenance was estimated based on experience at LAMPF. Conservative analyses of the release to the environment due to air leakage from the tunnel during normal beam operations yield a release of $87 \mathrm{Ci}$ per year at the surface. Similar conservative analyses for the release of activated air to the environment following beam shutdown for maintenance result in a release of $83 \mathrm{Ci}$ per year.

Power supplies used for the APT accelerator are heavy-duty industrial units that should last the life of the facility. Most other components of the accelerator are also anticipated to last the life of the facility. Two exceptions are klystrons and ion pumps, which will fail periodically and will be refurbished. Additional waste streams will result from failed or obsolete monitoring instrumentation, cooling system maintenance, and personal protection equipment (PPE).

Regular maintenance of the accelerator cooling system will generate a significant waste stream. However, as of the July 21-22, 1993 Working Group Meeting at LANL, the cooling system design had not been finalized. For cost reasons it is necessary to reduce the number of pumps and heat exchangers. Bechtel will study the temperature control scheme for CCL cooling loops to facilitate this reduction in required equipment. The design of the cooling system for the beam stop has also been deferred to a later date.

Accelerator waste streams are independent of the final choice of target design. Because of the potential for system components to be activated or contaminated by activated air, wastes from the accelerator have the potential to be radioactive. Solvents used in maintenance and items containing heavy metals can introduce hazardous components into the waste streams.

Wastes from accelerator operations are included in the following waste streams described in Appendix B: 
Batteries

Cooling System Maintenance

Instrumentation

Ion Pump Materials

Klystron Materials

Personal Protection Equipment

Solvent Rags

\section{A2. Target/Blanket Operations}

Waste streams for target/blanket operations include those generated through target fabrication operations, beam exposure operations, and target changeout operations.

There are currently two choices for APT target/blanket designs, the lithiumaluminum (LiAl) target design and the helium-3 (He-3) target design. Both target designs have the following characteristics:

Water-cooled beam entrance window separating target and accelerator Neutron source that is $\mathrm{D}_{2} \mathrm{O}$-cooled and moderated

Tritium production in a target blanket by neutron capture

Target blanket $\mathrm{H}_{2} \mathrm{O}$-cooled and moderated

Target chamber located in-line with the accelerator beam

Operation at low temperature and pressure

Periodic target changeout required

Two identical target assemblies for continuous operation during target changeout

In spite of these similarities, the materials used and resulting waste streams are quite different, as seen in the following summary of material and performance design parameters:

$\begin{array}{ll}\text { Item } & \frac{\text { LiAl Target Design }}{\text { Window }} \\ \text { Neutron Source } & \text { Pb Pins with Al Cladding } \\ \text { Al Pressure Tubes }\end{array}$

Tritium Production Blanket

Neutron Capture Reaction

Tritium Processing
LiAl with Al Cladding

$$
{ }^{6} \mathrm{Li3}+{ }^{1} \mathrm{n}_{0}-->{ }^{3} \mathrm{~T}_{1}+{ }^{4} \mathrm{He}_{2}
$$

Batch Processing Extraction Only at End of Exposure Time T-3 Inventory Increases Over Exposure Time
He-3 Target Design

Inconel-718

Tungsten

$\mathrm{Pb}$ Neutron Multiplier with Al Cladding

He-3 in Al Tubing

${ }^{3} \mathrm{He}_{2}+{ }^{1} \mathrm{n}_{0} \ldots{ }^{3} \mathrm{~T}_{1}+{ }^{1} \mathrm{H}_{1}$

Continuous Processing Constant Removal of T-3

Slipstream

T-3 Inventory Remains

Low and Constant 
$\frac{\text { Item }}{\text { Target Changeout Interval }}$

Annual Waste Streams from

Spent Components
LiAl Target Design

Target, 2 Years

Target Blanket, One Year

$12,400 \mathrm{~kg} \mathrm{~Pb}$

$41,000 \mathrm{~kg} \mathrm{LiAl}$

$3,700 \mathrm{~kg} \mathrm{Al}$
He-3 Target Desien

2.2 Years

$6,160 \mathrm{~kg} \mathrm{~Pb}$

$650 \mathrm{~kg} \mathrm{~W}$

$2,500 \mathrm{~kg} \mathrm{Al}$

$2,250 \mathrm{~kg}$ Inconel-718

$12,100 \mathrm{~kg}$ Stainless Steel

$2,000 \mathrm{~kg}$ Zircaloy 4

Major system components that contribute to waste streams for target /blanket operations are the window, the neutron source, and the tritium production blanket.

\section{Window}

The window provides a pressure boundary between the vacuum of the accelerator and target area. The He-3 target window is comprised of two walls of Inconel-718 with a gap between the walls for the flow of heavy water coolant. The LiAl target window is a similar design employing Al-1100.

\section{Neutron Source}

The neutrons needed for tritium production are produced by spallation of either lead or tungsten by high energy protons. Neutrons are produced either directly, being knocked out as a proton hits the nucleus, or as a decay product of an excited nucleus. The number of useful neutrons produced by lead or tungsten per proton absorbed is typically 20 for a $1 \mathrm{GeV}$ proton beam. In absolute terms, tungsten produces more neutrons per proton absorbed at a given proton kinetic energy; however, its higher neutron absorption cross section tends to cancel the advantage of the higher neutron-to-proton production ratio. The choice of spallation material is a function of the geometric design of the target. BNL's comparison analysis of the use of tungsten and lead indicated the greater absorption of neutrons by tungsten overcame the benefit of increased neutron-to-proton spallation production. Therefore, BNL has used lead as the source for the LiAl target design. LANL prefers tungsten as the neutron source for the He-3 target design, and has designed thin rods to minimize the neutron absorption of tungsten.

Once produced by the spallation mechanism (whether by lead or tungsten), the fast neutrons are thermalized by a moderator in a process similar to the thermalization of fast neutrons in a fission reactor. Heavy water is the proposed moderator and coolant.

\section{Tritium Production Blanket}

In the LiAl target design, tritium is produced in two areas, the beam expander duct, where the proton beam from the linac is magnetically expanded, and the 
blanket surrounding the neutron source array of Al-clad lead rods. Both the beam expander duct and the source blanket are constructed of $\mathrm{Al}$-clad LiAl plates. The source blanket consists of two assemblies, the U-Blanket, which covers the bottom and sides of the neutron source array, and the L-Blanket, which covers the top and back. As beam exposure progresses, the tritium inventory builds up in the target blanket. Tritium is extracted in a batch process after the beam expander and source blanket assemblies are removed. Blanket modules can be removed from the target chamber without removing the neutron source array.

In the $\mathrm{He}-3$ target design, $\mathrm{He}-3$ is circulated through the blanket in aluminum tubes, and a slipstream is continually removed for separation, keeping the tritium content at a low level.

\section{A2.1 Target Fabrication}

As the APT design progresses, target design and fabrication processes may change. The materials selected for the target and blanket modules were based on the following criteria: 1) favorable operating experience in similar radiation and temperature environments, 2) low neutron-capture cross sections to minimize parasitic neutron losses and maximize tritium production, and 3) for the lithium-aluminum, SRS experience in fabrication, operation, and tritium extraction.

Other criteria, such as mechanical attributes, safety, and waste streams, may dictate material changes as the target design evolves. The primary characteristics sought in any target material are high melting temperature, greater strength at elevated temperatures, improved material compatibility, and reduced source term or dose.

\section{LiAl Target}

The fabrication process specifications for $\mathrm{Al}-$ clad $\mathrm{Pb}$ target rods and $\mathrm{LiAl}$ blanket plates have not yet been defined. However, the current choices for materials and fabrication are:

Neutron spallation source: Commercially pure lead (ASTM B29) shrunk-cast onto Al-1100 tubes (ASTM B214). A barrier coating will be used between the aluminum tubes and the lead to prevent the migration of spallation by-products (primarily mercury and thallium) out of the lead. Preliminary plans are to use an anodized coating on the aluminum. An alternate method of fabrication, involving thermal spray coating of aluminum on cast or extruded lead rods, is also being investigated. The sheathed lead rods will be contained in 6061-T6 extruded aluminum pressure tubes and will be welded at each end to 6061-T6 wrought aluminum or A356 cast aluminum coolant supply headers. 
Tritium production blanket and beam expander: Al-clad Li-Al alloy (max 3 wt \% $\mathrm{Li}$; $\mathrm{Li}$ will be $50-90$ atom \% $\mathrm{Li}-6$ ) plates. The header coolant inlet and outlet nozzles will be 6061-T6 wrought aluminum or A356 cast aluminum.

Window: 6061-T6 aluminum.

Evaluation of alternate materials and design features continues. Some materials under consideration are lithium aluminate as a possible replacement for LiAl; tungsten and lead oxide as possible replacements for the lead; and Inconel, stainless steel, Zircaloy, and various aluminum grades as possible replacements for the essentially pure aluminum currently used for structural components. Alumium alloy, stainless steel, and a nickel-chromium-iron alloy are being considered as alternate cladding materials. Ceramic and metallic diffusion barriers are being examined. Inconel and some stainless steels are being looked at as possible window materials. In addition, increased loading of lithium, or further enrichment with Li-6 within the current SRS envelope may increase tritium production to where design and/or material modifications are required.

\section{He-3 Target}

The target/blanket assembly consists of 104 tungsten rod bundles distributed along an Inconel-718 chamber filled with $\mathrm{He}-3$. The proton beam enters the chamber through an Inconel-718 window. A proton beam backstop made of Zircaloy and lead is behind the chamber. An annulus of $\mathrm{D}_{2} \mathrm{O}$-cooled lead surrounds the chamber. The pre-conceptual design of the lead region has focused on an unclad, stacked-plate concept; however, an aluminum-clad design will be developed in the next program phase. Surrounding the lead is a ring of aluminum tubing containing $\mathrm{He}-3, \mathrm{a} \mathrm{D}_{2} \mathrm{O}$ moderator, another ring of $\mathrm{He}-$ 3 , and a $\mathrm{D}_{2} \mathrm{O}$ reflector. The entire assembly is contained in a steel tank.

The tungsten rods, Inconel window, Zircaloy and some of the lead components will be changed out after approximately 2.2 years of full power operation at 75\% capacity. Remaining components are expected to last the life of the facility. Standard metal manufacturing methods are expected to be used for target fabrication.

\section{Wastes from Target Fabrication}

Wastes from target fabrication operations are included in the following waste streams described in Appendix B:

Target Fabrication Wastes

Welding Wastes 


\section{A2.2 Target/Blanket Beam Exposure Operations}

Most of the wastes from exposure of the target/blanket to the neutron beam come from the target/blanket cooling system. Cooling system components are expected to last the life of the facility; however, routine maintenance will produce waste. Other waste streams would be protective clothing if for some reason the target/blanket chamber must be entered for inspection or maintenance activities.

\section{Target/Blanket Cooling System}

The target/blanket cooling system design is still in the preliminary stage. The main source heat exchanger(s) are expected to be one of the major cost items. Cost trade-off is required between heat exchanger size and plant coolant flow and pumping costs. The current design assumes a bare tube $\mathrm{D}_{2} \mathrm{O}$ to $\mathrm{H}_{2} \mathrm{O}$ exchanger, with $\mathrm{D}_{2} \mathrm{O}$ on the tube side and $\mathrm{H}_{2} \mathrm{O}$ on the shell side, for the neutron source and an $\mathrm{H}_{2} \mathrm{O}$ to $\mathrm{H}_{2} \mathrm{O}$ system for the blanket assemblies. Other design options, such as helical tube bundle heat exchangers, are still being evaluated. Preliminary cooling system parameters for both the LiAl and He-3 target designs are listed in Tables A1 and A2.

\section{Water Purification Systems}

The heavy and light water coolant systems for the target blanket require purification systems. A slip stream from each system is passed through filters and mixed ion exchange resin beds to remove corrosion products and radioactive contaminants. The dominant source of activity in the cooling water is the recoil of the spallation products near the cooled surfaces. Conductivity checks will determine when the resin beds are recharged. Water treatment chemicals will be added regularly to maintain the desired water chemistry. The heavy water coolant will have an added burden of tritium buildup in the coolant. The goal is to maintain this at or below $1.7 \mathrm{Ci} /$ iter.

\section{A2.3 Target Change-Out}

A confinement system will envelop the target area, the housing for the primary coolant loop components, and the compartments in which spent target handling, disassembly, and preparation for shipment activities are conducted. This confinement system will include an atmospheric cleanup system that oxidizes hydrogen isotopes and their compounds to water which is recovered by molecular sieve dryers.

A single target/blanket building design for the two target concepts has been deferred to the next design phase. Two target storage and handling pools are assumed at this time, each with a three-target capacity. Also deferred is an estimate of spallation products in pool water if spent targets are dismantled in the pool. 


\begin{tabular}{|c|c|c|c|c|c|c|}
\hline & $\begin{array}{l}\text { Cooling Load } \\
\text { per loop, MW }\end{array}$ & $\begin{array}{l}\text { No. } \\
\text { Loops }\end{array}$ & Coolant & $\begin{array}{l}\text { Hot Leg } \\
\text { Temp, F }\end{array}$ & $\begin{array}{l}\text { Cold Leg } \\
\text { Temp, F }\end{array}$ & $\begin{array}{l}\text { Flow Rate, } \\
\text { GPM }\end{array}$ \\
\hline \multicolumn{7}{|l|}{ Neutron Source } \\
\hline Primary Coolant & 81.5 & 2 & $\mathrm{D}_{2} \mathrm{O}$ & $\overline{221}$ & 140 & 6500 \\
\hline Secondary Coolant & 81.5 & $\overline{2}$ & $\mathrm{H}_{2} \mathrm{O}$ & $\overline{170}$ & 100 & 6500 \\
\hline $\begin{array}{l}\text { Circulating Water } \\
\text { System }\end{array}$ & 81.5 & $\overline{2}$ & $\overline{\mathrm{H}_{2} \mathrm{O}}$ & $\overline{121}$ & 85 & $\begin{array}{r}1550 \\
0\end{array}$ \\
\hline Primary RHR System & 1 & $\overline{2}$ & $\overline{D_{2} 0}$ & 180 & 150 & 150 \\
\hline Secondary RHR System & 1 & $\overline{2}$ & $\mathrm{H}_{2} \mathrm{O}$ & 150 & 120 & 150 \\
\hline \multicolumn{7}{|l|}{ Blanket } \\
\hline Primary Coolant & $\overline{13}$ & 2 & $\mathrm{H}_{2} \mathrm{O}$ & 210 & 180 & 9000 \\
\hline Secondary Coolant & $\overline{13}$ & $\overline{2}$ & $\overline{\mathrm{H}_{2} \mathrm{O}}$ & 170 & 100 & 1280 \\
\hline $\begin{array}{l}\text { Circulating Water } \\
\text { System }\end{array}$ & $\overline{13}$ & 2 & $\mathrm{H}_{2} \mathrm{O}$ & $\overline{121}$ & 85 & 2475 \\
\hline Primary RHR System & 0.12 & $\overline{2}$ & $\mathrm{H}_{2} \mathrm{O}$ & 180 & 150 & 85 \\
\hline Secondary RHR System & 0.12 & 2 & $\mathrm{H}_{2} \mathrm{O}$ & 160 & 130 & 85 \\
\hline \multicolumn{7}{|l|}{ Window } \\
\hline Primary Coolant & 0.5 & $\overline{2}$ & $\mathbf{H}_{2} \mathbf{O}$ & $\overline{176}$ & 142 & 101 \\
\hline Secondary Coolant & 0.5 & 2 & $\mathrm{H}_{2} \mathrm{O}$ & 122 & 100 & 86 \\
\hline $\begin{array}{l}\text { Circulating Water } \\
\text { System }\end{array}$ & 0.5 & 2 & $\mathrm{H}_{2} \mathrm{O}$ & 120 & 84 & 95 \\
\hline \multicolumn{7}{|l|}{ Shield } \\
\hline Primary Coolant & 10 & 1 & $\mathrm{H}_{2} \mathrm{O}$ & 154 & 100 & 1270 \\
\hline $\begin{array}{l}\text { Circulating Water } \\
\text { System }\end{array}$ & 10 & 1 & $\mathrm{H}_{2} \mathrm{O}$ & 121 & 85 & 1900 \\
\hline
\end{tabular}

Table A1. LiAl Target System Cooling Parameters 


\begin{tabular}{|c|c|c|c|c|c|c|}
\hline & $\begin{array}{l}\text { Cooling Load } \\
\text { per loop, MW }\end{array}$ & $\begin{array}{l}\text { No. } \\
\text { Loops }\end{array}$ & Coolant & $\begin{array}{l}\text { Hot Leg } \\
\text { Temp, F }\end{array}$ & $\begin{array}{l}\text { Cold Leg } \\
\text { Temp, F }\end{array}$ & $\begin{array}{l}\text { Flow Rate, } \\
\text { GPM }\end{array}$ \\
\hline \multicolumn{7}{|l|}{ Neutron Source } \\
\hline Primary Coolant & 46 & $\overline{2}$ & $\overline{\mathrm{D}_{2} \mathrm{O}}$ & 221 & 149 & 4188 \\
\hline Secondary Coolant & 46 & 2 & $\mathrm{H}_{2} \mathrm{O}$ & 154 & 100 & 5900 \\
\hline $\begin{array}{l}\text { Circulating Water } \\
\text { System }\end{array}$ & $\overline{46}$ & $\overline{2}$ & $\mathrm{H}_{2} \mathrm{O}$ & 121 & $\overline{85}$ & 8800 \\
\hline Primary RHR System & 0.93 & $\overline{2}$ & $\overline{\mathrm{D}_{2} \mathrm{O}}$ & 180 & 150 & 103 \\
\hline Secondary RHR System & 0.93 & $\overline{2}$ & $\mathrm{H}_{2} \mathrm{O}$ & 150 & 120 & 107 \\
\hline \multicolumn{7}{|l|}{ Blanket } \\
\hline Primary Coolant & 25.5 & 2 & $\overline{\mathrm{H}_{2} \mathrm{O}}$ & 158 & 122 & 4470 \\
\hline Secondary Coolant & 25.5 & $\overline{2}$ & $\mathrm{H}_{2} \mathrm{O}$ & 132 & 100 & 5500 \\
\hline $\begin{array}{l}\text { Circulating Water } \\
\text { System }\end{array}$ & 25.5 & 2 & $\mathrm{H}_{2} \mathrm{O}$ & 121 & 85 & 4900 \\
\hline Primary RHR System & 0.28 & $\overline{2}$ & $\mathrm{H}_{2} \mathrm{O}$ & 180 & 150 & 65 \\
\hline Secondary RHR System & 0.28 & $\overline{2}$ & $\mathrm{H}_{2} \mathrm{O}$ & 150 & 120 & 64 \\
\hline \multicolumn{7}{|l|}{ Window } \\
\hline Primary Coolant & 1.06 & 1 & $\mathrm{H}_{2} \mathrm{O}$ & 158 & 140 & 409 \\
\hline Secondary Coolant & 1.06 & $\overline{1}$ & $\overline{\mathrm{H}_{2} \mathrm{O}}$ & 140 & 100 & 182 \\
\hline $\begin{array}{l}\text { Circulating Water } \\
\text { System }\end{array}$ & 1.06 & 1 & $\mathrm{H}_{2} \mathrm{O}$ & 121 & 85 & 200 \\
\hline \multicolumn{7}{|l|}{ Shield } \\
\hline Primary Coolant & 15 & $\overline{1}$ & $\mathrm{H}_{2} \mathrm{O}$ & 154 & 100 & 1900 \\
\hline $\begin{array}{l}\text { Circulating Water } \\
\text { System }\end{array}$ & 15 & 1 & $\overline{\mathrm{H}_{2} \mathrm{O}}$ & 121 & 85 & 2850 \\
\hline
\end{tabular}

Table A2. Helium-3 Target System Cooling Parameters

\section{LiAl Target}

The target consists of four distinct sections which are assembled in a modular fashion and then disassembled after beam exposure:

- A Neutron Source Array that produces neutrons via spallation and evaporation processes induced by an incident proton beam. 
- The U and L Tritium Production Blankets that surround the neutron source on five sides (top, bottom, sides, and back) and produce tritium via neutron capture in $\mathrm{Li}-6$.

- The Beam Expander Duct that surrounds the proton beam expander chamber and captures neutrons leaking from the front face of the source region, again producing tritium via neutron capture in $\mathrm{Li}-6$.

The beam expander duct and blanket assemblies will be changed out at the end of each annual production cycle. The neutron source array will be used for two cycles prior to changeout. Water storage and transfer pools provide cooling and radiation shielding for remote disassembly and packing of spent target/blanket assemblies. The LiAl plates would be separated for on-site tritium processing and the $\mathrm{Pb}$ targets and remaining structural components would be dismantled, compacted and packaged for on-site storage or off-site disposal using remote underwater equipment. A water purification system is required to remove metal fines and corrosion products from the pool.

\title{
He-3 Target
}

The neutron source assembly is designed as a separate unit that can be removed and replaced during a routine maintenance period. An area is required for cooling and radiation shielding of spent tungsten and the beam entrance window removed from the target cavity. Remote handling apparatus to load packaged targets into shipping casks is in the early stages of conceptual development. Issues that will be addressed include protection of the remote handling equipment from radiation and an evaluation of submerged operations versus "dry" or "drip" operations where exposed components temporarily heat up and/or are cooled by auxiliary means.

\section{Wastes from Target Change-out}

Wastes from target change-out operations are included in the following waste streams described in Appendix B:

\author{
Catalyst Beds (Uranium or Platinum/Alumina) \\ Target Storage Pool Wastes \\ Zeolite Beds
}

\section{A3. Tritium Processing}

Waste streams from tritium processing include all wastes produced during tritium extraction, purification, enrichment, and storage for shipment. The tritium processing facility will be designed and operated to recover virtually all of the tritium produced in the targets and to minimize both tritium release to the environment and liquid and solid waste generation. Both the LiAl and He-3 process designs produce tritium that is $>99 \%$ pure. 


\section{LiAl Target}

Tritium processing will be performed at an on-site facility similar to the current tritium extraction facilities at SRS. Past experience at SRS facilities indicates that many significant waste streams do not come from the actual extraction and processing of tritium, but rather from maintenance activities. Previously, maintenance operations had to be performed in an "open" box, requiring the use of protective clothing. This "plastic suit work" added significantly to the amounts of low-level waste generated. The APT tritium processing facility will make use of the latest technology to enhance operational safety, ensure material safeguards and security, and avoid tritium losses to the environment. All process and waste systems are housed in enclosures designed to contain and allow recovery of tritium leaks. When processes are contained in glove boxes, routine maintenance operations can be performed through glove box ports without the use of a full-body plastic suit. These enclosures are maintained under negative pressure to prevent leakage of contaminated gases and can be filled with an inert gas atmosphere to minimize the formation of tritium compounds prone to skin absorption. Glove box gases are discharged to a tritium recovery system. Using these procedures, tritium releases to the atomosphere as a result of $\mathrm{LiAl}$ target processing are predicted to be $<10,000$ $\mathrm{Ci} / \mathrm{yr}^{1}$.

\section{He-3 Target}

The He-3 target tritium processing conceptual design is based upon demonstrated technology similar to that used at the TSTA facility that has been in operation at LANL for over 10 years. TSTA uses a triple containment scheme. The primary containment consists of the system tubing, vessels and valves. The secondary containment includes concentric tubing around the primary tubing and glove boxes for ancillary equipment. The volumes between the primary and secondary barriers are monitored for tritium leaks and the gas in these volumes can be sent to a tritium separation system for tritium recovery. The ternary containment is the surrounding room which is kept at a small negative pressure relative to the exterior and is monitored for tritium leaks. If there is a tritium release to the room, a high-capacity air purification system recovers the tritium. TSTA has redundant barriers to tritium release and redundant systems to recover the tritium if it leaks into any containment volume. Pumps and valves can be a major source of both leakage and mixed waste. None of the pumps used in TSTA use mercury or other lubricants that can become mixed waste. Bellows and other zero-leakage valves are used.

The He-3 target design specification for maximum allowable tritium discharge to the atmosphere is $20 \mathrm{mCi} / \mathrm{m}^{3}$ with a maximum stack discharge flow rate of $180 \mathrm{~m}^{3} / \mathrm{hr}^{3}{ }^{3}$ If a normal 2000 -hr operational year is assumed, this results in a predicted maximum annual discharge of $7200 \mathrm{Ci}$. This estimate is considered to be conservative based on the experience at TSTA, which has released approximately $300 \mathrm{Ci}$ of tritium to the atmosphere in over ten years of operation ${ }^{2}$. 


\title{
A3.1 Tritium Extraction Operations
}

\section{LiAl Target}

Blanket and beam expander assemblies will be separated into stacks of LiAl plates for tritium extraction in an on-site facility that uses an updated version of technology that has been in use at SRS for almost 40 years. The plates are sealed in stainless steel crucibles and melted in a vacuum furnace to release tritium, helium, and impurities such as protium, deuterium, water and methane. Heating is controlled so that the pressure of the gases escaping the heated targets is kept low to minimize the tritium being absorbed by the furnace walls. The furnace and associated process equipment are installed in glove boxes filled with nitrogen to contain any tritium that may leak out during insertion and removal of the crucibles. The furnace and accompanying lead shielding should last for the life of the facility. After extraction the crucible containing the spent melt is packaged for disposal as low-level solid waste. A stripper system removes tritium from the recirculating glove box atmosphere.

Wastes from tritium extraction processes for the LiAl target are included in the following waste streams described in Appendix B:

\author{
LiAl melts \\ Crucibles \\ Piping and Valves
}

\section{He-3 Target}

Since tritium is removed and processed as it is generated, the target never has more than 1 to 5 days inventory of tritium present. A slipstream of tritium $(0.1-1.0$ mole \%) is pulled using a palladium membrane diffuser and is purified. No significant waste streams result from tritium extraction with this target design.

\section{A3.2 Tritium Purification Processes}

Tritium purification and recovery consists of three separate processes:

1) Removal of impurities.

2) A transfer process that reduces hydrogen isotopes from the oxide form to the elemental form.

3) A concentration process that separates elemental tritium from other hydrogen isotopes.

\section{A3.2.1 Removal of Impurities}

AT SRS the hydrogen isotopes released in a target extraction furnace are separated from $\mathrm{He}-3$ (caused by tritium decay), $\mathrm{He}-4$ and impurity gases by 
permeation of the hydrogen isotopes through palladium-silver alloy diffusers. These diffusers have to be replaced at regular intervals and are addressed as a waste stream in Appendix B. A similar process will be used for the LiAl target process for APT.

For the He-3 target, purification requires the separation of impurities such as nitrogen, oxygen, nitrogen oxides, carbon dioxide, argon, ammonia, and methane. Helium also may be removed at this stage. One purification method is a selective diffusive membrane of palladium that passes only hydrogen. The alternative technology for separation of impurities uses molecular sieves at cryogenic temperatures to remove all impurities other than helium.

\section{A3.2.2 Transfer of Hydrogen Isotopes to Elemental Form}

Impurities such as ammonia and methane may contain tritium and cannot be released without treatment. Oxygen is added to the impurity stream and the ammonia, methane, and other hydrocarbons are oxidized in a catalytic reactor. Tritium in the impurity stream is oxidized to water, which is removed in a cold trap just warm enough not to condense carbon dioxide and sent to electrolysis cells where the oxygen is separated from the hydrogen. The hydrogen is then sent to an isotopic separation system.

\section{A3.2.3 Concentration of Elemental Tritium}

The He-3 system uses cryogenic distillation through four distillation columns to separate $\mathrm{T}_{2}, \mathrm{D}_{2}, \mathrm{DT}, \mathrm{HT}, \mathrm{HD}$, and $\mathrm{H}_{2}$. Processing of the LiAl target will use processes similar to those used at SRS facilities. At the SRS Tritium Extraction Facility the hydrogen isotopes are separated by batch cryogenic distillation. During normal operations the gas exhausted to the atmosphere has tritium concentrations in the range of 5 to 10 parts per million. New facilities at SRS use a thermal cycling absorption process based on metal hydride technology. This is a semi-continuous chromatographic separation process that uses $\mathrm{Pd} /$ Kieselguhr as the packing material.

\section{Cryogenic Distillation}

The relatively large mass difference between protium $(H)$, deuterium (D), and tritium (T) makes isotopic distillation a practical separation scheme. With recent improvements in the operation of cryogenic distillation columns, it is now possible to make very high purity $(>99 \%)$ tritium and stackable raffinate containing $<5 \mathrm{ppm}$ tritium in a single batch run.

Cryogenic distillation utilizes the liquid-gas equilibrium in the temperature range of liquid hydrogen ( 20 to $30 \mathrm{~K}$ ). A refrigeration system with helium circulation is used for safety.

Distillation columns are $15-20$ feet tall. The columns have a small diameter and require considerable insulation. They should last indefinitely and require minimal maintenance. The wastes generated from cryogenic distillation are 
mainly failed valves and instrumentation (i.e., temperature and pressure gauges).

\section{Hydride Bed Separation}

Hydrides can be used to do much of the separation and some of the pumping in tritium processing. The advantage of the hydride system is that its smaller volume provides significant cost savings. One possible problem with using hydrides in isotope separation is whether they can reduce the tritium concentration in the waste gas to the 5 to $10 \mathrm{ppm}$ of the cryogenic distillation process.

\section{A3.3 Tritium Storage}

Certain metals and alloys which react rapidly and reversibly with hydrogen at room temperature and atmospheric pressure to form metal hydride compounds represent a technology ideally suited to the handling and processing of tritium. The hydriding/dehydriding reaction can be used as a basis for the storage, pumping, compression, purification and separation of hydrogen isotopes. One of the most important advantages of using hydride technology in tritium processing is the compact size of hydride equipment, due to the fact that the volumetric density of hydrogen in typical hydrides is greater than that of liquid or solid hydrogen. This allows hydride beds to be installed in process hoods and glove boxes at locations where only minimal space is available and saves money through reduced numbers of glove boxes and the overall size of the processing facility. Other benefits of using hydride technology for tritium handling applications are improved safety during storage of tritium in the hydride form.

Wastes from tritium storage operations are included in the following waste streams described in Appendix B:

\section{Hydride Storage Beds}

\section{A3.4 Tritium Recovery Systems}

Tritium processes and waste systems are housed in enclosures designed to contain and allow recovery of tritium leaks. A tritium recovery system processes the atmosphere from enclosures to recover residual tritium. The system oxidizes hydrogen isotopes and their compounds to water which is then recovered by molecular sieve dryers. The output from the system may be stacked with no significant environmental impact.

Acceptable tritium levels in process enclosures are $<10^{-5} \mathrm{Ci} / \mathrm{m}^{3}$ in process buildings and $<10^{-3}$ to $10^{-1} \mathrm{Ci} / \mathrm{m}^{3}$ in glove boxes. System glove boxes are continuously cycled through a purge system to keep tritium at acceptable levels and to remove undesirable impurities. Tritium is a relatively benign radionuclide which is a hazard only if inside the body, where it can become incorporated as part of water or organic compounds. Exposure to tritium oxide 
(HTO) through inhalation or skin exposure is the most important type of tritium exposure because it results in the distribution of HTO throughout the soft tissue of the body. If tritiated hydrogen (HT) is inhaled, only a fraction is dissolved in the blood, and the rest is exhaled. Another hazard associated with tritium is its ability to diffuse into many substances, be converted into organic compounds, diffuse back to the surface, contaminate the surface, and be absorbed through the skin of a person touching the surface.

Glove boxes are inerted with nitrogen to discourage the formation of HTO. Tritium, protium, nitrogen, oxygen, and water are the key gas impurities in an inerted glove box system. Tritium comes from leakage of the process equipment. Protium comes mainly from the moisture in the air which leaks into the glove box or permeates through the gloves. Oxygen comes from air leaking in and permeation through the gloves. The oxygen level in a glove box is monitored and controlled at less than 1 vol\% by adjusting the purge rate. More than $99.9 \%$ of the moisture in the system is expected to be from glove box leaks and permeation through the gloves. All of this water is adsorbed in zeolite beds, along with a very small amount of tritiated water. The zeolite beds are regenerated and the water recovered is decomposed to recover hydrogen isotopes.

Tritium will also be recovered from the $\mathrm{D}_{2} \mathrm{O}$ coolant used in the target/blanket area. The He-3 design uses a catalytic vapor exchange system that processes moderator heavy water to recover tritium and removes light water that may leak from secondary coolant into the $\mathrm{D}_{2} \mathrm{O}$. The system strips DT from the moderator and uses cryogenic distillation to produce a DT-enriched stream from which the tritium is recovered. In the $\mathrm{LiAl}$ target design, $\mathrm{D}_{2} \mathrm{O}$ will be replaced and sent off-site for detritiation when tritium contamination reaches unacceptable levels. Since the detritiated $\mathrm{D}_{2} \mathrm{O}$ will be returned for reuse, no waste streams are produced.

Wastes from tritium recovery systems are discussed in Appendix B under the following waste streams:

\author{
Platinum/Alumina Beds \\ Uranium Beds \\ Zeolite Beds
}

\title{
A4. Support Facilities
}

The following is a list of support facilities currently proposed for APT:

Secondary Cooling Facilities. These facilities would include cooling towers (or possibly cooling ponds) for rejecting APT waste heat to the atmosphere. Potentially hazardous wastes from the secondary cooling facilities are addressed in Appendix B under Cooling System and Maintenance Wastes.

Electrical Substations. These facilities receive $500 \mathrm{MW}$ electric power from the commercial supply grid, convert it to the required voltages for various 
functions, and distribute it to the accelerator, target/blanket, processing system, and other on-site facilities.

Emergency Power Building. This facility houses diesel generators or gas turbines that will be used to provide short-term emergency power to support safety-related loads in the event of temporary failure of the off-site power supply.

Administration Building. This facility will house administrative, technical support, and clerical staff. It includes staff offices, a cafeteria, medical facilities, data processing, and a records center.

Operations and Utilities Building. This facility provides for operational control and monitoring of the accelerator target/blanket assemblies, tritium extraction facility, and associated support and safety systems. It also provides for operator training, including simulators; serves as the center for site safeguards and security; provides the personnel monitoring and access control facilities required for managing access to and from restricted radiological areas; and houses batteries that provide an uninterruptible power supply to the building during an emergency.

Maintenance Facilities. These facilities provide shop and service areas for maintaining all accelerator, target/blanket, and processing system components. They also provide warehousing and materials handling for consumables and spare parts.

Waste Treatment Facility. This facility will receive and treat all site-generated sanitary sewage for release to the environment in accordance with a National Pollutant Discharge Elimination System (NPDES) permit. An APT facility based on the LiAl target design generates $29,000 \mathrm{~m}^{3} \mathrm{yr}$ of liquid sewage at the accelerator facility and $5,900 \mathrm{~m} 3 / \mathrm{yr}$ at the tritium extraction facility . Annual solid sanitary wastes are $320 \mathrm{~m}^{3}$ and $65 \mathrm{~m}^{3}$, respectively, for the two facilities. For an APT facility based on the He-3 design, annual generation is $34,000 \mathrm{~m}^{3}$ of liquid sewage and $370 \mathrm{~m}^{3}$ of solid sewage.

Radioactive Waste Processing Building. This facility receives all solid, liquid, and gaseous radioactive waste, including fluids collected via the floor drains in potentially contaminated areas, for holdup, treatment, and packaging in preparation for either release or disposal at an appropriate permanent disposal facility.

Water Treatment Facility. This facility supplies treated water of the required quality for the various plant cooling systems: deionized water for the accelerator and klystrons, filtered water for the cooling tower makeup, and filtered and treated water for domestic use. The fire protection system will tap off of the station water supply upstream of the water treatment facility.

New Target Inspection and Storage Facility This facility provides for the unloading, receipt, inspection, and storage of new target/blanket assemblies 
fabricated off-site. Alternately, assembly of new neutron production targets will take place here if this is to occur on-site. The facility handling equipment will also be used to load packaged spent targets onto the transport equipment for removal to the final disposal site.

Decontamination Facility DOE Order 6430.1A states that the facility design shall include a dedicated area furnished with appropriate equipment and utilities for decontamination of tools and as much equipment as practical. A variety of solvents, some containing hazardous components, are used as decontamination solutions. Decontamination wastes have the potential to contain both radioactive and hazardous components and are included in Appendix B under the waste streams Solvent Rags and Spent Solvents.

Additional facilities needed to support an on-site tritium processing facility using the He-3 target concept are:

He-3 Storage. Tankage will be provided to store He-3 feed make-up. Capacity will be provided to accommodate a target/blanket system inventory during normal shutdown for maintenance or to collect inventory in the event of an emergency shutdown.

Monitoring and Control. Process systems are monitored and controlled by local computers dedicated to subsystem operations. All systems will fail to a safe status in the event of the loss of one or more control functions. A central computer has supervisory capability over local computers and the capability to independently monitor and control critical safety functions of each processing system. The central computer system will also monitor facility support systems.

Analytical Laboratory. A laboratory will be provided for routine analysis of process samples (mass spectrometry) and potentially contaminated materials (scintillation). Only non-hazardous scintillation cocktails will be used. Capability for real-time, on-line analysis of process streams (Raman spectroscopy) will also be included. Waste from the analytical laboratory may contain both radioactive and hazardous components, and is addressed in Appendix B under the waste stream called Analytical Laboratory Wastes.

Process Building. The process building will house all tritium processing support operations. Areas containing tritium will be designed to satisfy current DOEmandated seismic, tornado, and safety requirements for facilities handling radioactive materials.

Building Utilities. The building utilities system will provide those systems required for normal and emergency facility operations, including emergency and uninterruptible power supplies.

Fire Protection. Areas housing tritium processing equipment should not contain flammable materials. Fire protection systems will be provided for nonprocess areas. 
In addition to the preceding facility and process-specific waste streams, the following site-wide waste streams associated with overall maintenance and repair are discussed in Appendix B:

\author{
Absorbent Wipes \\ Aerosol Cans \\ Batteries \\ Butyl Rubber Gloves \\ Glove Boxes and Glove Box Parts \\ Latex Gloves \\ Paper \\ Plastic Sheeting \\ Plastic Shoe Covers \\ Plastic Suits and Air Hoses
}

The wastes from many facilities are not addressed specifically in Appendix B. Many of these facilities are not unique to APT, but are typical of other laboratory facilities at DOE. Many of these facilities generate wastes that are neither radioactive nor hazardous and which can be disposed of in a landfill or recycled. These include a variety of wastes from building maintenance, HVAC maintenance, office operations, lunch rooms, and maintenance of vehicles. Waste minimization for these wastes should include recycling programs for oil, metals, glass, paper and plastic.

\title{
References
}

1. BNL, Topical Report on a Pre-conceptual Design for the SpallationInduced Lithium Conversion (SILC) Target for the Accelerator Production of Tritium (APT), ATD/APT93-0025 (REV. 0), September 30, 1993.

2. Briefing on APT for Steve Sohinki, presented at LANL, April 26, 1994.

3. LANL, APT ${ }^{3}$ He Target / Blanket Topical Report, Volume 1, Revision 1, LA-CP-94-27, March 1994.

4. SNL, Accelerator Production of Tritium Programmatic Environmental Impact Statement Input Submittal, SAND93-2094, November 1, 1993. 


\section{Appendix B}

\section{APT Waste Streams}

Appendix B contains a list of waste streams for APT which have the potential to contain hazardous components, radioactive contamination, or both. Nonhazardous and non-radioactive waste streams are not addressed here, as the recycling, treatment, and/or disposal of these streams are well understood and do not create a technical challenge. Some of the wastes streams described here are identified as the result of a specific process or processes described in Appendix A. Other waste streams are generated site-wide through maintenance or monitoring activities, and cannot be linked to one specific process.

Each waste stream description contains the following information:

Type: Identifies the waste stream as either hazardous waste, low-level radioactive waste, or mixed waste. In this report the terms "low-level waste" and "mixed waste" do not fit the strict definitions contained in DOE 5820.2A because the radioactive contaminants present in APT wastes are produced by an accelerator; however, these wastes will still be managed as either low-level or mixed wastes. Where a stream can be more than one waste type, for roll-up purposes, the total weight and volume is divided 50:50 for a combination of any two of the three waste types and 40:40:20 for low-level, mixed and hazardous wastes.

Description: Waste stream physical matrix, RCRA hazardous waste codes present, and radioactive isotopes and activity levels present.

Generation: Describes the process or activity that generates the waste stream.

Annual Quantities: Gives estimated annual generation rate in both mass and volume. Quantities are based on design team estimates, experience of DOE facilities with similar operations or using similar components, and engineering judgment.

Waste Minimization: Lists recommended methods for reducing or eliminating the waste stream, or eliminating either the radioactive or hazardous component in mixed waste.

Treatment Options: Lists possible treatment technologies for LLW or MLLW. Descriptions of the listed treatment technologies may be found in Appendix C. It is assumed hazardous waste will not be treated, but will be packaged for treatment and/or disposal at a DOE-approved waste management facility.

Comments: Provides additional information pertinent to understanding the nature of the waste stream or its treatment which does not fit in other categories. 


\section{Absorbent Wipes}

Type: Low-level, Hazardous, or Mixed Waste.

Description: This waste stream consists of rags or other absorbent materials, such as discarded mop heads, that have been used to clean up a spill. The material used is chosen on the basis of convenience, cost, and availability. The radioactive or hazardous component in the waste depends on the composition of the spill being cleaned up.

Generation: This waste stream is generated in cleaning and decontamination operations, when absorbent materials are used to clean up spills or to absorb excess cleaning solutions.
Annual Quantities:
$5100 \mathrm{~kg}, 5.1 \mathrm{~m}^{3}$
$100 \mathrm{~kg}, 0.1 \mathrm{~m}^{3}$
(LiAl target)
(He-3 target)

Waste Minimization:

(a) Process design changes can eliminate the potential for spills or pooling of cleaning solutions.

(b) Product substitution. For example, SRS has investigated the use of polyester wipes as a substitute for the product they currently use in a variety of cleaning/decontamination situations. The polyester wipes were found to reduce the volume of generated wastes without diminishing performance. Another example of product substitution is the use of non-hazardous solvents.

Treatment Options:

Low-Level and Mixed Waste:

(a) Thermal desorption followed by compaction for storage and/or disposal.

(b) Incineration, followed by stabilization or vitrification of residue.

Hazardous Waste:

Ship to a DOE-approved commercial treatment and disposal facility.

\section{Comments:}

(a) In a 1992 PWA, absorbent wipes made up $1 \%$ of a total waste of 25,457 $\mathrm{ft}^{3}\left(721 \mathrm{~m}^{3}\right)$ at the SRS tritium processing facility.-Waste stream characteristics for the 1993 draft were estimated on the basis of purchasing records, observation of sample waste-handling activities, and interviews with operations personnel. 
(b) The He-3 target design estimate is based on the fact that the TSTA facility has not had a spill in over ten years of operation.

(c) While thermal desorption of volatile organics may convert a mixed waste to a low-level waste, if the off-gases are adsorbed on activated carbon, this becomes a secondary waste stream. 


\section{Aerosol Cans}

Type: Hazardous or Mixed Waste.

Description: Aerosol cans containing paints, cleaning solutions, oils, and pesticides. RCRA wastes codes include D001, D007, and D008. Aerosol cans are considered compressed gases.

Generation: Routine maintenance operations in process areas. Aerosol cans used in radiation areas may become contaminated and would be considered mixed waste if not emptied completely.

Annual Quantities: $\quad 200 \mathrm{~kg}, 0.2 \mathrm{~m}^{3} \quad$ (Both target designs)

Waste Minimization:

(a) Aerosol cans should be completely used up before disposal so they are no longer hazardous.

(b) Items used in radiation areas are not necessarily contaminated. Provide procedures for monitoring non-contaminated aerosol cans to eliminate their classification as mixed waste.

Treatment Options:

Mixed Waste:

Compaction followed by thermal desorption if cans contain liquid.

Hazardous Waste:

Ship to a DOE-approved commercial treatment and disposal facility.

Comments:

(a) Anticipated quantities of aerosol cans was based on generation rates reported by DOE facilities for the Federal Facilities Compliance Act (FFCA) Mixed Waste Inventory Report.

(b) While thermal desorption of volatile organics may convert a mixed waste to a low-level waste, if the off-gases are adsorbed on activated carbon, this becomes a secondary waste stream. 


\section{Aluminum Wastes}

Type: Low-level Waste.

Description: Aluminum metal used for cooling water headers and plenums, pressure tubes, and window, and beam expansion chamber structural components. The aluminum may be radioactive due to surface contamination or through activation reactions with protons and neutrons.

Generation: This waste stream is generated when components are changed out during routine target/blanket removal. Part of the waste is from cooling water headers and plenums in both the target and blanket arrays; the majority of the rest is the pressure tubes from the blanket arrays.

Annual Quantities:

$$
\begin{aligned}
& 3,700 \mathrm{~kg}, 2.5 \mathrm{~m}^{3} \text { (LiAl target) } \\
& 2,500 \mathrm{~kg}, 3.0 \mathrm{~m}^{3} \text { (He-3 target) }
\end{aligned}
$$

Waste Minimization:

No waste minimization efforts have been identified.

Treatment Options:

(a) Shredding and compaction, followed by packaging for storage or disposal.

(b) Metal recycling.

Comments:

(a) Important aluminum reactions with neutrons and protons are:

$$
\begin{array}{ll}
27 \mathrm{Al}(\mathrm{n}, \mathrm{p}) 27 \mathrm{Mg} & \mathrm{T} 1 / 2=9.5 \text { minutes } \\
27 \mathrm{Al}\left(\mathrm{n},{ }^{1 / 2} \mathrm{Na}\right. & \mathrm{T} 1 / 2=15 \text { hours } \\
27 \mathrm{Al}(\mathrm{p}, \mathrm{n}) 27 \mathrm{Si} & \mathrm{T} 1 / 2=5 \text { seconds }
\end{array}
$$

Excessive production of $\mathrm{Si}-27$ in the aluminum lattice is known to cause embrittlement.

(b) Waste density is for uncompacted waste and does not correspond to density of aluminum due to loose packing of irregular shapes. Weight and volume estimates are from Reference (8) for BNL and Reference (2) for LANL. 


\section{Analytical Laboratory Chemicals}

Type: Low-level, Hazardous, or Mixed Waste.

Description: Used, excess, or out-of-date chemicals. A variety of hazardous waste codes are possible.

Generation: Routine analytical chemistry procedures needed to support the APT facility.

Annual Quantities: $200 \mathrm{~kg}, 0.2 \mathrm{~m}^{3}$ (Both target designs)

Waste Minimization:

Use of micro-analytical equipment.

Treatment Options:

Will be a function of the type of chemical; e.g., solid, liquid, acid, base, etc.

Comments:

None. 


\section{Batteries}

Type: Hazardous or Mixed Waste.

Description: Multiple types of small batteries, such as nickel-cadmium, carbon-zinc, mercury, lead-acid, and alkaline batteries. RCRA waste codes expected include D001, D002, D003, D006, D008, D009.

Generation: This stream is generated by spent batteries from radiation monitoring devices and other instrumentation used in radiation areas. Batteries used in radiation areas have the potential to be contaminated, resulting in mixed waste.

Annual Quantities: $\quad 500 \mathrm{~kg}, 0.2 \mathrm{~m}^{3} \quad$ (Both target designs)

Waste Minimization:

(a) Changes in operating procedures, such as selection of equipment with rechargeable batteries, if practical.

(b) Batteries contained inside equipment used in radiation areas frequently are not contaminated. Procedures should be put into place to protect batteries from contamination when being changed out and to verify that batteries do not have surface contamination when sent for treatment and/or disposal.

(c) Implement decontamination procedures for surface contamination.

Treatment Options:

Mixed Waste:

Compaction, followed by encapsulation.

Hazardous Waste:

Send to a commercial facility for metals recycling or treatment and disposal, as appropriate.

Comment:

Larger batteries such as lead-acid automotive batteries are assumed to be recyclable and will not constitute a waste stream. Anticipated quantities were based on expected generation rates of some DOE facilities, as reported in the FFCA Mixed Waste Inventory Report. 


\section{Bubblers}

Type: Low-level Waste.

Description: Bubblers are jars that contain a viscous liquid such as glycol or a silicone fluid. The liquid in the bubblers is susceptible to tritium contamination. The liquids used in bubblers are not currently regulated under RCRA as hazardous waste.

Generation; Bubblers are used as resealing pressure relief valves for glove boxes. In the event of glove box excess pressure, gases will pass through the bubblers rather than causing physical damage to the glove box. Tritium in the glove box atmosphere will readily exchange with the hydrogen atoms in the bubbler liquid. Tritium glove boxes are normally maintained at a negative pressure and tritium levels in the boxes are kept low. Therefore, little activity will result in the bubblers unless an over pressure occurs.

Annual Quantities: Minimal. (Both target designs)

Waste Minimization:

No waste minimization efforts have been identified.

Treatment Options:

Drain and stabilize bubbler liquid; compact housing with discarded glove boxes and glove box parts.

Comment:

Mound uses glycol in their bubblers, SRS uses a silicone fluid. 


\section{Butyl Rubber Gloves}

Type: Low-level Waste.

Description: Butyl rubber is a copolymer of isobutylene (97\%) and isoprene (3\%). Butyl gloves are worn in conjunction with "plastic suit" work in areas of high tritium contamination. The gloves will have surface contamination of tritium and tritium will also diffuse into the glove material.

Generation: Due to the tendency of tritium to diffuse into organic materials, gloves must be changed at frequent intervals to protect workers. Full changeout of suits, gloves, and shoe covers four times a day is not unusual during maintenance activities.
Annual Quantities:
$4900 \mathrm{~kg}, 6.8 \mathrm{~m}^{3}$
(LiAl target design)
$420 \mathrm{~kg}, 0.6 \mathrm{~m}^{3}$
(He-3 target design)

Waste Minimization:

(a) Process design which minimizes maintenance activities that must be performed using plastic suits.

(b) Thicker gloves requiring less frequent change-outs may be an option, but trade-offs with manual dexterity must be considered.

Treatment Options:

(a) Shredding, followed by compaction for storage and/or disposal.

(b) Incineration, followed by stabilization or vitrification of residue.

\section{Comments:}

(a) In 1992, approximately 8000 pairs were used at the SRS Tritium Facility.

(b) Past experience at the SRS Tritium Facilities was that 2/3 of the wastes came from the tritium extraction process and 1/3 from tritium processing. Most of the waste came from maintenance activities rather than production activities, and the waste streams were felt to be independent of production.

(c) Annual quantities reflect that a tritium extraction furnace is not used with the He-3 target design. Based on the fact that no "plastic suit work" has been performed at the TSTA facility in over ten years of operation, this is felt to be a conservative estimate. 


\section{Cooling System Components and Maintenance}

Type: Low-level, Hazardous, or Mixed Waste.

Description: This waste stream includes replacement parts such as motors, seals, bearings, and failed pumps; empty water treatment chemical containers; and cooling tower media (a thick pad used to increase cooling surface area). Another waste is cooling tower water, which will contain anticorrosion and anti-foaming agents. Depending on circumstances, items in this waste stream may or may not be contaminated and may or may not contain hazardous components.

Generation: Major cooling components are expected to last the life of the APT facility. Pumps generally have a life expectancy of ten years. Cooling system components will require routine maintenance to provide effective cooling and will result in the generation of used chemical containers, solvent rags, and failed parts. The evaporation of cooling tower water will result in the buildup of minerals in the remaining water. Therefore, a bleed stream must be removed and new cooling water added to maintain the mineral concentration at acceptable levels. The bleed stream is waste and must be treated. Cooling tower media will become clogged with mineral deposits and will be replaced every year or two.

Annual Quantities: Cannot be determined at the pre-conceptual design stage.

Waste Minimization:

No waste minimization efforts have been identified.

Treatment Options:

Parts: Compaction, followed by packaging for storage or diposal.

\section{Wastewater:}

Treatment will be a function of impurities, but will include filtration, which will produce secondary waste streams of filters and ion exchange resins.

Wastewater must be treated to meet local standards for discharge under a National Pollutant Discharge Elimination System (NPDES) permit.

\section{Comments:}

(a) The APT system is expected to have at least three cooling systems, one for the heavy water coolant in the target/blanket area, one for the light water coolant in the target/blanket system, and one for the balance of the plant, which will include cooling for the accelerator components, such as klystrons. Proposed system parameters for the first two systems are listed in Tables A1 and A2 in Appendix A. 
(b) Cooling system sizing will be a trade-off between equipment costs and operating costs. At the time this report was published, these trade-offs were still being evaluated and the design of some cooling systems had been deferred.

(c) Ion Exchange Resin and Water Treatment Filters for the $\mathrm{D}_{2} \mathrm{O}$ and $\mathrm{H}_{2} \mathrm{O}$ cooling systems are included as separate waste streams because the quantities and levels of radioactivity are known.

(d) The make-up requirement for cooling tower water is estimated to be $20,000 \mathrm{~m}^{3}$ per year. 


\section{Crucibles}

Type: Low-level Waste.

Description: Crucibles are stainless steel containers used in tritium extraction. Crucibles become contaminated with tritium and other radioactive constituents present in the LiAl target material.

Generation: Pieces of LiAl target material are placed in sealed crucibles and heated in a furnace to bring about tritium extraction. After extraction, the tritium gas is pumped from the enclosed crucibles and the residual $\mathrm{LiAl}$ melt remains inside the crucible. The melt contains only residual amounts of radioactivity, since the extraction process recovers approximately $99.9 \%$ of the tritium present. Tritium diffuses into stainless steel at high temperature. Approximately 50 crucibles are discarded each year after one use.

Annual Quantities: $\quad 29,000 \mathrm{~kg}, 12 \mathrm{~m}^{3} \quad$ (LiAl target design only)

Waste Minimization:

There is no feasible alternative to the use of crucibles in this process.

Treatment Options:

(a) Compaction, followed by packaging for storage or disposal.

(b) Metal recycling.

Comment:

In the past, hollow LiAl pieces in open crucibles would reduce in volume in the furnace and the crucibles were used twice before being discarded. A new sealed crucible is now in the pre-conceptual design phase. These crucibles will be about a foot in diameter and about 8 feet long. 


\section{Gas Cylinders}

Type: Low-level, Hazardous, or Mixed Waste.

Description: Compressed gas cylinders, containing nitrogen, welding gases, or gases needed by equipment in the analytical laboratory. Gas cylinders are subject to surface contamination with tritium or activation products present in the APT system. Compressed gases are waste code D001.

Generation: Nitrogen is used for inerting a glove box atmosphere. Other compressed gases are used for welding and analytical chemical laboratory operations. If gas containers become contaminated and cannot be returned for recycling, they will become a waste stream.

Annual Quantities: $\quad$ None are anticipated. (Both target designs)

Waste Minimization:

(a) Minimize contamination so gas cylinders can be recycled.

(b) Decontamination procedures to remove surface contamination should be employed. Only smooth painted cylinders should be used to allow for easy decontamination.

Treatment Options:

N/A; used cylinders will be decontaminated if necessary and recycled.

Comments:

Decontamination may produce residues/solutions requiring stabilization. 


\section{Glove Boxes \& Glove Box Parts}

Type: Low-level Waste.

Description: Glove boxes for tritium handling are normally made from stainless steel with glass windows. Rubber gloves and O-rings require routine replacement to ensure the integrity of the glove box system. Lead-lined gloves are not anticipated as part of this waste stream.

Generation: Glove boxes would be discarded if for some reason they became highly contaminated or showed some type of structural failure. At elevated temperatures, tritium will diffuse into stainless steel and a highly contaminated glove box could become the source of tritium leakage. Gloves and O-rings degrade from exposure to light and chemicals or may fail from repeated use or physical injury and must be inspected and replaced at regular intervals. Tritium permeates organic materials such as the gloves, which may need to be replaced if they become a source of tritium leakage.

Annual Quantities: $\quad 350 \mathrm{~kg}, 0.5 \mathrm{~m}^{3} \quad$ (Both target designs)

Waste Minimization:

No waste minimization efforts have been identified.

Treatment Options:

Metal Parts:

Compaction, followed by packaging for storage or disposal.

Gloves, O-Rings:

(a) Shredding, followed by compaction for storage and/or disposal.

(b) Incineration, followed by stabilization or vitrification of residue.

\section{Comments:}

(a) Glove boxes are maintained at negative pressure and have an inert nitrogen atmosphere to prevent the formation of tritium oxide. Tritium monitors are present inside glove boxes to signal when tritium exceeds an acceptable level and glove boxes are flushed to a tritium recovery system when high levels occur. Bubblers are used as pressure relief valves to prevent glove box overpressures which could cause structural damage. The glove boxes in the APT system should be expected to last the lifetime of the system. 
(b) The lifetime of gloves and O-rings is dependent on exposure to light, chemicals, and mechanical stresses that could lead to physical failure. Some facilities replace gloves at six-month intervals, while others report gloves lasting for years. Quantities listed are based on glove changeouts every six months. 


\section{HEPA Filters}

Type: Low-level Waste.

Description: High-efficiency particulate air (HEPA) filters are filters capable of trapping and retaining at least 99.97 percent of all monodispersed particles $\geq$ $0.3 \mu \mathrm{m}$ in diameter. HEPA filters are generally made of a variety of paper and metallic materials.

Generation: Stack gases are passed through HEPA filters, and the filters require regular replacement.

Annual Quantities: $\quad .200 \mathrm{~kg}, 0.2 \mathrm{~m}^{3} \quad$ (Both target designs)

Waste Minimization:

A reusable HEPA filter is being developed.

Treatment Options:

N/A if reusable filters are used. Treatment for a conventional HEPA filter is a function of its composition; i.e., whether it is largely paper (thermal treament) or metal (compaction).

Comments:

(a) HEPA filters will not prevent the release of tritium to the atmosphere. However, HEPA filters may be used to remove particulates which may contain tritium contamination.

(b) Carbon filters may be used in conjunction with HEPA filters to remove organics from stack gases. 


\section{Hydride Storage Beds}

Type: Low-level Waste (potentially Mixed Waste).

Description: Hydride storage beds used at SRS are 4" in diameter and 3 feet long per unit. They have an inner container made of 3 " Schedule 40 stainless steel and an outer container made of 4" Schedule 10 stainless steel. Each unit has about 45 pounds of stainless steel and another 15 pounds of metal hydride material contained in the bed. The metal hydride storage beds contain nickel, which is under heavy scrutiny as an environmental hazard and is on some state lists as a hazardous material.

Generation: Helium buildup is the main failure mechanism for hydride beds. The expected bed lifetime is about five years.

Annual Quantities: $\quad 85 \mathrm{~kg}, 0.02 \mathrm{~m}^{3} \quad$ (Both target designs)

\section{Treatment Options:}

If it is possible to separate the hydride from its container, the depleted hydride would be stabilized and the container would be compacted. If the two cannot be easily separated, the entire unit would simply be packaged for storage and/or disposal, since compaction of the filled depleted hydride bed could result in an explosion or fire.

\section{Waste Minimization:}

No waste minimization efforts have been identified.

\section{Comments:}

(a) Certain metals and alloys, which react rapidly and reversibly with hydrogen at room temperature and atmospheric pressure to form metal hydride compounds, represent a technology ideally suited to the handling and processing of tritium. The hydriding/dehydriding reaction an be used as a basis for the storage, pumping, compression, purification and separation of hydrogen isotopes.

(b) The SRS tritium facility currently has 10-15 hydride beds in use, with 2 to 3 beds requiring replacement each year.

(c) The advantage of hydride systems is the much smaller volume of the apparatus and hence cost savings due to the reduced glove box space required.

(d) When metal hydrides are used for tritium capture and storage, it is ncertain whether the hydrides can reduce the tritium concentration in 
the waste gas to the 5 to 10 parts per million achieved during cryogenic distillation.

(e) As they are cycled and accumulate impurities, metal hydrides become finely divided powders that are potentially pyrophoric. 
Type: Mixed Waste.

Description: Inconel is the trademark for a group of corrosion-resistant alloys of nickel and chromium (D007). Inconel alloys have specific gravities which range from 7.91 to 8.44 ; the mean specific gravity is 8.3 . Activation products will be present in the waste material.

Generation: Inconel-718 is used in the He-3 target design to house the tungsten neutron source and for the proton beam entrance window. Based on existing proton irradiation experience, the Inconel components should last for approximately 2.2 years of service at the proposed proton fluxes.

Annual Quantities: $\quad 2,250 \mathrm{~kg}, 0.25 \mathrm{~m} 3$ (He-3 target only)

Waste Minimization:

No waste minimization efforts have been identified.

Treatment Options:

(a) Shredding and compaction. If the metal fails the Toxicity Characteristic Leaching Procedure (TCLP; EPA Method 1311, 40 CFR 261.24) leach limit for chromium, it would have to be stabilized or encapsulated prior to packaging for storage or disposal.

(b) Metal recycling.

\section{Comments:}

(a) The target is designed as a separate assembly that can easily be removed and replaced during a routine maintenance period. LANL target change-out plans anticipate decladding and shredding the Inconel for disposal.

(b) Leaching tests performed for SNL-NM indicate that chromium does not leach from Inconel alloys. 


\section{Instrumentation}

Type: Hazardous or Mixed Waste.

Description: Miscellaneous electronic instrumentation such as radiation monitoring devices, power supplies, computers, etc. All electronic components have the potential to leach heavy metals when subjected to TCLP testing and therefore are considered potentially hazardous waste. For example, waste circuit boards have been shown to contain RCRA codes D006, D008, and D011. As these devices will be used in regulated or radiation areas, there is also the possibility of radioactive contamination.

Generation: Equipment or parts from equipment would be discarded due to failures, obsolescence, or contamination.

Annual Quantities: $\quad 1000 \mathrm{~kg}, 1.0 \mathrm{~m}^{3} \quad$ (Both target designs)

Waste Minimization:

(a) Procedures should be established to ensure that instrumentation does not become contaminated, even when used in radiation areas.

(b) Equipment ready for disposal should be analyzed to determine if it is indeed contaminated.

(c) Use non-hazardous solder in instrumentation and instrument repairs.

(d) If only the surface is contaminated, decontaminate for recycle or disposal as hazardous waste.

Treatment Options:

Mixed Waste:

(a) Compaction, followed by encapsulation.

(b) Decontamination, followed by metal recycling.

Hazardous Waste:

Ship to a DOE-approved commercial treatment and disposal or recycling facility.

Comments:

(a) There are little data on which to estimate this waste stream.

(b) Decontamination may produce residues/solutions requiring stabilization. 


\section{Ion Exchange Resin}

Type: Low-level Waste.

Description: This waste stream is ion exchange resin used to purify both the light and heavy water coolants used in the target blanket area. Activity is present in the coolant from the recoil of the spallation products near the cooled surfaces and becomes deposited in the ion exchange resin during coolant purification.

Generation: The purification of heavy and light water coolant will be performed by processing a slipstream from the respective coolant loops which will be passed through filters and ion exchange resin to remove impurities.

Annual Quantities: $\quad 9000 \mathrm{~kg}, 9 \mathrm{~m}^{3} \quad$ (Both target designs)

Waste Minimization:

Series operation of two beds will ensure that each bed is used to the point of saturation, thus minimizing resin waste volume. See discussion below.

Treatment Options:

(a) Stabilization in concrete. This eliminates any need to dewater the resins prior to treatment or disposal.

(b) Incineration, followed by stabilization or vitrification of residue.

(c) Vitrification.

\section{Comment:}

After filtration, the coolant is processed through a pair of mixed bed ion exchangers. The pre-conceptual design provides for series operation so that the resin in the first bed in the series can be fully utilized to minimize resin waste volume. The beds in each pair are interconnected so that when the first bed saturates, inlet is switched to the second bed, the resin in the saturated bed is replaced, and it then becomes the new second bed. Bed life is estimated to be about three months for the first bed in series. 


\section{Ion Pump Materials}

Type: Low-level Waste.

Description: Titanium cathode materials from refurbished ion pumps.

Generation: Generation occurs from accelerator operations. Experience at the LANL LAMPF facility suggests that the titanium cathodes in ion pumps will need to be refurbished at a rate of 20 per year. Approximately one pound of titanium material is used in the refurbishing process.

Annual Quantities: $\quad 10 \mathrm{~kg}, 0.002 \mathrm{~m}^{3} \quad$ (Both target designs)

Waste Minimization:

No waste minimization effort has been identified.

Treatment Options:

N/A. Due to small volume, compaction prior to packaging for disposal is not necessary.

\section{Comment:}

The APT accelerator will require 460 ion pumps. Each ion pump has an aluminum-nickel-cobalt (ALNICO) magnet containing cobalt that becomes activated, but this magnet is removed and then reused after the refurbishing process. 


\section{Klystron Materials}

Type: Possibly Low-level Waste.

Description: Waste generated from refurbishing klystrons. The quantity and nature of waste depends on the level of refurbishing required. Materials in the waste can include aluminum oxide, molybdenum, tungsten, other high temperature metals, and copper. Precautions are being taken so that the klystrons will not become contaminated or activated. Waste should be nonhazardous and non-radioactive, but may become contaminated.

Generation: Waste generation results from accelerator operations. Based on experience with similar facilities, klystrons are assumed to be changed out at a rate of 25 per year. Most will require only the lowest level of repair, change-out of 25 pounds of ceramic material, mostly aluminum oxide and all nonhazardous. Medium level of repair to the gun requires tungsten, molybdenum, refractory metals and high temperature materials. Major repair requires that parts of the copper shell be removed. This copper can most likely be recycled.

Annual Quantities: $\quad 300 \mathrm{~kg}, 0.1 \mathrm{~m}^{3} \quad$ (Both target designs)

Waste Minimization:

No waste minimization efforts have been identified.

Treatment Options:

N/A. Due to small volume, compaction prior to packaging for disposal is not necessary.

Comments:

(a) Klystrons in the APT will most likely be sent out for refurbishment.

(b) There will be 46 water systems in the accelerator. Each water system will have 7 klystrons requiring $450 \mathrm{gpm}$ (322 klystrons total). Each water system will have a power supply (46 power supplies). Power supplies are utility plant quality and should have a $30-40$ year lifetime with some repairs, which would generate minimal amounts of waste. The power supplies will be air-insulated (no oil) and will have some type of semiconductor that may need to be changed out. Wastes from the maintenance of the power system and the cooling system are included under other waste streams.

(c) There is external lead x-ray shielding on the klystrons and this could be reused. 


\section{Latex Gloves}

Type: Low-level Waste.

Description: Thin rubber gloves, such as surgeon's gloves, contaminated with tritium or other activation products.

Generation: Gloves are typically worn double-layered so that bare-handed contact with the outer (working surface) glove is avoided during removal. During work in highly contaminated areas, gloves are changed often to preclude contamination by migration of tritium through the gloves via solution/diffusion mechanisms.

Annual Quantities: $\quad 28,000 \mathrm{~kg}, 40 \mathrm{~m}^{3} \quad$ (LiAl target design) $2,300 \mathrm{~kg}, 3.3 \mathrm{~m}^{3}$ (He-3 target design)

Waste Minimization:

(a) Past experience at SRS tritium facilities has shown that the majority of wastes are from maintenance activities rather than normal operations. Future facilities should be designed to minimize maintenance wastes.

(b) Substitution of a thicker, denser glove would slow the migration and might allow for the use of fewer gloves, but all alternative materials identified were deemed to be likely to diminish worker dexterity and lengthen worker exposure to the contaminated environment. Re-use of the inner glove is precluded by the potential for its contamination from the outer glove and other protective clothing during removal.

Treatment Options:

(a) Compaction for storage and/or disposal.

(b) Incineration, followed by stabilization or vitrification of residue.

\section{Comments:}

(a) In 1992, SRS Tritium Facilities purchased (and therefore it was assumed they consumed) 48,200 pairs of latex gloves. The expected volume for this quantity of gravity-settled gloves was $50 \mathrm{~m}^{3}$.

(b) Past experience at SRS Tritium Facilities was that 2/3 of the wastes came from the tritium extraction process and $1 / 3$ from tritium processing. Most of the waste came from maintenance activities rather than production activities, and the waste streams were felt to be independent of production. 
(c) Annual quantities reflect that no tritium extraction furnace is used with the He-3 target design. Since the TSTA facility has used approximatley ten pairs of gloves in over ten years of operation, this estimate is felt to be conservative. 


\section{Lead Shielding}

Type: Mixed Waste.

Description: Lead with surface radioactive contamination. The surface contamination can be either tritium or a variety of activation products.

Generation: Lead is used as a shielding material and can become contaminated on the surface. The largest amounts of lead in the system that are subject to surface contamination is the lead used in the extraction furnace areas as shielding.

Annual Quantities: Minimal. (Both target designs)

Waste Minimization:

Lead can be treated to remove the surface contamination and then reused.

Treatment Options:

Decontaminate for re-use.

Comments:

(a) The lead shielding in the extraction furnace area is anticipated to last the lifetime of the facility.

(b) Klystrons have lead x-ray shielding which can be reused as klystrons are pulled for refurbishment.

(c) Decontamination may produce residues/solutions requiring stabilization. 


\section{Lead Target Assemblies}

Type: Mixed Waste.

Description: This waste stream contains elemental lead (RCRA code D008) which has been exposed to a beam of protons for an extended period of time. For the LiAl target design, Al-clad lead plates are used as a neutron source. As the result of spallation and evaporation processes, lead nuclei are converted to lighter isotopes, many of which are very short-lived. The two spallation products of concern are mercury and thallium, with the majority of the remainder being refractory metals. In addition to spallation, there are some fragmentation processes which create some nuclides less than half the mass of lead. Fragmentation products will be at most $10 \%$ of the spallation products. Impurities in the lead, such as cobalt, and the aluminum cladding also become activated. The He-3 target design uses lead in the proton beam backstop and in an annulus around the target chamber to improve the neutron-to-proton production ratio.

Generation: Each LiAl lead target is expected to be used for two years and will then be replaced. The amount of lead to be replaced in the He-3 target design is based on changeout of $13,550 \mathrm{~kg}$ of $\mathrm{Pb}$ after a 2.2-year duty cycle.

Estimates presented are from Reference (7) for the BNL design and Reference (18) for the LANL design.

Annual Quantities:

$$
\begin{aligned}
& 12,400 \mathrm{~kg}, 2 \mathrm{~m}^{3} \text { (LiAl target) } \\
& 6,160 \mathrm{~kg}, 1.1 \mathrm{~m}^{3} \text { (He-3 target) }
\end{aligned}
$$

\section{Waste Minimization:}

(a) It is preferable to operate one target as long as possible. Target change-out is based on the expected lifetime of the aluminum cladding used on the lead pins. Alternate cladding materials could extend the life of a target.

(b) Substitution with a less hazardous material, such as a tungsten neutron generation target.

(c) Reprocessing and reuse of the lead is being considered.

\section{Treatment Options:}

(a) Macroencapsulation.

(b) Metal recycling. 


\section{Comments:}

(a) Lead as a spallation target must be enclosed in a cladding to retain spallation products and provide mechanical integrity. A concern with * lead is the production of mercury, which is produced in a gaseous state and is highly corrosive to aluminum.

(b) The neutrons needed for tritium production are to be produced by spallation of either lead or tungsten by high energy protons. Neutrons are produced either directly, being knocked out as a proton hits the nucleus, or as a decay product of the excited nucleus produced. The number of neutrons produced by lead or tungsten per proton absorbed is only moderately well known as a function of proton energy; approximately 20 neutrons/proton are produced from $1 \mathrm{Gev}$ beams. Tungsten produces more neutrons per proton absorbed at a given proton kinetic energy, but it has a higher neutron absorption cross section. BNL's comparison analysis of the use of tungsten and lead indicated the greater absorption of neutrons by tungsten overcame the benefit of increased neutron-to-proton spallation production. Therefore, the BNL design uses lead as the target material.

(c) The choice of spallation material is dependent on the geometric design of the target. By using thin tungsten rods with a lead annulus, LANL feels an efficient neutron production ratio can be maintained.

(d) Spent lead targets will contain 10-20 MCi of activity when removed from the target area. Due to the short half-lives of the activation products, after one year in storage the targets contain about $0.1 \mathrm{MCi}$ of activity. Storage of the lead targets in on-site pools while this decay occurs may cause the APT facility to be classified as a storage facility. 


\section{LiAl Melts}

Type: Low-level Waste.

Description: Melted lithium aluminum target material from which $99.9 \%$ of the tritium has been extracted. The melted material is contained in the stainless steel crucibles used for extraction; the crucibles and the contained melt are disposed of as a single unit. Both the melt and the crucibles are contaminated with tritium and activation products.

Generation: Generation of this waste is associated with extraction of tritium from irradiated LiAl targets. LiAl target plates are placed in sealed stainless steel crucibles and heated to melting temperatures in order to extract the tritium that is entrained in the material. The LiAl target design will generate approximately 50 crucibles/year containing melted LiAl.

Annual Quantities: $\quad 41,000 \mathrm{~kg}, 16 \mathrm{~m}^{3}$ (LiAl target only)

Waste Minimization:

Process optimization to increase the yield of tritium per weight of lithium aluminum target material.

Treatment Options:

(a) Compaction, followed by packaging for storage or disposal.

(b) Metal recycling.

\section{Comments:}

(a) The quantities given here are based on each target assembly being exposed for one year and then being sent for tritium extraction.

(b) Aluminum and Li-7 both undergo activation processes that quickly lead to stable nuclei, and hence are not a major problem:

$$
\begin{aligned}
& 27 \mathrm{Al}_{13}+1_{\mathrm{n}_{0}} \rightarrow 2 \mathrm{2}_{\mathrm{Al}} 14+0 \mathrm{~b}_{-1}+\mathrm{g} \\
& 7 \mathrm{Li}_{3}+1_{\mathrm{n}_{0}} \rightarrow 4 \mathrm{He}_{2}+4 \mathrm{He}_{2}
\end{aligned}
$$

The $\mathrm{Li}-7$ reaction goes either directly to $\mathrm{He}-4$ (as shown) or indirectly via the creation and rapid decay of a B-8 intermediate. The spallation process might create other radioactive nuclei in the targets, such as Na-22. 


\section{Paint Shop Wastes}

Type: Low-level, Hazardous or Mixed Waste.

Description: Paints, mineral spirits, lacquers, and/or solvent-containing thinners with hazardous components regulated by RCRA. Hazardous waste codes anticipated in this stream are: D001, D006, D007, D008, D009, D018, D035, D038, F002, F003, and F005.

Generation: For a facility that will be in use for 30 or more years, some painting is inevitable. Some applications will require paint products with hazardous components. Excess paint and thinner will eventually be disposed of when it exceeds the recommended shelf life or is no longer needed. Paints that are used in a restricted or radiation area may be considered contaminated.

Annual Quantities: $\quad 100 \mathrm{~kg}, 0.1 \mathrm{~m}^{3} \quad$ (Both target designs)

Waste Minimization:

(a) Product substitution and change in product composition, using products without hazardous components.

(b) Good operating practices to minimize waste, such as using up all product or using before expiration date.

(c) Analyze all residual paint used in a radiation area to determine if it has actually become contaminated.

(d) If only the surface of the can has become contaminated, decontaminate so residue will not require disposal as a low-level or mixed waste.

\section{Treatment Options:}

\section{Low-Level and Mixed Waste:}

(a) Thermal desorption, followed by compaction for storage and/or disposal.

(b) Incineration, followed by stabilization or vitrification of residue.

Hazardous Waste:

Ship to a DOE-approved commercial treatment and disposal facility.

\section{Comments:}

(a) While thermal desorption of volatile organics may convert a mixed waste to a low-level waste, if the off-gases are adsorbed on activated carbon, this becomes a secondary waste stream. 
(b) Anticipated quantities were based on the expected generation rates reported in the FFCA Mixed Waste Inventory Report. 


\section{Palladium-Silver Diffusers}

Type: Mixed Waste.

Description: Palladium-silver diffusers are about two feet long and one foot in diameter. Silver is a hazardous material with RCRA code D011. During use the diffusers will become contaminated with tritium.

Generation: Existing tritium processing at SRS uses palladium-silver alloy diffusers to separate hydrogen isotopes from $\mathrm{He}-3$ and $\mathrm{He}-4$ after targets are melted in crucibles to release the trapped gases. A similar APT facility will need two diffusers. Experience at SRS is that the diffusers must be replaced after two or three years of service. The He-3

target design also pumps the tritium slipstream through a palladium-silver membrane prior to isotope separation.

Annual Quantities: Minimal. (Both target designs)

Waste Minimization:

(a) Removal of dirt from the tritium extraction and processing lines to prolong diffuser lifetime.

(b) Improved manufacturing methods to eliminate current diffuser brazing failures.

Treatment Options:

Stabilization or encapsulation prior to packaging for storage and/or disposal.

Comment:

Failure of diffusers has been attributed to manufacturer brazing problems or to dirt in the current tritium processing lines. In a clean facility diffusers should last longer, but there is no experience to prove that. The hydrogen passing through the palladium will eventually cause embrittlement and swelling and will result in change-out even if current problems with brazing are resolved. 


\section{Paper}

Type: Low-level Waste.

Description: Commercially available kraft paper contaminated with tritium, swipes from contamination surveys, and note paper, empty boxes, and various wrap and packaging materials from restricted areas. Waste stream is expected to be compacted and to have a specific gravity of 0.7 .

Generation: Kraft paper is placed on laboratory surfaces as a contamination control method. When the paper becomes contaminated it is replaced with clean paper. Swipes are pieces of paper used to wipe surfaces that may be contaminated with tritium or other radionuclides; the paper is counted after the surface has been wiped. Other paper items are waste paper that has been discarded in a restricted area.

Annual Quantities: $\quad 20,000 \mathrm{~kg}, 28 \mathrm{~m}^{3}$ (LiAl target design) $4,000 \mathrm{~kg}, 5.6 \mathrm{~m}^{3}$ (He-3 target design)

Waste Minimization:

(a) Implementation of procedures to assure all deliveries are unpacked to the greatest possible extent in uncontrolled areas to prevent packing materials from being taken into controlled areas.

(b) Process design that uses triple containment and low-maintenance equipment to minimize areas where paper is used for contamination control.

Treatment Options:

(a) Compaction and packaging for storage and/or disposal.

(b) Incineration, followed by stabilization or vitrification of residue.

Comment:

Quantities for the $\mathrm{LiAl}$ target design are based on experience at the SRS Tritium Facility in 1992. Twenty-three percent of the total 1992 low-level wastes from that facility was either uncompacted paper or plastic sheeting. For a new APT facility which uses similar processes, wastes are expected to be compacted to $1 / 3$ their original volume. Due to the triple containment tritium processing system proposed for the He-3 target design, this waste stream was estimated to be only $20 \%$ of the current SRS waste stream. Since the TSTA facility does not use kraft paper, this estimate is felt to be reasonable. 


\section{Photographic Shop Wastes}

Type: Hazardous or Mixed Waste.

Description: Waste chemicals and photographic film waste with RCRA waste codes D002, D007, D008, D009, D011, and U151.

Generation: Normal wastes from an on-site photographic laboratory.

Annual Quantities: $\quad 100 \mathrm{~kg}, 0.1 \mathrm{~m}^{3} \quad$ (Both target designs)

Waste Minimization:

(a) Substitution of materials, such as use of digital photographic equipment.

(b) Analyze all residuals used in a radiation area to determine if it has actually become contaminated.

(c) If only the surface of the container has become contaminated, decontaminate so residue will not require disposal as a mixed waste.

Treatment Options:

Treatment of phtographic chemical waste will be a function of the type of chemical. Due to the small volume, solid waste such as used film cartridges would not require compaction prior to packaging for disposal.

Comment:

Quantities estimated are based on waste streams reported by DOE facilities in the Federal Facilities Compliance Act Mixed Waste Inventory Report of April 1993. 


\section{Piping and Valve Wastes}

Type: Low-level Waste.

Description: Metal pipes and valves that have failed from normal wear and tear or which have failed from exposure to harsh environments. The metal may have just surface contamination, may have tritium diffused into the metal, or may have been activated. Stainless steel, aluminum, and copper will be the most common materials in this waste stream.

Generation: This waste stream is generated when failed or structurally weakened lines and valves are changed out. Experience at the SRS tritium processing facilities indicates that normal wear and tear rather than radiolysis or hydrogen embrittlement is responsible for change-out of piping and valves.

Annual Quantities: $\quad 450 \mathrm{~kg}, 0.1 \mathrm{~m}^{3} \quad$ (Both target designs)

Waste Minimization:

No waste minimization efforts have been identified.

Treatment Options:

N/A. Due to small volume, compaction prior to packaging for disposal is not necessary.

\section{Comment:}

Tritium has a finite solubility in all materials and will tend to diffuse through containing barriers. The permeability of hydrogen through different materials differs by orders of magnitude. Since they are highly permable to hydrogen, polymers and silica glass are not used in modern primary tritium containment. Some metals, such as Type 300 stainless steels, aluminum, tungsten, and copper have low permeabilities. 


\section{Plastic Sheeting}

Type: Low-level Waste.

Description: Plastic sheeting which is contaminated with tritium and/or activation products.

Generation: "Tents" of plastic are built around maintenance activities as a contamination control measure. These plastic "tents" are changed out as they become contaminated.

.. Annual Quantities: $16,000 \mathrm{~kg}, 23 \mathrm{~m}^{3}$ (Li Al target design) $1,400 \mathrm{~kg}, 2 \mathrm{~m}^{3} \quad$ (He-3 target design)

Waste Minimization:

Past experience at the SRS tritium facilities has shown that the majority of wastes are from maintenance activities rather than normal operations. Future facilities should be designed to minimize maintenance wastes.

Treatment Options:

(a) Compaction, followed by packaging for storage and/or disposal.

(b) Incineration, followed by stabilization or vitrification of residue.

\section{Comments:}

(a) Quantities anticipated are based on current Savannah River Tritium Facilities experience. From a 1992 PWA for the Tritium Facilities at SRS, 23\% of the total uncompacted low-level waste from that facility was either paper or plastic sheeting.

(b) Past experience at the SRS Tritium Facilities was that 2/3 of the wastes came from the tritium extraction process and $1 / 3$ from tritium processing. Most of the waste came from maintenance activities rather than production activities, and the waste streams were felt to be independent of production.

(c) Annual quantities reflect that no tritium extraction furnace is used with the He-3 target design. Since the TSTA facility uses only about $10 \mathrm{~kg}$ of plastic sheeting per year, this estimate is felt to be conservative. 


\section{Plastic Shoe Covers}

Type: Low-level Waste.

Description: Thick plastic shoe covers with surface and sub-surface contamination with tritium. Other radioactive isotopes and hazardous materials may also contaminate the surface of the shoe covers, depending on the environment in which the shoe cover is being used.

Generation: Shoe covers are worn to protect personnel from tritium, which is readily absorbed through the skin in some chemical forms. Shoe covers also serve as a contamination control measure and are discarded after one wearing.
Annual Quantities:
$42,000 \mathrm{~kg}, 60 \mathrm{~m}^{3}$ (LiAl target design)
$3,500 \mathrm{~kg}, 5 \mathrm{~m}^{3}$ (He-3 target design)

Waste Minimization:

(a) Use and reuse of specially labeled shoes that are worn only in radiation areas.

(b) Substitution of a thick, impermeable boot which could be washed and reused.

Treatment Options:

(a) Compaction, followed by packaging for storage and/or disposal.

(b) Incineration, followed by stabilization or vitrification of residue.

\section{Comment:}

(a) Based on purchasing records, the SRS Tritium Facility used 163,000 pairs of shoe covers in 1992. At SRS, shoe covers are typically worn double-layered over washable cloth booties or over plastic suit feet and booties. Crumpled for disposal, these shoe covers would fill $227 \mathrm{~m}^{3}$. The assumption was made that the shoe covers could be compacted to onethird of that volume.

(b) Past experience at SRS Tritium Facilities was that 2/3 of the wastes came from the tritium extraction process and $1 / 3$ from tritium processing. Most of the waste came from maintenance activities rather than production activities, and the waste streams were felt to be independent of production.

(c) Annual quantities reflect that no tritium extraction furnace is used with the He-3 target design. Since, in over ten years of operation, plastic 
shoe covers have been used an average of less than once a year at the TSTA facility, this estimate is considered conservative. 


\section{Plastic Suits and Air Hoses}

Type: Low-level Waste.

Description: This waste stream consists of thick plastic suits and connecting breathing air hoses. Suits used for tritium work are generally 9 mil suits, but 12 mil and welders' suits are also used. Air hoses are 25, 50, 100, or 150 feet long with 25 feet being the most commonly used size. The suits will have surface and subsurface contamination of tritium. Surface contamination of other isotopes or of hazardous chemicals encountered while wearing the suit is also possible.

Generation: This waste stream is generated whenever workers are required to work in tritium exposure areas. There is no respirator for tritium work; to reduce radiation exposure due to inhalation and absorption of tritium through the skin, work involving exposure to tritium is done using plastic suits with an independent compressed-air breathing air system and a supplied air source. Four suits per day per worker is usual and workers are required to work in pairs. Tritium diffuses into plastic, making reuse of the suits unacceptable.

\begin{tabular}{|c|c|}
\hline Annual Quantities: & $\mathrm{m}^{3}$ \\
\hline
\end{tabular}

Waste Minimization:

(a) Due to the highly contaminated nature of the environment in which plastic suits are normally worn, and since the inside of the suit comes into intimate contact with personnel and personal clothing, no scheme for reuse of suits has been considered. The capacity to compact wastes "in-house" should be pursued to reduce the volume of this waste. Hoses were found to displace up to 6.5 times their actual volume, and a commercial chipper/shredder should be investigated as a volume reduction method.

(b) Substitution of an alternative hose material to allow reuse of hoses should be investigated. Substitution with non-hydrogenated materials would preclude chemically-bonded tritium.

(c) Experience indicates that much of the waste from current tritium facilities comes from maintenance activities rather than normal operations. Future process design should look at ways to minimize the maintenance activities which generate the bulk of this waste stream.

Treatment Options:

(a) Shredding, followed by compaction and packaging for storage and/or disposal. 
(b) Incineration, followed by stabilization or vitrification of residue.

\section{Comments:}

(a) Anticipated quantities for the LiAl target design are based on 1992 experience at the SRS Tritium Facilities. Based on purchasing records, observation of sample waste-handling activities, and interviews with operations personnel, thirty-seven percent of the total waste from that facility was from plastic suits and hoses.

(b) Past experience at SRS Tritium Facilities was that 2/3 of the wastes came from the tritium extraction process and $1 / 3$ from tritium processing. Most of the waste came from maintenance activities rather than production activities, and the waste streams were felt to be independent of production.

(c) Annual quantities reflect that no tritium extraction furnace is used with the He-3 target design. Since plastic suits and air hoses have never been used in over ten years of operation at the TSTA facility, this estimate is considered conservative. 


\section{Platinum/Alumina Catalyst Bed}

Type: Low-level Waste.

Description: Alumina is aluminum oxide, $\mathrm{Al}_{2} \mathrm{O}_{3}$, which is noncombustible and nontoxic. The material will be contaminated with tritium.

Generation: Stripping systems are used to recover tritium from waste gases before they are sent to the stack. These stripper systems operate by pumping the gas over a heated Pt/Alumina catalyst bed (Englehard Deoxo D) to oxidize the molecular hydrogen isotopic species to tritiated water. The tritiated water is then adsorbed on zeolite beds before the gas is sent to the stack. The beds are expected to be changed out once a year.

Annual Quantities: $\quad$ Minimal.

Treatment Options:

Stabilization or macroencapsulation prior to packaging for disposal.

Waste Minimization:

No waste minimization method has been identified.

Comments:

None. 


\section{Solvent Rags}

Type: Low-level, Hazardous, or Mixed Waste.

Description: Rags or paper products (such as Kim-Wipes) that have been impregnated with solutions used for decontamination, cleaning, degreasing, spill clean-up and various maintenance activities. The solutions may contain hazardous components and/or may also become contaminated with radioactive or hazardous components wiped from the object being cleaned.

Generation: Routine maintenance, cleaning, degreasing, and decontamination activities.

Annual Quantities: $\quad 100 \mathrm{~kg}, 0.1 \mathrm{~m}^{3}$ (Both target designs)

Waste Minimization:

(a) Product substitution, to eliminate RCRA hazardous solvents.

(b) Change to mechanical/physical stripping/cleaning devices to avoid solvent use.

Treatment Options:

Low-Level and Mixed Waste:

(a) Thermal desorption followed by compaction for storage and/or disposal.

(b) Incineration, followed by stabilization or vitrification of residue.

Hazardous Waste:

Ship to a DOE-approved commercial treatment and disposal facility.

\section{Comments:}

(a) Current environmental regulations make it advantageous to avoid the generation of mixed waste. Use of non-hazardous cleaning agents is advisable when the solvent rags will come in contact with radioactive materials. Commercially available rags impregnated with a decontamination solution (brand name Maslin Wipes) have been tested by Sandia National Laboratories/New Mexico for hazardous components and have been found to be non-hazardous.

(b) While thermal desorption of volatile organics may convert a mixed waste to a low-level waste, if the off-gases are adsorbed on activated carbon, this becomes a secondary waste stream. 


\section{Spent Solvents}

Type: Low-level, Hazardous or Mixed Waste.

Description: Residues of solutions used for decontamination, cleaning, or degreasing during equipment maintenance or repair. The solvents may be inherently hazardous and/or may become contaminated with radioactive or hazardous materials during the cleaning process.

Generation: Cleaning, maintenance, repair, degreasing and decontamination activities.

Annual Quantities: $\quad 200 \mathrm{~kg}, 0.2 \mathrm{~m}^{3} \quad$ (Both target designs)

Waste Minimization:

(a) Product substitution, to eliminate RCRA hazardous solvents.

(b) Change to mechanical/physical stripping/cleaning devices to avoid solvent use.

Treatment Options:

Low-level and Mixed Waste:

Incineration, followed by stabilization of treatment residue, or just stabilization. Considering that the annual volume estimate is small, the latter approach may be more practical.

Hazardous Waste:

Ship to a DOE-approved commercial treatment and disposal facility.

Comment:

A new, non-hazardous and environmentally safe solvent for cleaning metal surfaces is available through Organitec, a Tennessee-based company. 


\section{Stainless Steel}

Type: Low-Level Waste.

Description: The Inconel neutron source vessel and the surrounding blanket of lead, $\mathrm{He}-3$ and $\mathrm{D}_{2} \mathrm{O}$ are contained in a stainless steel vessel. Associated piping and structural framework are also stainless.

Generation: The entire neutron source assembly is changed out every 2.2 years. About $80 \%$ (by weight) of the lead in the assembly will be re-used; all other components, including the steel housing, are replaced.

Annual Quantities: $\quad 12,100 \mathrm{~kg} ; 1.6 \mathrm{~m}^{3}$ (He-3 target only)

Waste Minimization:

No waste minimization efforts have been identified; metal may be decontaminated and recycled.

Treatment Options:

(a) Shredding and compaction for storage and/or disposal.

(b) Metal recycling.

Comments:

None. 


\section{Target Fabrication Wastes}

Type: Hazardous Waste.

Description: Metals scraps, including lead scraps (RCRA code D008).

Generation: Target fabrication operations, including machining, extrusion, and welding.

Annual Quantities: Cannot be determined at this stage of design.

Waste Minimization:

Recycling of metal scraps.

Treatment Options:

Ship to a DOE-approved commercial treatment and disposal facility.

Comment:

LiAl target materials include lead, lithium/aluminum, and aluminum.

Materials in He-3 target components include Inconel, Zircaloy, and tungsten. 


\section{Target Storage Pool Wastes}

Type: Low-level Waste.

Description: Filters and ion exchange resin used to purify water in spent target storage pools. The waste will be contaminated with a variety of activation products and can contain tritium contamination.

Generation: Lead and tungsten spallation targets are very radioactive when removed from the target chamber. However, the bulk of this radioactivity is due to short-lived activation products, and will be reduced substantially after six to twelve months' storage. Spent spallation targets are stored in water to remove the heat of radioactive decay. The LiAl target blankets are also stored and disassembled under water.

\section{Annual Quantities: $\quad 5,300 \mathrm{~kg}, 5.3 \mathrm{~m}^{3} \quad$ (Both target designs)}

Waste Minimization:

No waste minimization efforts have been identified.

Treatment Options:

\section{Filters:}

(a) Shredding, followed by compaction for storage and/or disposal.

(b) Incineration, followed by stabilization or vitrification of residue.

Ion Exchange Resin:

(a) Stabilization in concrete. This eliminates any need to dewater the resins prior to treatment or disposal.

(b) Incineration, followed by stabilization or vitrification of residue.

(c) Vitrification.

\section{Comments:}

(a) Lead spallation targets are used for a two-year cycle.

(b) Tungsten spallation targets are changed out at 2.2-year intervals.

(c) Design of a pool cleanup system has been deferred. Analysis of the spallation products present in storage pools has also been deferred. 
(d) BNL design teams predict $2,400 \mathrm{~kg}(1 \mathrm{~m} 3)$ low-level waste generated per year from a target disassembly basin. The composition of the waste would be aluminum fines, scrap metal, and filters. 


\section{Tungsten}

Type: Low-level Waste.

Description: Tungsten is a non-hazardous, metallic, hard, brittle, gray solid with a specific gravity of 19.3. During a 600-day irradiation, spallation products build up in the tungsten rod bundles. At 1 second after irradiation the total amount of activity in one rod bundle is estimated to be $1,633,000 \mathrm{Ci}$. The activity decays to $810,000 \mathrm{Ci}$ after 1 day, $385,000 \mathrm{Ci}$ after 30 days, and $54,000 \mathrm{Ci}$ after one year.

Generation: The neutron source for the He-3 target uses solid tungsten rods cooled with heavy water. The neutron soruce assembly is designed as a separate unit that can be removed and replaced during a routine maintenance period after approximately 2.2 years of service.

\section{Annual Quantities: $\quad 650 \mathrm{~kg}, 0.034 \mathrm{~m}^{3}$ (He-3 target only)}

Waste Minimization:

No waste minimization efforts have been identified.

Treatment Options:

N/A; pack for storage and/or disposal.

\section{Comments:}

(a) The tungsten rod bundles are made up of $1 / 8$ inch diameter rods that are wrapped with 0.04 inch diameter wire to provide proper spacing in the bundle. The wire wraps around each rod four times and is continuously attached to the rod over its 1.05-meter length. The rods are arranged into a 91-rod bundle with a hexagonal pitch determined by the wire wrap. Each rod bundle is contained in an Inconel can that is 0.030 inch thick.

(b) The neutrons needed for tritium production are produced by spallation of either lead or tungsten by high energy protons. Neutrons are produced either directly, being knocked out as protons hit the nucleus, or as a decay product of the excited nucleus produced. The number of neutrons produced by lead or tungsten per proton absorbed is only moderately well known as a function of proton energy; typically approximately 20 neutrons/proton are produced from a $1 \mathrm{GeV}$ proton beam. Tungsten produces more neutrons per proton absorbed, at a given proton kinetic energy, but it has a higher neutron absorption cross section. BNL's comparison analysis of the use of tungsten and lead indicated the greater absorption of neutrons by tungsten overcame the benefit of increased neutron-to-proton spallation production. Therefore, BNL suggests using lead for the neutron source target. LANL prefers 
tungsten. By using suitably thin rods they reduced the neutron absorption of tungsten so that tungsten appeared to be a better choice. Tungsten has the additional advantage of having a much higher melting temperature.

(c) The choice of spallation material is dependent on target geometry. 


\section{Uranium Beds}

Type: Low-level Waste.

Description: Uranium beds are about four feet long and two feet in diameter. The bed material is initially metal shavings of depleted uranium, but as the bed is used the material is oxidized to uranium oxide.

Generation: Uranium is consumed recovering tritium adsorbed as tritiated water on zeolite or molecular sieve beds. The zeolite beds are regenerated for reuse by heating them under recirculating hydrogen gas which passes through heated uranium beds to reduce the tritiated water to hydrogen isotopes. This mixture of hydrogen isotopes is then pumped to cryogenic distillation columns for isotopic separation.

Annual Quantities: $\quad 350 \mathrm{~kg}, 0.1 \mathrm{~m}^{3} \quad$ (LiAl target design only)

Waste Minimization:

Substitution of a less hazardous material such as magnesium beds or platinum/alumina catalyst beds.

Treatment Options:

N/A; beds are sealed, self-contained units that can be packaged in glove boxes under a nitrogen atmosphere for disposal. However, the uranium must be completely oxidized to meet disposal Waste Acceptance Criteria.

\section{Comment:}

While uranium and uranium oxide are not hazardous materials under RCRA, the depleted beds are a fire hazard because the finely divided powder that forms can ignite spontaneously in air. 


\section{Vacuum Pumps}

Type: Low-level or Mixed Waste.

Description: Vacuum pumps that have failed and which are contaminated with radionuclides. Heavy metals may be present, which would cause the waste stream to be mixed waste. Pumps could also contain used oil, which is a listed waste in some states; however, current designs use fluidless pumps for all processes (e.g., tritium pumping and coolant circulation) where pumping is required.

Generation: Pump failure. For equipment contained in glove boxes, replacement of a failed unit may be preferable to repairing a contaminated pump.

Annual Quantities: $\quad 300 \mathrm{~kg}, 0.2 \mathrm{~m}^{3} \quad$ (Both target designs)

Waste Minimization:

(a) Vacuum pumps in glove boxes should be protected from physical damage and receive preventive maintenance to prevent failure.

(b) To eliminate pump oil as a waste stream, fluidless pumps and/or blowers will most likely be used in the tritium processing facilities.

Treatment Options:

Low Level:

Disassemble and compact for convenient packaging.

Mixed:

Disassembly and compaction, followed by macroencapsulation.

Comment:

Fluidless vacuum pumps are sensitive to particulate, chemical, and mercury attack. The gas in tritium processing lines must be kept very clean. 


\section{Waste Oil}

Type: Low-level or Mixed Waste.

Description: Lubrication oil used in vacuum pumps, blowers, robotic equipment, and vehicles operated in process buildings. Due to bearing wear or the tendency of oil to accumulate organic contaminants, waste oils have been found to contain the following RCRA codes: D005, D006, D008, D009, D018, F001, F003, F004, and F005. If falling mercury drop pumps or mercury diffusion pumps are used, mercury contamination (D009) will be present. Past experience at SRS has shown pump oil associated with tritium facilities can have tritium activity levels ranging from background to $185 \mathrm{Ci} /$. Used oil is regulated as a hazardous waste in the State of California.

Generation: Routine maintenance of oil-lubricated equipment.

Annual Quantities: Minimal. (Both target designs)

Waste Minimization:

(a) Use of fluidless, all-metal pumps for tritium pumping.

(b) Use of oil-free blowers for discharges to stacks.

(c) Use of cooling system pumps that are water-cooled and lubricated.

Treatment Options:

Since volume will be small, stabilization will be the most practical treatment.

\section{Comments:}

(a) For over a decade, there has been an ongoing effort at the SRS Tritium Facility to develop and evaluate fluidless, all-metal pumps to replace mercury diffusion pumps and Sprengel falling mercury drop pumps; the majority of these pumps have now been replaced. Double containment bellow-sealed pumps and fluidless, all-metal scroll pumps are viable candidates. However, these pumps are sensitive to particulate, chemical, and mercury attack, so the process lines must be kept very clean.

(b) RTF will not use pumps that use mercury or organic lubricants. 


\section{Water Treatment Filters}

Type: Low-level Waste.

Description: Glass fiber paper water treatment filters used to purify cooling water in the target/blanket system. Each filter unit after dewatering and compaction will produce $2.0 \mathrm{ft}^{3}$ of waste. Due to spallation products entering the coolant, the filters will become radioactive.

Generation: Spent water treatment filters will result from routine replacement in the water purification systems for both the light and heavy water cooling systems. Purification uses both filters and ion exchange beds. The anticipated service life for filters and beds is 3 to 4 months. Target/blanket cooling will result in seven spent filters per year.

Annual Quantity: $1600 \mathrm{~kg}, 1.6 \mathrm{~m}^{3} \quad$ (Both target designs)

Waste Minimization:

No waste minimization efforts have been identified.

Treatment Options:

(a) Compaction and packaging for storage and/or disposal.

(b) Incineration, followed by stabilization or vitrification of residue.

Comment:

The goal is to maintain the tritium level in the moderator coolant at or below 1.7 Ci/liter. 


\section{Welding Wastes}

Type: Hazardous or Mixed Waste.

Description: Hazardous welding wastes can include spent welding rods and acids used to etch metals for welding. Welding in controlled areas or repairs of contaminated components may result in a mixed waste stream.

Generation: Maintenance activities and preparation of radioactive shipping containers. Welding wastes also result from target fabrication.

Annual Quantities: Minimal.

Waste Minimization:

(a) Specify Metal Inert Gas (MIG) welding, which has minimal end waste.

(b) Mechanically prepare materials for welding.

(c) Weld in uncontrolled areas when possible.

Treatment Options:

Metal:

Stabilize metal fines and small pieces ( $\leq 6 \mathrm{~cm}$ in diameter).

Acid:

Neutralization, followed by stabilization.

Comments:

(a) Mechanical preparation will eliminate acids as a waste stream component, but will result in additional non-hazardous wastes such as grinding brushes and metal shavings. Other non-hazardous wastes from welding include welding gloves, fluxes, and slag.

(b) If the waste is only mixed because of its corrosive characteristic, it will be a low-level waste after neutralization. 


\section{Zeolite Beds}

Type: Low-level Waste.

Description: Zeolite is either a naturally hydrated silicate of aluminum and either sodium or calcium or both, of the type $\mathrm{Na}_{2} \mathrm{O} \cdot \mathrm{Al}_{2} \mathrm{O}_{3} \cdot \mathrm{nH}_{2} \mathrm{O}$; or an artificial ion exchange resin. Artificial zeolites are made in a variety of forms, ranging from gelatinous to porous and sand-like, and are used as gas adsorbents, water softeners, drying agents, and catalysts. Molecular sieves are a group of adsorptive desiccants which belong to the zeolite family. The outstanding characteristic of these materials is their ability to undergo dehydration with little or no change in crystal structure. The dehydrated crystals are interlaced with regularly spaced channels of molecular dimensions that comprise almost $50 \%$ of the total volume of the crystals. The empty cavities in an activated molecular sieve have a strong tendency to recapture the water molecules that have been driven off. This waste stream is molecular sieve contaminated with tritium and the molecular sieve container.

Generation: Zeolite beds are used as "getters" to remove tritium and tritium compounds from the air. Molecular sieves are used in the tritium recovery system. Effluent gases from glove boxes and room air are passed over a catalyst bed to oxidize hydrogen isotope gases. The resulting tritiated water, regular water, and HTO are then captured by the molecular sieve. The molecular sieve used in APT can be regenerated and reused until a physical breakdown in the material necessitates its replacement. At that time the entire unit, the holder and the molecular sieve, will be replaced.

Annual Quantities: Minimal.

Waste Minimization:

No waste minimization efforts have been identified.

Treatment Options:

N/A; beds are sealed, self-contained units that can be packaged in glove boxes for disposal.

\section{Comments:}

(a) At TSTA the same molecular sieve was used for 10 years (not continuous use). The material was then replaced to investigate hold-up of tritium on the bed and not because of failure.

(b) At RTF, type 3A zeolite is used in the beds. Since zeolite 3A does not adsorb $\mathrm{CO}_{2}$, the $\mathrm{CO}_{2}$ generated by the oxidation of organics goes out with the purge gas and does not accumulate in the zeolite beds. 


\section{Zircaloy 4}

Type: Mixed Waste.

Description: Zircaloy is the trademark for alloys of zirconium with low percentages of tin, iron, chromium (D007), and nickel. It is used as cladding for nuclear fuel elements and other reactor applications.

Generation: Zircaloy 4 will be used in the backstop for the He-3 target, where it will be exposed to fairly low flux conditions. The backstop will be changed out along with other target components at 2.2-year intervals, due to the possibility of radiation-induced swelling in the material.

Annual Quantities: $\quad 2000 \mathrm{~kg}, 0.32 \mathrm{~m}^{3}$ (He-3 target only)

Waste Minimization:

No waste minimization efforts have been identified.

Treatment Options:

(a) Shredding and compaction. If the metal fails the Toxicity Characteristic Leaching Procedure (TCLP; EPA Method 1311, 40 CFR 261.24) leach limit for chromium, it would have to be stabilized or encapsulated prior to packaging for storage or disposal.

(b) Metal recycling.

\section{Comments:}

(a) The backstop will consist of about $4330 \mathrm{~kg}$ of Zircaloy 4. Due to low flux conditions, the backstop may not need to be changed as frequently as other target components, and may even last the life of the APT facility.

(b) The presence of chromium makes the Zircaloy backstop a mixed waste. However, leaching studies on other alloys at SNL-NM have shown that chromium does not leach readily. 


\section{Appendix C}

\section{Treatment and Disposal of APT Waste}

The major sources of APT waste are PPE from routine maintenance and the target/blanket assemblies that must be changed out every 1-2 years. Waste streams from these activities account for $\sim 97 \%$ (weight and volume $\%$ ) of all waste from the LiAl target design and $\sim 74 \%$ of the waste generated with the He-3 target design. The primary treatment for these wastes would be incineration of PPE followed by stabilization of the ash residue and compaction of the target/blanket assembly waste metal. The possibility of melting and recycling the target/blanket metals should also be considered. Solid waste containing RCRA characteristic metals not amenable to recycling would have to be encapsulated in a polymer matrix to minimize leaching after disposal.

Solid wastes whose volumes are so small that compaction would be impractical merely require packaging for disposal. Examples include the waste from refurbishment of accelerator ion pumps $\left(0.002 \mathrm{~m}^{3}\right)$ and the tungsten rods used as the neutron source in the $\mathrm{He}-3$ target design $\left(0.034 \mathrm{~m}^{3}\right)$.

Appendix $\mathrm{C}$ describes the technologies required for APT waste treatment, evaluates relevant existing and planned treatment facilities at DOE sites, and discusses waste disposal options. This discussion is organized into the following sections:

C1. Treatment Technologies

C1.1 Compaction

C1.2 Thermal Desorption

C1.3 Incineration

C1.4 Stabilization

C1.5 Vitrification

C1.6 Encapsulation

C1.7 Metals Recovery

C2. Existing and Planned DOE Waste Treatment Facilities

C2.1 Hanford

C2.2 Idaho National Engineering Laboratory (INEL)

C2.3 Los Alamos National Laboratory (LANL)

C2.4 Oak Ridge

C2.5 Pantex

C2.6 Savannah River Site (SRS)

C3. Waste Disposal

C3.1 Low-Level Waste

C3.2 Mixed Waste

C3.3 Hazardous Waste 


\section{C1. Treatment Technologies}

Treatment technologies applicable to APT wastes include compaction, thermal desorption, incineration, stabilization, vitrification and encapsulation.

\section{C1.1 Compaction}

Large-volume metallic wastes, such as the LiAl melts and crucibles, and aluminum target/blanket components can be cut up and compacted to $1 / 2$ to $1 / 3$ their original volume. BNL proposes that target/blanket components that are highly activated be compacted in the target storage pool. Conversations with groups that operate compactors indicate that tritium poses no particular problem for compaction of less contaminated waste, such as PPE. Ramp Industries of Denver, $\mathrm{CO}$ stated they have been compacting tritiumcontaminated PPE waste for 9 years with no significant releases. This record includes four drums with a total H-3 activity of $\sim 1500 \mathrm{Ci} 1$.

While the greatest volume reduction of PPE waste would be achieved through incineration, if this is not feasible, these wastes could also be compacted. During compaction a drum of waste experiences an area force of 4-5M lbs. Under this force, PPE waste usually reaches a density of $55-60 \mathrm{lbs} / \mathrm{ft}^{3}$ or 880 $950 \mathrm{~kg} / \mathrm{m}^{3}$. This corresponds to a volume reduction factor of 3-5.

\section{C1.2 Thermal Desorption}

Thermal desorption consists of heating waste to a point where volatile liquid contaminants can be driven off, and either condensing the vapors or adsorbing them on activated carbon. Since waste containing $>1 \%$ liquid is not acceptable for disposal, this process is often used to drive off residual liquid prior to waste compaction. If a radioactive waste is mixed due to the presence of organic solvents, thermal desorption removes the hazardous constituents, leaving a low-level waste. This treatment could be used for APT waste streams such as absorbent wipes and solvent rags; however, if activated carbon is used, it becomes a secondary waste stream that must be treated.

\section{C1.3 Incineration}

Incineration is the thermal decomposition of organic constituents through high temperature $\left(760-1550{ }^{\circ} \mathrm{C}\right)$ oxidation reactions. Hydrocarbon wastes are converted to carbon dioxide and water vapor; wastes containing nitrogen, sulfur, and/or halogens produce nitrites, nitrates, ammonia, sulfites, sulfates, and halogen acids, respectively. Air particulates are filtered and exhaust gases are cooled, scrubbed, and neutralized in an air emissions control system prior to release to the system exhaust stack. Ash residues can be stabilized in cement or vitrified into a glass-like solid for disposal.

Solid wastes are generally treated in a rotary kiln furnace or a fixed hearth furnace. Wastes are fed to the combustion chamber via rams, gravity feed, air lock feeders, vibratory or screw feeders, or belt feeders. Containerized waste is 
gravity-fed or ram-fed. The rotary kiln furnace is a refractory or metal-lined cylinder, mounted at a slight inclination from horizontal, that slowly rotates to enhance the mixing of solids with combustion air. A forced-draft air circulation system provides oxygen for combustion and turbulence for mixing. The rotation also moves the ash to the lower end of the kiln, where it is removed. Rotary kiln systems usually have a secondary combustion chamber, or afterburner, following the kiln for further combustion of volatilized waste components.

Fixed hearth, or controlled air or starved air incineration, is a two-stage process. Waste is ram-fed into the primary chamber, where it is burned in a "starved" atmosphere whose oxygen content is insufficient for complete combustion. The Products of Incomplete Combustion (PICs; primarily carbon monoxide and volatile hydrocarbons) pass into a secondary chamber where additional air is injected to complete the combustion process. Due to the reduced air flow in the primary chamber, combustion gas velocities are lower, and, as a result, there is less entrainment and carryover of ash particulates into the secondary chamber and the exhaust gases.

An innovative technology that has several advantages for incineration of radioactive waste is the plasma arc centrifugal furnace. This system uses plasma energy to vitrify material dropped into a tub spinning at 20-50 rpm. The tub has an axial hole for tapping slag, which cools into a glass-like solid that is a leach-resistant, homogeneous product. A metal layer forms on top of the slag, and can be drawn off separately. Organics are burned to completion in a secondary combustion chamber. The advantages of this system for radioactive waste treatment are:

- Whole drums of waste can be inserted and treated.

- Metals separation, combustion of organics and solidification of residue can be achieved with a single process.

- Because there is only one system, waste handling is minimized.

Incineration is recommended for treatment of PPE wastes, which account for over half the total weight and volume of waste for both target designs.

Shredding of this waste prior to combustion will increase combustion efficiency. Incineration followed by vitrification or stabilization of residues will generally reduce the initial waste volume by about a factor of 20 . During trial burns, the Waste Experimental Reduction Facility (WERF) incinerator at the INEL has achieved volume reduction factors as high as $\mathbf{8 0}$.

Incineration of tritiated waste will result in tritium in the exhaust gases. Some of this will adhere to particulates and be trapped in the exhaust HEPA filters. As exhaust gases are rapidly cooled and water vapor condenses, some of the remaining tritium should be trapped by the scrubber system; however, most will go up the stack as tritiated water vapor (Ref 8). Stack gas would be monitored so that the permitted tritium release limit is not exceeded. Exhaust gas filters and scrubber solutions will be secondary waste streams. 


\section{C1.4 Stabllization}

Stabilization immobilizes heavy metals by chemically binding them in a solid matrix. This decreases the potential for metals to leach out after disposal if the waste were to be exposed to moisture or weak acids. The two most common stabilization agents are Portland cement and lime/pozzolan.

While cement-based products are used for stabilization of inorganic solids and aqueous liquids, a series of non-hazardous compounds based on Montmorillonite clay can be used to stabilize aqueous liquids, organic liquids such as used oil, and organic/aqueous liquid mixtures. These compounds are sold under the trade names Aquaset and Petroset.

The estimated total annual volume of primary APT waste streams for which stabilization is the proposed treatment is $<0.1 \mathrm{~m}^{3}$ for both designs. This waste is primarily organic solvents, which, if incineration were used for PPE, could also be incinerated.

\section{C1.5 Vitrification}

Vitrification processes involve dissolving waste at high temperatures (1100 $1400^{\circ} \mathrm{C}$ ) in a pool of molten glass that usually consists of soda ash, lime, silica, boron oxide, and other glassmaking constituents. Molten glass is periodically withdrawn from the bottom of the furnace and cooled. This process is an alternative to stabilization for immobilization of incinerator ash prior to disposal. Vitrification is also suitable for ion exchange resins, chemical cleaning and decontamination solutions, and inorganic sludges and slurries; however, from an energy use standpoint, it is only practical for large volume waste streams that will be generated on a regular basis.

Vitrification is an effective means of immobilizing both hazardous inorganic and radioactive constituents. Both alpha and beta emitters will be sealed in the glass matrix, and, if gamma-emitting radionuclides are present, the gamma dose rate will be reduced as a result of the increased density of the vitrification matrix.

If the new treatment standards proposed by EPA for toxic metals 3 are implemented, the Toxicity Characteristic Leaching Procedure (TCLP) concentration limit for chromium will decrease by a factor of 15 , from the current $5.0 \mathrm{mg} / 1$ to $0.33 \mathrm{mg} /$ (non-wastewater limit, 3 ). Cemented wastes may not meet this limit, but tests using wastewater treatment sludges and ion exchange resins have shown that vitrification will 2 .

\section{C1.6 Encapsulation}

Encapsulation is primarily applicable to solid wastes containing hazardous metal constituents, such as discarded circuit boards or instrumentation. The waste is shredded, dried, mixed with an organic polymer (e.g., polyethylene), 
thermosetting resin, or asphalt at $120-130^{\circ} \mathrm{C}$, and allowed to cure into a solid mass prior to disposal. As with all waste immobilization processes, the goal is to minimize leaching after disposal. This process is not suitable for wastes that decompose at these temperatures or that contain strong oxidizers such as nitrites, chlorates, or perchlorates that can react with the binder material.

APT waste streams for which encapsulation is the proposed treatment include batteries for which recycling is impractical, instrumentation, and the lead that will be used in the target/blanket designs. Total annual waste volume is about $3 \mathbf{m}^{3}$ for both target designs. Macroencapsulation (encapsulating an entire mass, rather than microencapsulation, which coats individual particles of a waste) is the BDAT for radioactive lead solids; however, target/blanket materials will have to be held in the target storage pool to allow activation products to decay prior to treatment.

\section{C1.7 Metals Recovery}

The large volumes of aluminum, lead, stainless steel, Inconel, and Zircaloy wastes generated by APT could be recovered by melting in a plasma arc or rotary kiln furnace under a reducing atmosphere. Whether or not this is economically feasible will be a function of how long the target/blanket and associated structural materials would have to cool before processing. He-3 target design lead, aluminum and Inconel parts that are not directly in the neutron beam will decay to an activity level of about $3 \mathrm{Ci} / \mathrm{kg}$ in 3 years. Total activity in comparable parts of the LiAl target design is expected to be lower due to the fact that the neutron flux density is lower and the total exposed mass is greater.

Retech Inc. (Ukiah, CA) has signed a cooperative research and development agreement with Westinghouse Idaho Nuclear Co. to develop melting technologies that will allow reuse of radioactively contaminated metals. Using its plasma arc centrifugal furnace technology, Retech will melt stainless steel containing surrogates for radioactive constituents and evaluate the fate of the surrogates during the process of melting, pouring and cooling the test metal.

\section{C2. Existing and Planned DOE Waste Treatment Facilities}

Sites under consideration as possible locations for a future tritium production facility include INEL, NTS, Oak Ridge, Pantex and SRS. NTS is a disposal site for low-level waste (see Section C3.1), but has no on-site treatment facilities. Pantex only has encapsulation facilities. The other three sites, Hanford and LANL all have existing and/or planned incineration and compaction capabilities. Relevant treatment facilities at INEL, Oak Ridge, Pantex, SRS, LANL and Hanford are summarized in Table C1. Only those facilities that have at least passed DOE Key Decision Zero (KD-0, Approval of Mission Need) are listed. Typically at this stage, conceptual design and the preparation of National Environmental Policy Act (NEPA) documentation have been 


\section{Existing and Planned DOE Waste Treatment Facilities Relevant for APT}

\begin{tabular}{|c|c|c|c|c|c|}
\hline Site & Facility & Sreatment(s) & Allowable Waste & $\begin{array}{l}\text { Design Capacity, } \\
\mathrm{m}^{3} / \mathrm{yr}\end{array}$ & $\begin{array}{l}\text { Estimated } \\
\text { Startup Date }\end{array}$ \\
\hline \multirow[t]{2}{*}{ Hanford } & $\begin{array}{l}\text { Waste Receiving } \\
\text { \& Processing } \\
\text { Facility, WRAP I }\end{array}$ & $\begin{array}{l}\text { Compaction, } \\
\text { Stabilization }\end{array}$ & Low-level & 1400 & FY97 \\
\hline & $\begin{array}{l}\text { Waste Receiving } \\
\text { \& Processing } \\
\text { Facility, WRAP II }\end{array}$ & $\begin{array}{l}\text { Macroencap- } \\
\text { sulation, } \\
\text { Stabilization }\end{array}$ & Low-level, Mixed & 1500 & FY99 \\
\hline \multirow[t]{2}{*}{ INEL } & $\begin{array}{l}\text { Waste Experimental } \\
\text { Reduction Facility, } \\
\text { WERF }\end{array}$ & $\begin{array}{l}\text { Incineration, } \\
\text { Stabilization }\end{array}$ & Low-level, Mixed & $\begin{array}{c}49,625 \text { (incin.) } \\
2,765 \text { (stab.) }\end{array}$ & $\begin{array}{l}\text { TBD for } \\
\text { restart }\end{array}$ \\
\hline & $\begin{array}{l}\text { HEPA Filter } \\
\text { Leaching System }\end{array}$ & $\begin{array}{l}\text { Chemical } \\
\text { Extraction }\end{array}$ & Low-level, Mixed & 83 & TBD \\
\hline LANL & $\begin{array}{l}\text { Controlled Air } \\
\text { Incinerator }\end{array}$ & Incineration & Low-level, Mixed & $\begin{array}{l}\text { 200, solids } \\
300, \text { liquids }\end{array}$ & TBD \\
\hline Oak Ridge & TSCA Incinerator & Incineration & Low-level, Mixed & 15,716 & $\begin{array}{l}\text { Operating, } \\
\text { liquids only }\end{array}$ \\
\hline \multirow[t]{2}{*}{ Pantex } & Building 11-9 & Encapsulation & n Low-level, Mixed & 43 & TBD \\
\hline & $\begin{array}{l}\text { Hazardous Waste } \\
\text { Treatment \& } \\
\text { Processing Facility }\end{array}$ & $\begin{array}{l}\text { Compaction, } \\
\text { Stabilization, } \\
\text { Encapsulation }\end{array}$ & Low-level & 500 & FY98 \\
\hline \multirow[t]{3}{*}{ SRS } & $\begin{array}{l}\text { Consolidated } \\
\text { Incineration Facility, } \\
\text { CIF }\end{array}$ & Incineration & Low-level, Mixed & $\begin{array}{r}100,424, \text { solids } \\
340, \text { liquids }\end{array}$ & 1996 \\
\hline & $\begin{array}{l}\text { CIF Ashorete } \\
\text { Facility }\end{array}$ & Stabilization & Low-level, Mixed & 2,426 & 1996 \\
\hline & $\begin{array}{l}\text { Hazardous Wasted } \\
\text { Mixed Waste } \\
\text { Disposal Facility }\end{array}$ & $\begin{array}{l}\text { Macroencap- } \\
\text { sulation, } \\
\text { Stabilization }\end{array}$ & Low-level, Mixed & $\begin{array}{l}73 \text { (macro.) } \\
484 \text { (stab.) }\end{array}$ & TBD \\
\hline
\end{tabular}

initiated. While planned, unapproved facilities are not listed in Table C1, they are discussed in the text.

If DOE were to approve shipment of APT waste to commercial treatment facilities, Diversified Scientific Services (DSSI) and Scientific Ecology Group (SEG), both in Oak Ridge, TN, could be utilized for low-level PPE waste streams. Both DSSI and SEG have incinerators that can accept low-level, tritium-contaminated waste, and SEG also has stabilization and compaction capabilities. 


\section{C2.1 Hanford}

The Hanford Waste Receiving and Processing Facilities (WRAP I and II) are designed to prepare on-site low-level waste (WRAP I) and mixed low-level waste (WRAP IIA) for disposal. WRAP I includes systems for adsorption, compaction, stabilization and packaging. The facility is in the detailed design stage. Ground-breaking ceremonies were held on April 15 of this year, and construction is scheduled to be completed in December, 1996. WRAP II, which is at the KD-0 stage, will conduct waste grouting, macrocencapsulation and stabilization operations. An incineration facility with a design capacity of 550 $\mathrm{m}^{3} / \mathrm{yr}$ is planned but unapproved.

\section{C2.2 Idaho National Engineering Laboratory (INEL)}

INEL treatment facilities applicable to APT waste streams include the Waste Experimental Reduction Facility (WERF) incinerator, the WERF Waste Stabilization Unit, and the HEPA Filter Leaching System.

The WERF incinerator began processing beta/gamma emitting low-level waste in September, 1984. The first trial burn of mixed waste was conducted in 1986. In February, 1991, the WERF incinerator began a planned shutdown for routine maintenance and system upgrades. The facility has not operated since. Efforts are currently underway to obtain the necessary DOE and state permits for facility restart.

The WERF incinerator is a dual-chamber, controlled air unit that burns solid and liquid wastes. The facility can accept F, P, U and some K-listed wastes. During its operational period, WERF treated approximately $3,000 \mathrm{~m}^{3} / \mathrm{yr}$ of waste, operating well below its permitted capacity. The WERF Waste Stabilization Unit was primarily used to stabilize WERF incinerator ash with Portland cement.

The HEPA Filter Leaching System uses chemical extraction to remove vapors and particulates trapped by the filters. Testing was begun in January, 1994. Based on test results, the State of Idaho will make a regulatory ruling as to whether or not treated filters may be disposed of as low-level waste under the Debris Rule. Therefore, the startup date for this facility cannot be determined at this time.

INEL also has the capability to perform small-scale macroencapsulation and stabilization of waste as it is generated or accumulated subject to the limitations of 40 CFR 262.34. This generator treatment is limited to on-site waste, and, for each individual process, a 30-day notice and waste analysis plan must be supplied to the regulator.

The Mixed and Low-Level Waste Treatment Facility is a planned, unapproved facility with a design capacity of $60 \mathrm{~m}^{3} / \mathrm{yr}$. Proposed treatment technologies include chemical precipitation, decontamination, incineration, 
macroencapsulation, lead recycling, neutralization, sizing, stabilization, and thermal desorption.

INEL is negotiating with the State of Idaho through the FFCA process to be able to treat off-site low-level and mixed waste. Treated waste would be returned to the generator for disposal.

\section{C2.3 Los Alamos National Laboratory (LANL)}

Los Alamos has one existing facility designed to treat solid and liquid low-level and mixed waste, the Controlled Air Incinerator (CAI), a dual-chamber model that was originally built to demonstrate that transuranic waste could be successfully incinerated. Solid waste is fed to the incinerator in $1 \times 1 \times 2 \mathrm{ft}$ boxes; a vortex injection burner is used to feed liquid waste. There is currently no facility to treat incinerator ash; however, cementation, encapsulation and vitrification are all under investigation as possible stabilization options.

The CAI is currently not operating, awaiting DOE and state approval of NEPA documentation supporting a change in operational status from $R \& D$ to routine waste treatment. A restart date is subject to the availability of funds and permit issuance.

\section{C2.4 Oak Ridge}

The Toxic Substance Control Act (TSCA) incinerator at the Oak Ridge K-25 site treats low-level, mixed and hazardous liquid wastes, including polychlorinated biphenyls (PCBs), RCRA materials, and low-level uraniumcontaminated wastes. The facility includes a receiving, sorting and storage system, PCB and non-PCB waste receiving, storage and blending tanks, a waste feed system, a dual-chamber rotary kiln incinerator, a process gas cleanup system, and a wastewater discharge system. Ash residues are stored as mixed waste.

The TSCA incinerator, which began operating in 1991, was originally built to incinerate tank wastes. The facility currently accepts only liquid waste and is permitted to accept off-site waste from the Portsmouth and Paducah gaseous diffusion plants, Oak Ridge National Laboratory, the Y-12 site, Fernald, and Reactive Metals, Inc. Oak Ridge expects to have incinerated the bulk of inventory liquids by the end of FY95, at which point the facility could be used to treat solids if $\mathrm{DOE}$ were to approve.

There are no specific air release limits on tritium for the TSCA incinerator; however, whether a waste is processed is determined by whether or not the allowed total annual dose ( $7.5 \mathrm{mrem}$ ) to workers will be exceeded during waste handling operations. Waste activity levels cannot exceed $1800 \mathrm{pCi} / \mathrm{g}$.

The Oak Ridge Reservation Mixed Waste Treatment Facility is a planned, unapproved facility that is in the pre-conceptual design stage. Proposed treatment systems include incineration $\left(882 \mathrm{~m}^{3} / \mathrm{yr}\right)$, stabilization (735 


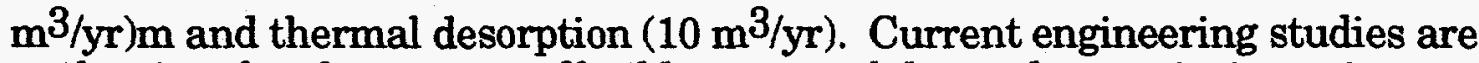
evaluating the alternatives of building new solid mixed waste incineration capability or enhancing the capabilities of the TSCA incinerator.

\section{C2.5 Pantex Plant}

Pantex has a pilot-scale encapsulation facility that is currently not permitted. A study that demonstrated that LDR treatment standards could be achieved using epoxy-based encapsulation has been completed; however, it is currently not known whether the current system will be expanded to a full-scale facility. The permitting process has not been initiated.

The Hazardous Waste Treatment and Processing Facility is an approved size reduction and waste immobilization facility that will include systems for stabilization of containerized and bulk liquid low-level wastes, and encapsulation of low-level and mixed wastes. The facility Critical Design Review was completed and NEPA documentation submitted on 9/30/93. Construction is estimated to be completed in FY95/96. The application for an operating permit was submitted to the State of Texas on 10/31/94.

\section{C2.6 Savannah River Site (SRS)}

SRS has two planned waste treatment facilities that are relevant for APT: the Consolidated Incineration Facility (CIF) and the Hazardous Waste/Mixed Waste Disposal Facility (HW/MW DF). The CIF is a dual-chamber rotary kiln incinerator designed to handle solid and liquid low-level and mixed waste. Ash will be stabilized with Portland cement in the CIF Ashcrete Facility, which is an integral part of the CIF that is not designed to operate separately. As of $10 / 93$, construction was $22 \%$ complete. Construction is scheduled to be completed in March, 1995, with full-scale operation by February, 1996. The facility will be permitted only for treatment of on-site waste.

The HW/MW DF will include treatment systems for waste handling (sorting and size reduction), acid leaching and chemical precipitation, stabilization of solid and liquid wastes, soil washing, macroencapsulation of lead, roasting/retorting of mercury-contaminated soil and equipment, amalgamation of elemental mercury, and wastewater cleanup. Systems applicable to APT are the macroencapsulation and stabilization units.

NEPA documentation is currently being prepared for the HW/MW DF. A decision as to whether an Environmental Assessment or Environmental Impact Statement will be required is pending. A project rescoping that will impact cost and schedule has been submitted to DOE. Until the NEPA and project scope questions have been answered, schedule and milestones cannot be defined. 


\section{C3. Waste Disposal}

The Waste Acceptance Criteria (WAC) of facilities that could be used for disposal of APT low-level and mixed waste are summarized in the following discussion. All waste destined for off-site disposal rather than on-site storage must be packaged according to Department of Transportation regulations for hazardous and/or radioactive materials.

\section{C3.1 Low-Level Waste}

DOE Order 5820.2A requires that all DOE LLW be disposed of at a DOE disposal facility. At the present time, there are only three-DOE disposal sites that accept off-site waste: Hanford, the Nevada Test Site, and Savannah River. Barring policy changes, APT low-level waste that meets the site's WAC would be sent to one or more of these facilities. A formal application and approval process must be completed before waste can be shipped to any of these sites. Hanford, Nevada, and Savannah River will not accept the following for disposal:

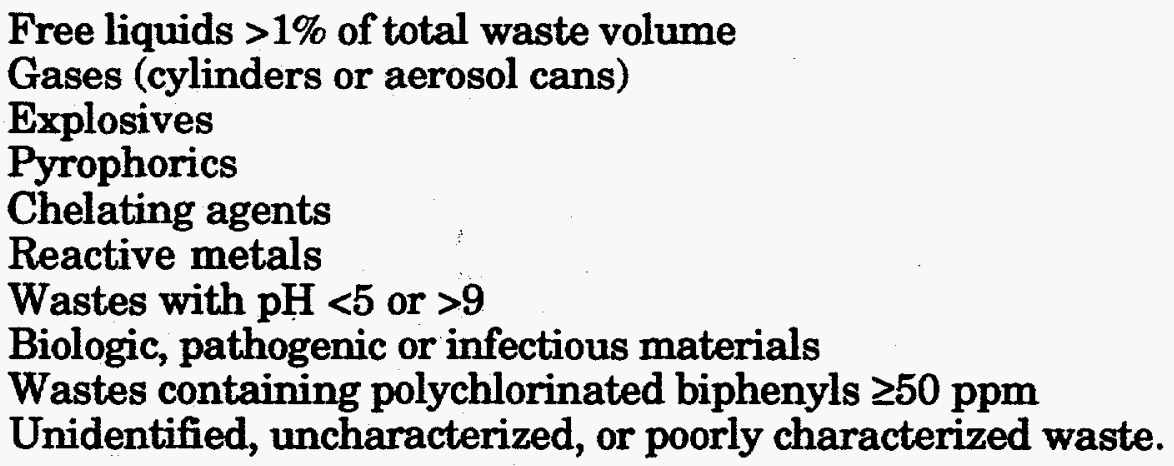

All three sites require that, upon or immediately after generation and before packaging, the physical and chemical characteristics and radionuclide content of all LLW be determined and recorded for use during all subsequent stages of the waste management process; i.e., on-site treatment, packaging, segregation, transportation, off-site treatment, storage and disposal. Additional site-specific requirements and restrictions may be found in the WAC for each site. General information about each low-level and mixed waste disposal site is summarized Table C2.

\section{C3.2 Mixed Waste}

No DOE facility is currently authorized to dispose of MLLW; however, some shipments of MLLW to Hanford for storage have been allowed on a case-bycase basis. These shipments have been primarily either mixed waste containers whose surface dose rate exceeded $200 \mathrm{mrem} / \mathrm{hr}$ and therefore required remote handling; "special waste", defined as waste that requires special handling; or unique waste, such as decommissioned reactor vessels. Hanford, NTS and Savannah River all have planned MLLW disposal facilities that have passed $\mathrm{KD}-0$. This means these sites have a recognized mission need 
Table C2

Low-Level and Mixed Waste Disposal Sites

\section{A. Low-Level Waste}

\begin{tabular}{|c|c|c|c|}
\hline Site & Location & Site Contact & WAC Document \\
\hline Hanford & Richland, WA & $\begin{array}{l}\text { Don Plowman } \\
(509) 376-7848\end{array}$ & WHC-EP-0063 \\
\hline Nevada Test Site & Nye County, NV & $\begin{array}{l}\text { Jim Henderson } \\
\text { (702) } 794-1417\end{array}$ & NVO-325, Rev. 1 \\
\hline Savannah River & $\begin{array}{l}\text { Portions of Aiken, } \\
\text { Barnwell, and } \\
\text { Allendale Counties, } \\
\text { SC }\end{array}$ & $\begin{array}{l}\text { Joanne Steingard } \\
\text { (803) 557-9661 }\end{array}$ & \\
\hline
\end{tabular}

\section{B. Mixed Waste}

Envirocare of

Utah, Inc.

Clive, UT

Susan Rice
(801) 532-1330

RCRA Part B

Permit; Utah

Dept of

Environmental

Quality, Division

of Radiation

Control,

Radioactive

Material License

and have been approved for funding for conceptual design of mixed waste disposal facilities.

Envirocare of Utah, Inc. is the only commercial facility in the United States permitted to accept MLLW. Envirocare is licensed to accept both low-level and mixed waste, including Class A LLW, debris, by-product material (e.g., uranium and thorium mill tailings), and F-listed solvents. In addition to requiring a detailed description of the waste, its history, physical properties, and chemical and radioactive constituents, Envirocare requires that the following analytical data be supplied for each MLLW:

- Gamma spectral analysis for all naturally occurring and man-made radionuclides. If radionuclides are known to be present that cannot be easily quantified by gamma spectroscopy, radiochemical analysis must be provided. 
- $\quad$ Paint Filter Liquids Test, EPA Method 9095, for dry solids and stabilized wastes.

- TCLP results for heavy metals and volatile and semi-volatile organics.

All analyses must be performed at either a Utah-certified or EPA CLP (Contract Laboratory Program) laboratory. Five 1-kg representative waste samples must be sent to Envirocare and may be analyzed by them prior to waste acceptance.

At the present time, Envirocare is the only disposal option for APT mixed waste that meets its WAC.

\section{C3.3 Hazardous Waste}

APT hazardous waste may be disposed of at any convenient DOE-approved commercial facility that will accept it.

\section{References}

1. Conversation with John Lucas, president of Ramp Industries, May 4, 1994.

2. J. B. Mason, Modular Enviroglass TM Vitrification Technology for LowLevel Radioactive and Mixed Wastes, VECTRA Document No. SP-501001, Rev.2, VECTRA Technologies, Inc., Richland, WA.

3. Proposed Rules, Federal Register, Vol 58, No. 176, Tuesday, September 14, 1993. 


\section{Appendix D}

\section{Waste Stream Inventory by Waste Type}

Appendix D lists the masses $(\mathrm{kg})$ and volumes $\left(\mathrm{m}^{3}\right)$ for each low-level, mixed and hazardous waste stream discussed in Appendix B. Where a waste stream can be more than one waste type, for roll-up purposes, the total weight and volume is divided 50:50 for a combination of any two of the three waste types and 40:40:20 for wastes that can be either low-level, mixed or hazardous. 
Waste Stream

Absorbent Wipes

Aluminum

Analytical Laboratory Chemicals

Butyl Rubber Gloves

Crucibles

Glove Box Parts

HEPA Filters

Hydride Beds

Ion Exchange Resin

Ion Pump Materials

Klystron Materials

Latex Gloves

LiAl Melts

Paint Shop Wastes

Paper

Piping and Valves

Plastic Sheeting

Plastic Shoe Covers

Plastic Suits and Air Hoses

Spent Solvents

Solvent Rags

Stainless Steel

Target Storage Pool Wastes

Tungsten

Uranium Beds

Vacuum Pumps

Water Treatment Filters

TOTAL (Rounded Off)
LiAl Target Design Mass, $\mathrm{kg}$ Vol, $\mathrm{m}^{3}$

2,040

3,700

80

4,900

29,000

350

200

85

9,000

10

300

28,000

41,000

40

20,000

450

16,000

42,000

144,000

80

40

2.0

2.5

0.08

6.8

12.0

0.5

0.2

0.02

9.0

0.002

0.1

40.0

16.0

0.04

28.0

0.1

23.0

60.0

208.0

0.08

0.04

$-$

5,300

$-$

5.3

- -

350

150

0.1

1.600

0.1

1.6

349,000
He-3 Target Design Mass, kg Vol, $\mathrm{m}^{3}$

40

0.04

$2,500 \quad 3.0$

$80 \quad 0.08$

$420 \quad 0.6$

$350 \quad 0.5$

$\begin{array}{ll}200 & 0.2\end{array}$

$85 \quad 0.02$

$9,000 \quad 9.0$

$10 \quad 0.002$

$300 \quad 0.1$

$2,300 \quad 3.3$

$40 \quad 0.04$

$4,000 \quad 5.6$

$450 \quad 0.1$

$1,400 \quad 2.0$

$\mathbf{3 , 5 0 0} \quad \mathbf{5 . 0}$

$12,000 \quad 17.0$

$\begin{array}{ll}80 & 0.08\end{array}$

$40 \quad 0.04$

$12,100 \quad 1.6$

$5,300 \quad 5.3$

$670 \quad 0.04$

$150 \quad 0.1$

$1.600 \quad 1.6$

$56,600 \quad 55.3$ 
APT Mixed Waste Streams

Waste Stream

Absorbent Wipes

Aerosol Cans

Analytical Laboratory Chemicals

Batteries

Inconel-718

Instrumentation

Lead

Paint Shop Waste

Photographic Shop Waste

Spent Solvents

Solvent Rags

Vacuum Pumps

Zircaloy 4

TOTAL (Rounded Off)
LiAl Target Design Mass, kg Vol, m3 2,040

100

80

250

-- - -

500

12,400

40

50 ,

80

40

150

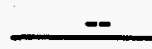

15,700
2.0

0.1

0.08

0.1

0.5

2.0

0.04

0.05

0.08

0.04

0.1

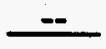

5.1
He-3 Target Design Mass, kg Vol, m3

40

0.04

100

0.1

80

0.08

250

0.1

2,260

0.25

500

0.5

6,160

1.1

40

0.04

50

0.05

80

0.08

40

0.04

150

0.1

1.970

$\underline{0.32}$

11,700

2.8

APT Hazardous Waste Streams

\begin{tabular}{|c|c|c|c|c|}
\hline Waste Stream & \multicolumn{2}{|c|}{ LiAl Target Design } & \multicolumn{2}{|c|}{ He-3 Target Design } \\
\hline & Mass, $\mathrm{kg}$ & Vol, $\mathrm{m}^{3}$ & Mass, $\mathrm{kg}$ & Vol $\mathrm{m}^{3}$ \\
\hline Absorbent Wipes & 1,020 & 1.0 & 20 & 0.02 \\
\hline Aerosol Cans & 100 & 0.1 & 100 & 0.1 \\
\hline Analytical Laboratory Chemicals & 40 & 0.04 & 40 & 0.04 \\
\hline Batteries & 250 & 0.1 & 250 & 0.1 \\
\hline Instrumentation & 500 & 0.5 & 500 & 0.5 \\
\hline Paint Shop Waste & 20 & 0.02 & 20 & 0.02 \\
\hline Photographic Shop Waste & 50 & 0.05 & 50 & 0.05 \\
\hline Spent Solvents & 40 & 0.04 & 40 & 0.04 \\
\hline Solvent Rags & 20 & $\underline{0.02}$ & 20 & $\underline{0.02}$ \\
\hline TOTAL (Rounded Off) & 2,060 & 1.9 & 1,040 & 0.9 \\
\hline
\end{tabular}




\section{Appendix E}

\section{Waste Stream Inventory by Type and Source - PEIS Format}

The PEIS breaks out waste streams by type (low-level, mixed or hazardous) and source (accelerator waste, target/blanket waste, and waste from tritium extraction and purification.) In the following tables, if a waste stream could come from any of these three sources, such as piping and valves or paint waste, the total for the waste type has been divided by three, since at this stage of the design, it is felt that any of the sources is equally probable.

Data in Appendices D and E agree to within round-off error. 
Summary - PEIS Data

Low-Level Waste

Waste Stream

Accelerator Waste

Target/Blanket Waste

H-3 Extraction \& Purification

TOTAL (Rounded Off)

\section{Mixed Waste}

Waste Stream

Accelerator Waste

Target/Blanket Waste

H-3 Extraction \& Purification

TOTAL (Rounded Off)

Hazardous Waste

Waste Stream

Accelerator Waste

Target/Blanket Waste

H-3 Extraction \& Purification

TOTAL (Rounded Off)
LiAl Target Design Mass, $\mathrm{kg}$ Vol, $\mathrm{m}^{3}$

590

0.2

19,900

18.5

$\underline{328,000} \quad 397$

$348,000 \quad 416$
He-3 Target Design Mass, $\mathrm{kg}$ Vol, $\mathrm{m}^{3}$

590

0.2

$31,400 \quad 20.7$

$24,600 \quad 34.4$

$56,600 \quad 55.3$
LiAl Target Design He-3 Target Design Mass, $\mathrm{kg}$ Vol. $\mathrm{m}^{3}$

$$
430
$$

0.4

12,800

2.4

$\underline{2.500}$

2.4

15,700

5.2
LiAl Target Design Mass, $\mathrm{kg}$ Vol, $\mathrm{m}^{3}$

340

340

0.3

0.3

$1.400 \quad 1.3$

$\mathbf{2 , 0 8 0}$

1.9

He-3 Target Design Mass, $\mathrm{kg}$ Vol, $\mathrm{m}^{3}$ 340

0.3

340

0.3

$360 \quad 0.3$

$1,040 \quad 0.9$ 
Accelerator Waste - Data for PEIS Table 7-1

Low-Level Waste

Waste Stream

Analytical Laboratory Chemicals

Ion Pump Materials

Klystron Materials

Paint Shop Waste

Piping and Valves

Spent Solvents

Solvent Rags

Vacuum Pumps

\begin{tabular}{cl} 
Mass, kg & Vol, m$^{3}$ \\
26.7 & 0.027 \\
10.0 & 0.002 \\
300 & 0.1 \\
13.3 & 0.013 \\
150 & 0.033 \\
26.7 & 0.027 \\
13.3 & 0.013 \\
50.0 & $\underline{0.033}$ \\
\hline
\end{tabular}

590.0

0.248

\section{Mixed Waste}

\section{Waste Stream}

Aerosol Cans

Analytical Laboratory Chemicals

Batteries

Instrumentation

Paint Shop Waste

Photographic Shop Waste

Spent Solvents

Solvent Rags

Vacuum Pumps
Mass, $\mathbf{k g}$

33.0

26.7

83.3

167.0

13.3

16.7

26.7

13.3

50.0

430
$\mathrm{Vol}, \mathrm{m}^{3}$

0.033

0.027

0.033

0.17

0.013

0.017

0.027

0.013

0.033

0.366 
Hazardous Waste

Waste Stream

Aerosol Cans

Analytical Laboratory Chemicals

Batteries

Instrumentation

Paint Shop Waste

Photographic Shop Waste

Spent Solvents

Solvent Rags

\begin{tabular}{|c|c|}
\hline Mass, kg & Vol, $\mathrm{m}^{3}$ \\
\hline 33.0 & 0.033 \\
\hline 13.3 & 0.013 \\
\hline 83.3 & 0.033 \\
\hline 167.0 & 0.17 \\
\hline 6.7 & 0.007 \\
\hline 16.7 & 0.017 \\
\hline 13.3 & 0.013 \\
\hline 6.7 & 0.007 \\
\hline 340 & 0.293 \\
\hline
\end{tabular}


LiAl Target Waste - Data for PEIS Table 7-2

Low-Level Waste

Waste Stream

Aluminum

Analytical Laboratory Chemicals

Ion Exchange Resin

Paint Shop Waste

Piping and Valves

Spent Solvents

Solvent Rags

Target Storage Pool Wastes

Vacuum Pumps

Water Treatment Filters

\begin{tabular}{|c|c|}
\hline Mass, $\mathrm{kg}$ & Vol, $\mathrm{m}^{2}$ \\
\hline 3,700 & 2.5 \\
\hline 26.7 & 0.027 \\
\hline 9,000 & 9.0 \\
\hline 13.3 & 0.013 \\
\hline 150 & 0.033 \\
\hline 26.7 & 0.027 \\
\hline 13.3 & 0.013 \\
\hline 5,300 & 5.3 \\
\hline 50.0 & 0.033 \\
\hline 1.600 & 1.6 \\
\hline 19,880 & 18.546 \\
\hline
\end{tabular}

\section{Mixed Waste}

Waste Stream

Aerosol Cans

Analytical Laboratory Chemicals

Batteries

Instrumentation

Lead

Paint Shop Waste

Photographic Shop Waste

Spent Solvents

Solvent Rags

Vacuum Pumps
Mass, $\mathbf{k g}$

33.0

26.7

83.3

167.0

12,400

13.3

16.7

26.7

13.3

50.0

12,830
$\mathrm{Vol}, \mathrm{m}^{3}$

0.033

0.027

0.033

0.17

2.0

0.013

0.017

0.027

0.013

0.033

2.366 
Hazardous Waste

Waste Stream

Aerosol Cans

Analytical Laboratory Chemicals

Batteries

Instrumentation

Paint Shop Waste

Photographic Shop Waste

Spent Solvents

Solvent Rags

\begin{tabular}{rl} 
Mass, kg & $\frac{\text { Vol. }}{3}^{3}$ \\
\hline 33.0 & 0.033 \\
13.3 & 0.013 \\
83.3 & 0.033 \\
167.0 & 0.17 \\
6.7 & 0.007 \\
16.7 & 0.017 \\
13.3 & 0.013 \\
6.7 & 0.007 \\
340 & 0.293
\end{tabular}


APT LiAl Target Tritium Extraction and Purification Waste - Data for PEIS Table 7-3

Low-Level Waste

Waste Stream

Absorbent Wipes

Analytical Laboratory Chemicals

Butyl Rubber Gloves

Crucibles

Glove Box Parts

HEPA Filters

Hydride Beds

Latex Gloves

LiAl Melts

Paint Shop Waste

Paper

Piping and Valves

Plastic Sheeting

Plastic Shoe Covers

Plastic Suits and Air Hoses

Spent Solvents

Solvent Rags

Uranium Beds

Vacuum Pumps

\begin{tabular}{cc} 
Mass, kg & $\frac{\text { Vol, } \mathrm{m}^{3}}{2,040}$ \\
26.7 & 0.027 \\
4,900 & 6.8 \\
29,000 & 12 \\
350 & 0.5 \\
200 & 0.2 \\
85 & 0.02 \\
28,000 & 40 \\
41,000 & 16 \\
13.3 & 0.013 \\
20,000 & 28 \\
150 & 0.033 \\
16,000 & 23 \\
42,000 & 60 \\
144,000 & 208 \\
26.7 & 0.027 \\
13.3 & 0.013 \\
350 & 0.1 \\
50 & 0.033 \\
\hline 328,205 & 396.766
\end{tabular}


Mixed Waste

Waste Stream:

Absorbent Wipes

Aerosol Cans

Analytical Laboratory Chemicals

Batteries

Instrumentation

Paint Shop Waste

Photographic Shop Waste

Spent Solvents

Solvent Rags

Vacuum Pumps

\begin{tabular}{cl} 
Mass, $\mathrm{kg}$ & $\mathrm{Vol}_{\mathrm{m}}{ }^{3}$ \\
\hline 2,040 & 2.0 \\
33 & 0.033 \\
26.7 & 0.027 \\
83.3 & 0.033 \\
167 & 0.17 \\
13.3 & 0.013 \\
16.7 & 0.017 \\
26.7 & 0.027 \\
13.3 & 0.013 \\
50 & 0.033 \\
\hline 2,470 & 2.366
\end{tabular}

Hazardous Waste

Waste Stream

Absorbent Wipes

Aerosol Cans

Analytical Laboratory Chemicals

Batteries

\begin{tabular}{cl} 
Mass, kg & Vol, $\mathrm{m}^{3}$ \\
1,460 & 1.5 \\
33 & 0.033 \\
13.3 & 0.013 \\
83.3 & 0.033 \\
167 & 0.17 \\
6.7 & 0.007 \\
16.7 & 0.017 \\
13.3 & 0.013 \\
6.7 & $\underline{0.007}$ \\
\hline 1,800 & 1.793
\end{tabular}


He-3 Target Waste - Data for PEIS Table 7-4

Low-Level Waste

Waste Stream

Aluminum

Analytical Laboratory Chemicals

Ion Exchange Resin

Paint Shop Waste

Piping and Valves

Spent Solvents

Solvent Rags

Stainless Steel

Target Storage Pool Wastes

Tungsten

Vacuum Pumps

Water Treatment Filters

\begin{tabular}{|c|c|}
\hline Mass, $\mathrm{kg}$ & $\mathrm{Vol}, \mathrm{m}^{3}$ \\
\hline 2,500 & 3.0 \\
\hline 26.7 & 0.027 \\
\hline 9,000 & 9.0 \\
\hline 13.3 & 0.013 \\
\hline 150 & 0.033 \\
\hline 26.7 & 0.027 \\
\hline 13.3 & 0.013 \\
\hline 12,100 & 1.6 \\
\hline 5,300 & 5.3 \\
\hline 670 & 0.035 \\
\hline 50.0 & 0.033 \\
\hline 1.600 & 1,6 \\
\hline 31,450 & 20.681 \\
\hline
\end{tabular}

\section{Mixed Waste}

Waste Stream

Aerosol Cans

Analytical Laboratory Chemicals

Batteries

Inconel-718

Instrumentation

Lead

Paint Shop Waste

Photographic Shop Waste

Spent Solvents

Solvent Rags

Vacuum Pumps

Zircaloy 4

\begin{tabular}{cl} 
Mass, kg & Vol. $^{3}$ \\
\hline 33.0 & 0.033 \\
26.7 & 0.027 \\
83.3 & 0.033 \\
2,260 & 0.25 \\
167.0 & 0.17 \\
6,160 & 1.1 \\
13.3 & 0.013 \\
16.7 & 0.017 \\
26.7 & 0.027 \\
13.3 & 0.013 \\
50.0 & 0.033 \\
1.970 & 0.32 \\
\hline 10,820 & 2.036
\end{tabular}


Hazardous Waste

Waste Stream

Aerosol Cans

Analytical Laboratory Chemicals

Batteries

Instrumentation

Paint Shop Waste

Photographic Shop Waste

Spent Solvents

Solvent Rags

\begin{tabular}{cl} 
Mass, kg & $\frac{\mathrm{Vol}, \mathrm{m}^{3}}{33}$ \\
13.3 & 0.033 \\
83.3 & 0.013 \\
167 & 0.033 \\
6.7 & 0.17 \\
16.7 & 0.007 \\
13.3 & 0.017 \\
6.7 & 0.013 \\
\hline 340 & 0.007 \\
\hline
\end{tabular}


APT He-3 Target Tritium Extraction and Purification Waste - Data for PEIS Table 7-5

Low-Level Waste

Waste Stream

Absorbent Wipes

Analytical Laboratory Chemicals

Butyl Rubber Gloves

Glove Box Parts

HEPA Filters

Hydride Beds

Latex Gloves

Paint Shop Waste

Paper

Piping and Valves

Plastic Sheeting

Plastic Shoe Covers

Plastic Suits and Air Hoses

Spent Solvents

Solvent Rags

Vacuum Pumps

\begin{tabular}{cl} 
Mass, kg & $\frac{\text { Vol, m}}{3}$ \\
\hline 40 & 0.04 \\
26.7 & 0.027 \\
420 & 0.6 \\
350 & 0.5 \\
200 & 0.2 \\
85 & 0.02 \\
2,300 & 3.3 \\
13.3 & 0.013 \\
4,000 & 5.6 \\
150 & 0.033 \\
1,400 & 2.0 \\
3,500 & 5.0 \\
12,000 & 17.0 \\
26.7 & 0.027 \\
13.3 & 0.013 \\
50 & $\underline{0.033}$ \\
\hline 24,575 & 34.406
\end{tabular}

Mixed Waste

Waste Stream

Mass, $\mathbf{k g}$

${\mathrm{Vol}, \mathrm{m}^{3}}^{3}$

Absorbent Wipes

40

0.04

Aerosol Cans

33

Analytical Laboratory Chemicals

26.7

0.033

Batteries

83.3

0.027

Instrumentation

167

0.033

Paint Shop Waste

13.3

0.17

Photographic Shop Waste

16.7

0.013

Spent Solvents

26.7

0.017

Solvent Rags

13.3

0.027

Vacuum Pumps 
Hazardous Waste

Waste Stream

Absorbent Wipes

Aerosol Cans

Analytical Laboratory Chemicals

Batteries

Instrumentation

Paint Shop Waste

Photographic Shop Waste

Spent Solvents

Solvent Rags

\begin{tabular}{cl} 
Mass, kg & $\frac{\text { Vol, } \mathrm{m}^{3}}{0.02}$ \\
\hline 20 & 0.033 \\
33 & 0.013 \\
13.3 & 0.033 \\
83.3 & 0.17 \\
167 & 0.007 \\
6.7 & 0.017 \\
16.7 & 0.013 \\
13.3 & $\underline{0.007}$ \\
6.7 & 0.313
\end{tabular}




\section{Appendix $F$ \\ Waste Stream Inventory by Waste Treatment Category}

Appendix $\mathrm{F}$ lists the masses $(\mathrm{kg})$ and volumes $\left(\mathrm{m}^{3}\right)$ for each low-level, mixed and hazardous waste stream by waste treatment category. Where a waste stream can be more than one waste type, for roll-up purposes, the total weight and volume is divided 50:50 for a combination of any two of the three waste types and 40:40:20 for wastes that can be either low-level, mixed or hazardous. 
Shredding \& Compaction, $\underline{Q R}$ Incineration and Stabilization of Residue

A. Low-Level

\section{Waste Stream}

Absorbent Wipes

Butyl Rubber Gloves

Latex Gloves

Paper

Plastic Sheeting

Plastic Shoe Covers

Plastic Suits \& Air Hoses

Solvent Rags

Target Storage Pool Wastes-Filters

Water Treatment Filters

\section{B. Mixed}

\section{Waste Stream}

Absorbent Wipes

Solvent Rags

\section{Hazardous}

Waste Stream

Absorbent Wipes

Solvent Rags
LiAl Target Design Mass, $\mathrm{kg}$ Vol, $\mathrm{m}^{3}$

$$
2,040
$$

2.0

4,900

6.8

$28,000 \quad 40.0$

$20,000 \quad 28.0$

$16,000 \quad 23.0$

$42,000 \quad 60.0$

$144,000 \quad 208.0$

40

0.04

800

0.8

1.600

259,380 $\frac{1.6}{370.24}$
He-3 Target Design Mass, $\mathrm{kg} \mathrm{Vol}^{\mathrm{m}} \mathrm{m}^{3}$

$40 \quad 0.04$

$420 \quad 0.6$

$2,300 \quad 3.3$

$4,000 \quad 5.6$

$1,400 \quad 2.0$

$3,500 \quad 5.0$

$12,000 \quad 17.0$

$40 \quad 0.04$

$800 \quad 0.8$

$1.600 \quad 1.6$

$26,100 \quad 35.98$
LiAl Target Design Mass, $\mathrm{kg}$ Vol, $\mathrm{m}^{3}$ 2,040

2.0

$\frac{40}{2,080}-\frac{0.04}{2.04}$
He-3 Target Design Mass, $\mathrm{kg}$ Vol, $\mathrm{m}^{3}$ $40 \quad 0.04$ $\frac{40}{80} \quad \frac{0.04}{0.08}$
LiAl Target Design Mass, $\mathrm{kg}$ Vol. $\mathrm{m}^{3}$

\begin{tabular}{rr}
1,020 & 1.0 \\
20 & 0.02 \\
\hline 1,040 & 1.02
\end{tabular}

He-3 Target Design Mass, $\mathrm{kg}$ Vol, $\mathrm{m}^{3}$ 20 0.02

20 $\quad 0.02$

$40 \quad 0.04$ 
Shredding \& Compaction OR Metals Recovery

A. Low-Level

\section{Waste Stream}

Aluminum

Crucibles

Glove Box Parts

LiAl Melts

Stainless Steel

Vacuum Pumps

B. Mixed

Waste Stream

Aerosol Cans

Inconel-718

Zircaloy 4

c. Hazardous
LiAl Target Desion Mass, $\mathrm{kg}$ Vol. $\mathrm{m}^{3}$

\begin{tabular}{|c|c|c|c|}
\hline 3,700 & 2.5 & 2,500 & 3.0 \\
\hline 29,000 & 12.0 & - & - \\
\hline 350 & 0.5 & 350 & 0.5 \\
\hline 41,000 & 16.0 & - & - \\
\hline - & - & 12,100 & 1.6 \\
\hline 150 & 0.1 & 150 & 0.1 \\
\hline 74,200 & 31.1 & 15,100 & 5.2 \\
\hline
\end{tabular}
Mass, $\mathrm{kg}$ Vol, $\mathrm{m}^{3}$
He-3 Target Design

LiAl Target Design

He-3 Target Design Mass, $\mathrm{kg}$ Vol, $\mathrm{m}^{3}$ Mass, $\mathrm{kg}$ Vol, $\mathrm{m}^{3}$

$$
\begin{array}{ccrr}
100 & 0.1 & 100 & 0.1 \\
- & - & 2,250 & 0.25 \\
- & - & \underline{2,000} & \underline{0.32} \\
\hline 100 & 0.1 & 4,350 & 0.67
\end{array}
$$

Waste Stream

Aerosol Cans

Waste Stream

\begin{tabular}{|c|c|c|}
\hline Waste Stream & LiAl Target Design & He-3 Target Design \\
\hline & Mass, kg Yol, $\mathrm{m}^{3}$ & Mass, kg Vol, m 3 \\
\hline Ion Exchange Resins & 13,500 & 13,500 \\
\hline
\end{tabular}

LiAl Target Design Mass, $\mathrm{kg}$ Vol, $\mathrm{m}^{3}$ 100

0.1

He-3 Target Design Mass. $\mathrm{kg}$ Vol, $\mathrm{m}^{3}$ 100 0.1

Dewatering, Followed By Incineration or Vitrification - Low-Level Waste Only 
Shredding and/or Compaction, Followed By Encapsulation $\underline{O R}$ Metals Recovery

A. Mixed

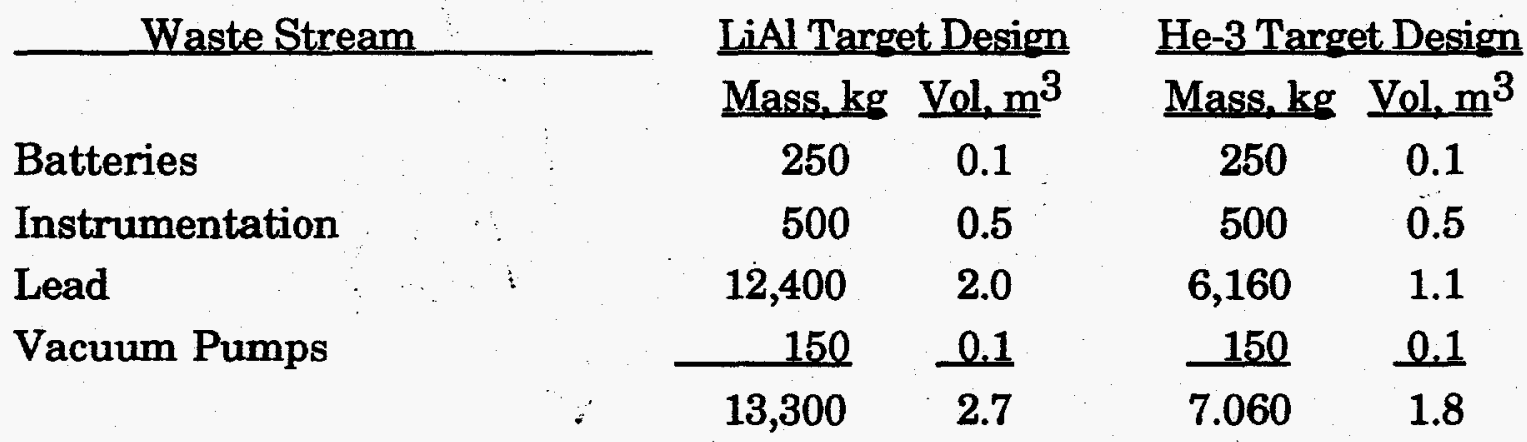

\section{B. Hazardous}

Waste Stream

Batteries

Instrumentation
LiAl Target Design Mass, $\mathrm{kg}$ Vol, $\mathrm{m}^{3}$

250

500

750
0.1

$\underline{0.5}$

0.6
He-3 Target Design Mass, $\mathrm{kg}$ Vol, $\mathrm{m}^{3}$

250

0.1

500

0.5

750

0.6

Stabilization or Incineration - Spent Solvent Waste Stream Only

\section{Waste Type}

Low-Level

Mixed

Hazardous
LiAl Target Design Mass, $\mathrm{kg}$ Vol, $\mathrm{m}^{3}$

\begin{tabular}{rr}
80 & 0.08 \\
80 & 0.08 \\
40 & 0.04 \\
\hline 200 & 0.20
\end{tabular}

He-3 Target Design Mass, $\mathrm{kg}$ Vol, $\mathrm{m}^{3}$

80

80

0.08

40

0.08

200 $\underline{0.04}$

0.20

Incineration Followed By Stabilization of Residue - Paint Shop Waste Stream Only

\begin{tabular}{|c|c|c|c|c|}
\hline Waste Type & \multicolumn{2}{|c|}{ LiAl Target Design } & \multicolumn{2}{|c|}{ He-3 Target Design } \\
\hline & Mass. kg & Vol. $\mathrm{m}^{3}$ & Mass, kg & Vol, $\mathrm{m}^{3}$ \\
\hline Low-Level & 40 & 0.04 & 40 & 0.04 \\
\hline Mixed & 40 & 0.04 & 40 & 0.04 \\
\hline Hazardous & $\frac{20}{100}$ & $\frac{0.02}{010}$ & $\frac{20}{100}$ & $\frac{0.02}{0.10}$ \\
\hline
\end{tabular}


No Treatment Required or Practical; Package for Storage and/or Disposal - Low-Level Waste Only

Waste Stream

Hydride Storage Beds

Ion Pump Materials

Klystron Materials

Piping \& Valves

Tungsten

Uranium Beds

Other *

A. Low-Level

Waste Stream

Analytical Laboratory Chemicals HEPA Filters

\section{B. Mixed}

Waste Stream

Analytical Laboratory Chemicals Photographic Shop Wastes

\section{Hazardous}

Waste.Stream

Analytical Laboratory Chemicals Photographic Shop Wastes
LiAl Target Design Mass, $\mathrm{kg} \mathrm{Vol}^{\mathrm{m}} \mathrm{m}^{3}$ 85

10

300

450

0.02

0.002

0.1

0.1

$350 \quad 0.1$

1,195
LiAl Target Design Mass, $\mathrm{kg} \mathrm{Vol}^{\mathrm{m}} \mathrm{m}^{3}$ $40 \quad 0.04$ $\frac{50}{90} \quad \underline{0.05}$
He-3 Target Design Mass, kg Vol. $\mathrm{m}^{3}$

85

0.02

10

0.002

300

0.1

450

0.1

650

0.034

$\underline{350}$

0.1

1,845

0.356

\begin{tabular}{|c|c|c|c|}
\hline \multicolumn{2}{|c|}{ LiAl Target Design } & \multicolumn{2}{|c|}{ He-3 Target Design } \\
\hline Mass, kg & $\mathrm{Vol}, \mathrm{m}^{3}$ & Mass, kg & $\underline{\mathrm{V}} \mathrm{l}, \mathrm{m}^{3}$ \\
\hline 80 & 0.08 & 80 & 0.08 \\
\hline 200 & 0.2 & $\underline{200}$ & 0.2 \\
\hline 280 & 0.28 & 280 & 0.28 \\
\hline
\end{tabular}

LiAl Target Design Mass, $\mathrm{kg}$ Vol. $\mathrm{m}^{3}$

$80 \quad 0.08$

$50 \quad \underline{0.05}$

130

0.13

He-3 Target Design Mass, $\mathrm{kg} \mathrm{Vol}, \mathrm{m}^{3}$

80

0.08

50

0.05

130
He-3 Target Design Mass, $\mathrm{kg}$ Vol, $\mathrm{m}^{3}$ 40 0.04 $\underline{50} \quad \underline{0.05}$ $\begin{array}{ll}90 & 0.09\end{array}$

* These are wastes for which treatments cannot a priori be defined. Treatment of analytical and photographic chemicals will be a function of the 
type of chemical; e.g., solid, liquid, acid, base, etc. Treatment of HEPA filters will also be a function of their composition; i.e., whether they are largely paper (thermal treatment) or metal (compaction). 
DISTRIBUTION:

10 MS 0720 S. D. Carson, 6626

10742 J. E. Kelly, 6414

10720 C. D. Massey, 6626

$1 \quad 1175$ L. A. Miller, 6513

11303 P. K. Peterson, 7573

19018 Central Tech Files, 8523-2

50899 Technical Library, 13414

10619 Print Media, 12615

$2 \quad 0100$ Document Processing, 7613-2 For DOE/OSTI 